\title{
Cultivating Dissent:
}

The Struggle Over Representing Farmers' Interests in Ontario

by

Neville McGuire

A thesis submitted to the Faculty of Graduate Studies and Research in partial fulfillment of the requirement for the degree of

Master of Arts

School of Journalism and Communication

Carleton University

January 14, 2009

(C) 2009, Neville McGuire 
Library and

Archives Canada

Published Heritage

Branch

395 Wellington Street

Ottawa ON K1A 0N4

Canada
Bibliothèque et

Archives Canada

Direction du

Patrimoine de l'édition

395 , rue Wellington

Ottawa ON K1A ON4

Canada

Your file Votre référence

ISBN: 978-0-494-51995-0

Our file Notre référence

ISBN: 978-0-494-51995-0

NOTICE:

The author has granted a nonexclusive license allowing Library and Archives Canada to reproduce, publish, archive, preserve, conserve, communicate to the public by telecommunication or on the Internet, loan, distribute and sell theses worldwide, for commercial or noncommercial purposes, in microform, paper, electronic and/or any other formats.

The author retains copyright ownership and moral rights in this thesis. Neither the thesis nor substantial extracts from it may be printed or otherwise reproduced without the author's permission.
AVIS:

L'auteur a accordé une licence non exclusive permettant à la Bibliothèque et Archives Canada de reproduire, publier, archiver, sauvegarder, conserver, transmettre au public par télécommunication ou par l'Internet, prêter, distribuer et vendre des thèses partout dans le monde, à des fins commerciales ou autres, sur support microforme, papier, électronique et/ou autres formats.

L'auteur conserve la propriété du droit d'auteur et des droits moraux qui protège cette thèse. $\mathrm{Ni}$ la thèse ni des extraits substantiels de celle-ci ne doivent être imprimés ou autrement reproduits sans son autorisation.
In compliance with the Canadian

Privacy Act some supporting forms may have been removed from this thesis.

While these forms may be included in the document page count, their removal does not represent any loss of content from the thesis.
Conformément à la loi canadienne sur la protection de la vie privée, quelques formulaires secondaires ont été enlevés de cette thèse.

Bien que ces formulaires aient inclus dans la pagination, il n'y aura aucun contenu manquant.

\section{Canada'}




\begin{abstract}
This thesis offers an empirical examination of how a small, radicalized group called The Lanark Landowners' Association quickly emerged to mobilize farmers across Ontario in the early $2000 \mathrm{~s}$, and in doing challenged the institutional legitimacy of the largest agricultural organization in the province: The Ontario Federation of Agriculture. The existing body of literature tackling agrarian collective action would paint this case as either an interpersonal or structural matter; however, by bringing the social embeddedness of participants to the forefront, I offer up a theoretical framework that focuses on the ongoing dynamics between organization, collective identity and the mobilization of consensus. Drawing from data collected through a series of interviews, this study finds that the structure of the Federation impacted its ability to reflect the interests of farmers. This in turn provided a valuable opportunity for the Landowners' to mobilize farmers, though the group was unable to secure their long-term commitment.
\end{abstract}




\section{Acknowledgments}

This project could not have reached completion without the help of many people to whom I am very grateful. A special thanks to my supervisor, Joshua Greenberg, who sparked my interest in social movements several years ago. Josh's guidance, support and friendship have been invaluable in the creation of this thesis. I would also like to extend my appreciation to Sheryl Hamilton and Aaron Doyle, who were both kind enough to share their insights on my topic. And of course to Carole Craswell, who over the years has been an incredible help.

My thanks to David Mackay, Ellard Powers and Lauretta Rice at the National Farmers' Union. Their dedication to preserving and protecting family farms is inspiring.

On a more personal note, I am indebted to my friends and family for putting up with me while I researched and wrote this thesis, especially Dani, who was willing to offer her unwavering love and encouragement even on my pondering days. 


\section{Table of Contents}

\section{Abstract}

\section{Acknowledgments}

\section{List of acronyms}

Introduction

Chapter 1: Literature review

Agricultural organizations, policy networks and mobilization

The collective agrarian identity

Towards a more inclusive paradigm

Chapter 2: Theoretical framework

Multi-organizational fields

(Re)conceptualizing Actors: SMOs and the (re)constuction of identity

Identity and the construction of meaning in the context of multi-organizational fields

The destabilization of multi-organizational fields through institutional limitations

Chapter 3: Research methodology

\section{Chapter 4: Case study}

Understanding the field: A history of the OFA

Contextualizing agriculture in 2003-2004

From grievance to (in)action

Denying protest: The effects of the "iron law" on OFA activities

The Lanark Landowners' Association

Selling consensus: The construction of LLA collective action frames

Competing protests

Conclusion

References 


\section{List of Acronvms}

CFFO Christian Federation of Farmers Ontario

LLA Lanark Landowners' Association

NFU National Farmers' Union

OFU Ontario Farmers' Union

OLA Ontario Landowners' Association

OFA Ontario Federation of Agriculture

UCC Union catholique des cultivateurs 


\section{Introduction}

You know Neville, it's really sad what's going on. I doubt that family farms will exist when you have a family of your own. There'll be no reason to live in the country.

Everyone will just live in cities.

Margaret Mackay, conversation, 2008

Burn down your cities and leave our farms, and your cities will spring up again if by magic, but destroy our farms, and grass will grow in the streets of every city.

William Jennings Bryan, Cross of Gold speech, 1896

I grew up on a small family farm in the Upper Ottawa Valley region of eastern Ontario. Throughout my childhood I've worked on numerous neighboring farms, devoted many summer evenings to baling hay, and have spent what seems like eons planting, raking, fertilizing, and plowing fields. At the time I despised the early mornings, constant smell of diesel, lime and manure, the monotony of chores, and the unpredictability of farm animals, which would on one day require a nurturing hand, only to infuriate you the next by wandering into neighboring crops. Yet when I chat with city-born friends, I realize just how much I value my farming roots. While I have missed out on some experiences that could come with an (sub)urban upbringing, they have no clue how to deliver a calf, the correct way to hook up "power take-off" driveshaft, how to install a high tensile fence, or how to tend to a potato patch. They have never churned butter, killed a large animal, or spent a grueling afternoon in a hay mow. For some, the history of food begins at the grocery store. Others are much more conscious, and they try very hard to "eat local," but where I'm from, eating local is less of an initiative than it is a given my mother often jokes that we live off the "100 metre diet."

Many of the people that I've met recently find my background to be a very novel thing, and I am often introduced to new people as "the farmer." The curiosity of my 
peers, however, has led me to realize how unique my upbringing has now become. It's pretty rare that I come across people that have been brought up on farms, yet alone in the countryside. Those with whom I've grown up - myself included - have on the most part moved away from, or sold their family farms, preferring to seek a career in urban areas where service-oriented jobs are plentiful and considerably more lucrative than what is offered in the Upper Ottawa Valley.

This demographic shift and the deterioration of family farms have caused a great deal of concern amongst many of the people in my home region, especially my stepfather, David Mackay, who also happens to be the current president of the Renfrew county branch of the National Farmers' Union (NFU). He sees the two processes as interrelated: that is, rural degradation is a side effect of the decline in small family farms, which have in the past spurned the most amount of economic activity in rural regions. Without the economic opportunities posed by family farms, he says, rural Ontario is bound to dry up. According to "The Panel on the Role of Government" (2004), he is right; there is a correlation between farming and the size of rural populations - the latter being the dependent variable.

The precarious future of small family farms is the result of a multitude of economic, political, and cultural factors stretching well beyond the borders of the Ottawa Valley. Yet the many conversations I've had with my stepfather and other farmers has promulgated a personal curiosity over why people aren't doing anything to address this very serious issue, wherever its core may lie. It is generally assumed that poor governance is affecting agriculture, but then, why are farmers not protesting as they

\footnotetext{
${ }^{1}$ The goal of the Panel was to "examine the future role of government in the context of promoting economic growth, strong communities, fiscal responsibility and accountability" (Panel on the Role of Government, 2004, p. 1).
} 
perhaps did in the past? It is not implied that the key to understanding the deteriorating conditions of Ontario's agricultural sector lies solely in understanding agrarian political action, but that it is one of the many components of the multifaceted impediments that farmers face in changing their economic, political, and social conditions.

I tell my stepfather that for my thesis I will be studying modern agrarian protest in Ontario, but am not quite sure where to start. He suggests that I contact a man by the name of Ellard Powers whom Dave has occasionally called on for advice in his capacity as an organizer with the NFU.

On April 21, 2008, Ellard Powers welcomed me into his home with a smile and firm handshake, which took me by surprise given his old age. Coordinating the meeting had been difficult for both of us; I had to travel from Toronto - a four and a half hour drive away - and he had recently been spending most of his time at the hospital where his wife had just undergone surgery for a bad hip. But Powers is as enthusiastic to meet with me as I am with him because as he says, "the only way things are gonna change is by creating awareness." In a sense, his appearance, weathered by time and over-exposure to the elements of farm life, is the new face of agrarian activism. He tells me that I'm not the first to come knocking at his door for an interview; just months prior a gentleman had sat him down for several long sessions regarding the history of farm organizations in Ontario. For some reason or another, it seems that the topic is generating more attention nowadays than that it had in the past.

Since the 1960s, Powers has been involved in one capacity or another in the province's agricultural sector: he was a director of the Ontario Milk Marketing board, which he helped establish; a former vice-president of the NFU; a CEO of the Ontario 
Dairy Commission; and, of course a farmer. Local farmers also recently honoured him with an induction into the Renfrew County Agricultural Hall of Fame. Though he is still a card-carrying member and occasional consultant for the NFU, he has since left his farm and moved into the village of Beachburg, Ontario.

With all this experience behind him, Powers possesses a wealth of knowledge about agricultural policy and economics, and, as a proponent of grassroots change, he's also well versed in protest politics. Throughout his career Powers participated and helped organize numerous agrarian rallies, but none would compare to the scale of the protest that he organized in 1967 to advocate for government aid for farmers. It was the first large-scale protest that he planned, and with it, he admits that he had his anxieties:

I remember talking to some of the guys saying 'are these guys really gonna show up?' We were trying as much as we could to tone down people's optimism - the press particularly - on how many of them were going to show up. At the same time we were doing everything in the country to make sure that people came. Back then when farmers were pressed too much, they would turn to militancy... that's why... we had to arrange for marshals across the province, and [had to get] the guys from out west to marshal their people because we didn't want things to get out of hand - you'd lose your point if people get upset, even more so then than now... But they showed. I mean, Quebec guys marshaled their buses across the river, and they marched across the bridge. 10000 farmers, about 6 in a row! Boy I'll tell you it was gratifying seeing those boys show up. They all showed (interview, April 21, 2008).

In the following years the federal and provincial governments introduced an unprecedented series of policies aimed at securing a viable agricultural sector in the province for years to come. Powers is adamant that without protests, the changes would have never occurred. He himself takes very little credit for this protest and the ones that followed, preferring to see them as a case of farmers acting collectively to demand changes that they wanted to see enacted, and which in the end they achieved. 
On the other hand, Powers also draws attention to the role that formal agricultural organizations played in mobilizing farmers. In particular, he draws attention to the amount of commitment that practicing farmers pledged to groups, and the dedication of their leaders to grassroots action:

I wouldn't say that a whole lot of people gave more commitment than I did, or more time. But I happened to be in a good position because my wife was a real good farmer on her own, and even though we were struggling financially, we could handle it. There were others who spent enough time there and enough of their money that they had to quit, they had to go home to try and save their farms. The first president that I worked with... when he went into a meeting with a suit on he had to make sure his cuffs didn't show on his shirt because they were worn off. And we always had to share a room together... In those days we were so short of money, when the secretary-treasurer sent out work for us, or when we had an executive meeting, he'd tell us 'fellas, we can't pay the rent, telephone bill, and all the rest to run the office.' Me, the president, the vice-president, the women's president and the junior president, we'd go canvas for a few days and bring in some money both to be able to pay whatever expenses, and to keep the office going (interview, April 21, 2008).

But with a tragic tone in his voice, he tells me that now he "doesn't see that dedication anywhere today."

Since those early days a dizzying array of organizations have emerged on the province's agricultural scene. Despite what modern leaders say, the grassroots ethos described by Powers has been severely marginalized in the sector, and farmers have lost the central role they once played in organizational decision-making. Part of the reason for this is that the industry has grown significantly more complex since the 1960 s, now requiring a large, intensely hierarchical, and bureaucratic organizational structure to ensure the effective management of regional, national, and international economic activities pertaining to agriculture. Yet at the same time, it seems that these groups have 
done very little to improve the economic conditions of farmers in Ontario; with the exception of a handful of commodities, the family operated agricultural sector in the province has been growing weak for the past two decades, making the industry in the 1960s and early 1970 s seem prosperous.

In order to receive tax breaks and qualify for other publicly funded farm programs, Ontario farmers are by law required to pledge membership to one of three "general farm organizations": the NFU, the Christian Federation of Farmers Ontario (CFFO), and the Ontario Federation of Agriculture (OFA). In theory, with three groups vying for the same members, competition should exist amongst the province's general farm organizations, and the democratic ideals related to the accurate representation of constituents' interests should be defended. Yet very little resembles these elements in the province's agricultural polity.

Through ties with the government, and the subsequent political and economic benefits of such an arrangement, the OFA has concretized its presence as the most important farm organization in the province. While the overwhelming majority of farmers belong to the Federation, so do most of the province's agricultural lobby groups that represent farmers' interests usually according to region and the type of commodity they produce - i.e. poultry, maple syrup, soy, etc. These special interest groups sit alongside farmers at the OFA decision-making table. Their inclusion, however, has posed new dynamics in agricultural politics in Ontario. Today, Ontario's agricultural landscape is a mess of overlapping and contradictory relationships and interests, but most paths can be traced in some way or another back to the Federation. 
With the centrality of the OFA, it is little wonder that farmers have grown incredibly dependent on it to represent them in the sector's decision-making arenas, in governmental policy circles, and - most germane to this study - to lead them into protest. In the language of "actor network theory" (Latour, 1986), we could say that farming groups have established themselves as the "obligatory point of passage" for really any meaningful change for farmers. In the language of social movement studies, we can also conceptualize the provincial farmers' social movement industry as monopolistic, dominated by a small, select handful of organizations all linked with the Federation.

The organizational landscape poses serious implications for understanding agrarian protest in Ontario. Ellard Powers, like many other people interviewed for this project, points to the structural limitations put into play by these modern organizations. In some way or another, most farmers have expressed concern over the ways that agricultural organizations have been driving divisions between farmers. They tell me that without a collective sense of being, farmers will never be able to control the trajectory of their own industry and, consequently, the future of their lives. Accordingly, there has developed a general consensus that there needs to be fewer agricultural groups and more inter-organizational coordination before beneficial conditions for farmers can come into fruition. A few though, oddly enough, have called for more organizations.

Although the power of the OFA remains unmatched today, in the early 2000s an upstart organization called The Lanark Landowners' Association (LLA) challenged the legitimacy and monopolistic positioning of the Federation. Originally focused on rural property rights, the LLA transformed itself into a powerful movement professing to represent and advance the interests of all rural peoples, including farmers. This thesis 
tells the story of the LLA; it examines how a small, radicalized group successfully emerged into a fully fledged movement in what was an already dense organizational field, and how it came to challenge the institutional legitimacy of the biggest player in Ontario's crowded agricultural and agrarian sector. It is also a study of the ways that two ideologically different organizational structures grew into conflict with each other, and the subsequent antagonistic dynamics that developed between them. Though on the surface these are macro-level issues involving organizations, I argue in this thesis that we can better understand the shifting field of agrarian politics by also paying attention to the micro-level, interpersonal, and cognitive factors that contributed to the changes that occurred in rural and agrarian politics in Ontario during this period.

There are multiple overlapping threads of social movement studies that could be employed in such an examination. Jordan et al. note (2002) that the study of social movements has been divided into two distinguishable "clusters" or traditions: new social movement theory, which focuses on issues relating to collective identity, culture and emotion, and the "political process" approach" (p. 5), a more traditional model built on the ideas of the resource mobilization and political opportunity paradigms. In its most stripped down form, this other stream of theory seeks to understand the resources that contribute to movement success, as well as the structural conditions that have provided the "ruptures" through which opportunities are borne and movements emerge. Newer incarnations of this paradigm have begun focusing on "the dynamics of state-society relations, as well as the study of movement organizations, activist networks and the cultural framing processes that movements deploy" (Jordan et al., 2002, p. 6). More recently, scholars have taken upon themselves a project to overcome the dualisms that 
exist between these two areas by merging the insights of each area into what may in the future become known as the "third" tradition.

This project locates itself under this steadily growing tradition. In order to probe into the topic of modern agrarian activism in Ontario, I draw on many of the constructivist insights into organizational dynamics brought to social movement studies by Bert Klandermans (1989; 1992; 1997), David Snow and Robert Benford's (1988) "politics of signification," and, to a lesser degree the Michel/Weber "iron law of oligarchy" (Piven \& Cloward, 1979). It is argued that in "dense" social movement industries, such as Ontario's agricultural sector, we can best understand the emergence of new social movement organizations, mobilization, and the overall character of protest by examining the interplay between organizational dynamics and the mobilization of consensus in the minds of existing and potential participants in a social movement.

Armed with this theoretical insight, this project aims to answer three key research questions. The fact that the LLA was able to garner tremendous support in a social movement industry that housed a limited pool of potential adherents deserves explanation. I therefore first ask how dynamics in the sector's multi-organizational field created the opportunities for the LLA to mobilize the consensus of farmers whom had grown so dependent on government-endorsed social programs and subsidies. Second, I aim to probe into understanding the ways that SMOs attempt to contain ideological factionalism during protest cycles involving antagonistic relations with other groups. This question is directly related to counter-framing. Third, it is critical to question the motivations behind farmers' decisions to participate with the LLA. Agrarian protest is typically understood as being focused on material redistribution; however, it is rare to 
come across a movement that has continually fought so hard and won so little. If agriculture were like most other industries in the economy, wouldn't it react to falling profits like most markets? In a failing industry, why is it that farmers do not move on to more profitable initiatives? The answers to these questions, I propose, lie in the cultural dimensions of agriculture work, which undoubtedly play a role in the trajectory of agrarian protest.

This thesis is organized in five sections. Chapter 1 outlines and surveys the limited body of literature tackling the issue of agrarian protest in past and present contexts. The literature is thematically grouped into two streams: structural analyses, concerned primarily with the hierarchies and dynamics of agricultural organizations, and studies devoted to the interpersonal dimensions of agrarian action, involving such concepts as meanings, consensus, and identity. I argue that a paradigmatic tension between these two areas exists in the literature.

Chapter 2 offers the theoretical framework that provides the basis for the case study. It attempts to better position social constructivist theories of social action within the established canon of organizational theories, particularly Klandermans (1992) notion of multi-organizational fields. This concept presents an excellent perspective to view the processes through which individuals come to participate in a social movement, and that ways that inter-organizational dynamics inform mobilization. By reconceptualizing actors as first and foremost socially embedded in prior relations, such a theoretical paradigm allows this study to address the analytical tensions between structure and actors evident in the literature on agrarian protest. In accordance with the theoretical framework, Chapter 3 outlines the research methodology employed in the project. 
Chapter 4 presents the case study, focusing on a period of time (2003-2005) that I argue is characterized by a heightened level of farmer activism in Ontario. The chapter starts with a brief historical analysis of how the Federation was able to situate itself as the most dominant agricultural organization in the province, and how this positioning affected the occurrence of protest amongst farmers. Then I examine the cultural and political opportunities that contributed to the successful framing projected by the LLA. Finally, the chapter closes with an examination of the antagonistic dynamics that ensued between the OFA and the LLA after it became apparent that the Landowners' were infringing on Federation turf. In the conclusion, I discuss the findings of this study and suggest other possible directions of study.

While this study aims to make theoretical contributions to the area of organizational dynamics and the mobilization of consensus, its primary concern is in making empirical contributions to the nascent field of agricultural social movements. Exploring this case can lead to a better understanding not only of modern agricultural politics from a protest perspective, but also why significant grassroots-oriented change in agricultural sectors seldom come to fruition, and the obstacles that new movements must face when they do. For decades small family farmers around the world have been fighting for a fair international marketplace, yet as this project will illustrate, it is not necessarily supranational organizations or poor governance structures that are subverting the viability of agriculture; rather it is the paradoxical mandates of smaller farmers' groups that often poses the greatest challenges to them. 


\section{Chapter 1: Literature review}

Widespread social change usually involves challenging dominant beliefs, systems, or institutions; it follows that it rarely comes without a struggle. When people perceive an issue as a full-blown problem, it is commonly believed that they will act collectively to bring about change. Goodwin and Jasper (2004) define a social movement as "a collective, organized, sustained, and noninstitutional challenge to authorities, powerholders, or cultural beliefs and practices" (p. 3). However, it is important to note that in some a social movement aspires to preserve the current order of things - or in some cases revert to earlier ones - and counter the claims of challengers ${ }^{2}$.

The field of social movement studies has a rich and winding history; behind the many paradigmatic shifts has been a constant debate about the function, abilities, and agency of humans as social actors. Though not explicitly considered social movement studies, sociologists treated collective action as a form of "deviance or pathology... Social movements were seen in terms of 'mob psychology' or as an expression of social breakdown and anomie" (Flacks, 2004, p. 135). Whether it was peasant revolts, industrial strikes or more substantial popular revolutions, collective behaviour was seen as a phenomenon in which individuals were merely part of a "mass," lacking any agency of their own. Collective actors were also portrayed in this framework as irrational, emotionally unstable, and generally lacking any self-control (Couch, 1968). Easily persuaded by "magnetic leaders" who could persuade people from bystander to participant, the "mob mentality" occurred in any act involving individuals coming

\footnotetext{
${ }^{2}$ For example, the "anti-cure" movement arose after development in embryonic stem cell research.
} 
together to express grievances over a social order that excluded and oppressed them (Edelman, 2001, p. 287).

As events unfolded, however, it became apparent that these theoretical conceptions were problematic. Edelman (2001) argues they could in part explain the phenomenon of activism in totalitarian societies, but was of limited use in analyzing "turmoil in largely democratic, affluent polities in the 1960s" (p. 287). As an example, Kornhauser's (1959) notion that only marginalized people would participate in collective behaviour could not explain the widespread culture of activism in the 1960s, which involved, among other demographics, middle-class whites with relative comfort and affluence. In 1965, Mancur Olson offered up a new lens through which to view individuals acting en masse. An economist, Olson rejected the notion that participants could be easily persuaded via emotional appeals and that collective behaviour was an irrational act - in fact he argued quite the opposite, positing that individuals come to participate in collective action through a rational process of weighing and assessing the benefits of participation, and that emotions were of little consequence to analysis. Three years later Carl Couch (1968) put the metaphorical nail in the coffin of "mob" approaches to collective behaviour in his "debunking" survey of the accumulated body of literature pertaining to the topic.

By the 1960s social movement studies as we know it now began to take shape, and scholars interested in the area began to emphasize movements as a form of "politics as other means...collective actors [pursuing] interests with intelligible strategies and rational goals" (Flacks, 2004, p. 135). By the mid-1970s understanding social movements 
became less a matter of pseudo-individual psychoanalytics, and more about examining broader, increasingly macro socio-political processes.

Throughout the 1970s, resource mobilization theory (RMT) (McCarthy \& Zald, 1973) quickly grew to be the dominant hegemonic paradigm for understanding social movements. For RMT scholars, social movements were akin to conventional political groups; they were institutionalized forces, but unlike entrenched political groups, social movements had to "pay higher costs to gain a comparable degree of influence within the polity" (Buechler, 1993, p. 218). Scholars began to redefine the study of social movements and activism from an examination of instances of "deviance and social disorganization to a case study in political and organizational sociology" (Ibid.). Basing their theories largely on Olson's assertions about the rational actor, interest grew in understanding the processes through which people become motivated to participate in social action. If taking part in collective action was a matter of "weighing the relative costs and benefits of movement participation and opting for participation when potential benefits outweigh[ed] the anticipated costs" (Ibid.), then mobilization became a matter of how movements solicited, coaxed, and secured participants (Snow et al., 1980, p. 799). One way to answer this question was to examine how movements acquired resources, the value of said resources, and the methods in which they were allocated in order to meet movement goals.

With this shift came a surge in interest about the role of the social movement organization. In traditional resource mobilization studies, preexisting forms of organization were an essential resource in achieving movement goals (Jenkins, 1983; Edwards \& McCarthy, 2004, pp. 136-137), and accordingly, studying their structures 
became a topic of choice in the area (e.g. McCarthy \& Zald, 1977). By the early 1980s, the resource mobilization paradigm had advanced to a "multifactored model... emphasizing resources, organization, and political opportunities" (Jenkins, 1983, p. 527).

But the 1980s also marked a significant point of rupture for resource mobilization theory. While the paradigm had been gaining momentum in the United States throughout the 1970s, another approach, so-called "new social movements theory," had matured relatively autonomously to great reception in Europe (Edelman, 2001, p. 291). Like resource mobilization theory, this new approach also grew out of civil unrest in the 1960s, but European scholars such as Alain Touraine (1981) and Alberto Melucci (1984) took an altogether different explanatory angle than their American counterparts. While RMT tended to peg agency onto the dynamics of organizational structures, new social movement scholars saw agency as paramount in understanding participation in collective action. By politicizing identity, and making participation itself a motivation, these scholars were able to situate individuals within a collectivity without recourse to either structural determinism or the overly individualistic, unfounded assumptions of earlier collective behaviour theories. Moreover, new social movements theory could explain why resource poor movements, such as the labour rights movement during the depression, could succeed despite their shortcomings.

The ideas of new social movements theory guided the discipline to delve deeper into two areas that had been previously overlooked: grievances and ideology (Jenkins, 1983). By peering into the values, beliefs, symbols, and returning an emphasis on the emotional dimensions implicit in mobilization, scholars were led to a relatively new pursuit regarding the ways that movements struggled over the "production of mobilizing 
and countermobilizing ideas and meanings" (Benford \& Snow, 2000). Drawing from the work of Goffman (1959), frame theorists asserted that social movements were not necessarily born from the availability of political opportunities and the effective allocation of resources by movement organizations. Rather, mobilization, and therefore social change, was increasingly contingent on a movement's ability to construct and convey particular versions of reality for constituents, antagonists, and bystanders or observers (Snow \& Benford, 2000). The framing paradigm reconstructed the actor as a signifying agent either actively engaged in frame construction or the interpretation of frames. Though types of frame theory have gained popularity in other disciplines such as linguistics, political science, policy studies, and communication and media studies, in no other field has it such an amount of currency as social movement studies (Benford \& Snow, 2000, p. 611).

Most of the historical turns and theoretical developments in social movements studies manifest themselves in the limited body of literature tackling the topic of agrarian protest. While the bulk of authors have directed their analytical focus toward agricultural organizations, and their relationships to activism and policy networks, several have also paid attention to processes related to identity and meaning.

\section{Agricultural organizations, policy networks and mobilization}

While agricultural organizations are designed to represent groups of farmers in economic and policy circles, they are also central players in farmer mobilization efforts. Although these types of organizations are more formal than interpersonal, they do provide a forum which sustains interaction over long periods of time, and subsequently 
functions as a means by which farmers can come to agree upon a common purpose and a common set of grievances in times when collective action is perceived to be necessary. Hence, organizations can be conceptualized as "pre-existing mobilization structures" (della Porta \& Kriesi, 1999, p. 9) that offer members a space in which they are able to forge not only alternative visions, but also the means to achieving these visions by developing more articulated grievances, and in some cases, protest strategies.

As several authors show, the ebbs and flows of the global economy often steer the trajectory of modern agrarian movements. Della Porta and Kriesi (1999) point out that although social movements in the globalized world are facing new constraints in their efforts to forge social change, globalization has also opened up new opportunities for collective action. Hendrickson and Heffernan's (2002) study of "food chain clusters" is a case in point. They argue that the "global corporate regime," which constitutes the modern agriculture economy, has shifted the market's interests from the farmer/producer to the ostensible needs of the consumer. In this arrangement food has been completely removed from "the sphere of personal relationships" (Hendrickson \& Heffernan, 2002, p. 348) and situated within the instrumental rationality of the "systems world" (Habermas, 1987).

Of course neither market restructuring nor the economy itself have ever been systems with predictable outcomes (Saul, 1997). Hendrickson and Heffernan argue that since the market is always in flux, weaknesses will emerge and new opportunities for resistance will be opened up, thereby presenting social movements with new chances to undermine the domination of global corporate food regimes. The authors outline the success of an alternative food movement - the Kansas City Food Circle - that 
successfully challenged the foundations of the global agricultural system by nurturing a localized relationship between producers and consumers through the establishment and effective promotion of a farmers' market in the city's downtown core, thereby ordering food "back into the lifeworld" (Hendrickson and Heffernan, 2002, p. 352).

The success of the Kansas City Food Circle was not instantaneous. Rather, the sustainable food movement grew out of the long-term efforts of organic farmers concerned with the economic and environmental viability of industrial farming practices. These ongoing efforts established a strong communicative network through which farmers were able to collectively develop the logic behind their alternative marketplace, as well as to design promotional and educational materials oriented toward urban populations. Thus, as this case illustrates, forms of agricultural collective action often require a great deal of coordination and commitment on behalf of members to ensure success.

This perspective links economic structure, particularly the global market, with movement practices; however, what these authors do not address is the political relationships within which movements are typically entangled. The reality is that the modern policy environment has positioned more institutionally robust organizations, particularly in the developed world, into a complicated situation. On one hand they "must defend [their] power, influence and reputation in... public policy [forums]. On the other hand, [they] must be able to stake out ideas about the future and identify the possibilities and threats for the organization and its members" (Gundelach, 2005, p. 251). Organizations, then, must simultaneously be a threat and an ally to a particular political system. As a result, organizations are rarely transparent communication channels linking 
farmers to policy forums; rather they play an intermediary role that for reasons of authority and political legitimacy will often disrupt the preferred discourses of farmers that can sometimes be anti-institutional, radical, and outside of the boundaries of what is considered "rational discussion."

Gundelach (2005), in his study of a Danish agricultural organization, shows that striking a balance between such interests is a difficult task, and in doing so reveals a whole other array of heterogeneous and contradictory relations within an already diverse assemblage of political and corporate actors. Contradiction occurs due to the close proximity that agricultural organizations occupy in relation to policy communities, agribusinesses, and other subsidiary organizations. This has resulted in an organizational impotence when it comes to leading or directly partaking in collective action, for doing so would threaten to undermine a particular organization's institutional legitimacy. For example, in the Danish context the strong political influence of the Presidium of the Danish Agricultural Council "mitigated against it taking an anti-State stance" (Ibid., p. 259), even though this was the desire of many farmers belonging to the group.

In focusing on the organization as his central unit of analysis, Gundelach is concerned with the social flows in macro-structures and their relation to broader change. Most notable in this study is the manner in which he illustrates how organizational structure is epiphenomenal of collective identity. By following the development of "visions" within the Danish organization, it becomes apparent that these types of groups are actually very diverse networks of micro and meso-actors ${ }^{4}$ who must continually struggle to negotiate and define a collective identity by overcoming interest-based

\footnotetext{
${ }^{3}$ By "visions" Gundelach means the image of the future direction of the organization.

"In this thesis "micro" refers to the interpersonal level, "meso" refers to the organizational level, and

"macro" is an abstraction of systematic, or large scale structures such as the government.
} 
differences, though in the eyes of actors on the periphery the group appears to be a coherent whole. In the Danish context, Gundelach shows that "organizational structures alone are not enough to create unity" (Ibid., p. 255), and in this case it took a shared class history, a common economic and democratic vision, and above all, cultural heritage to forge a collective sense of "we."

Halpin and Martin (1999), who also conceive that agricultural groups lie on the division between politics and identity - or are, as Klandermans (2002, p. 275) puts it, "identity organizations" - indicate that organizational elites shape visions in accordance with the nature of the corporatist relationships within which they are entwined. Thus, the identities of farmers that claim membership to groups that are embedded within political and economic structures are shaped by an agenda emanating from "above," yet internalized "below."

This is not to imply that farmers swallow whole all claims to identity. Halpin and Martin (1999) show that the discourses of capitalism propounded by organizational elites can be incompatible with farmers" interests, which can be thought of as having a "dual nature" (p. 84) combining commodified relations of production with familial and communal interests. Because the calculated rationality of economic discourse is not sufficient in itself to align interests, organizational elites must rhetorically and ideologically frame the benefits of membership in order to mitigate the occurrence of collective action. For example, in 1994 the New South Wales Farmer Association (NSWFA) launched an intra-organization communication campaign that equated family farms with small businesses, neglecting the social and cultural aspects of agriculture. According to the NSWFA, farmers were better off when they focus on operating and 
expanding their enterprises, but were expected to leave matters of the market to their group's leadership and management. This view, however, was not congruent with the needs and desires of its members, and, along with a sense that the organization was representing its members inadequately, this influenced farmers to revoke membership in the organization, causing a crisis of confidence within the group's elite cadre. The NSWFA reacted by marketing more services and material benefits exclusively to its members, such as reduced telephone rates, travel, and fertilizer. Though Halpin and Martin's study was published too soon to reach any grounded conclusions about the effectiveness of the strategy, they hint that the NSWFA was experiencing splits within its coalition at the time of publication (p. 94). Nevertheless, there is evidence that in certain contexts organizations may actually mitigate the chances of collective action occurring by "promoting a willingness to pay and not to act" (Ibid., p. 92), and in turn attempting to force a particular economically-oriented identity onto members.

Of course collective action sanctioned and backed by interest groups does indeed occur, but the proximity of organizations to the state, policy networks, and private enterprises also poses roadblocks to what Snow and Benford (1992) have called attribution, ${ }^{5}$ the process by which collective actors peg responsibility and blame for a particular problem on an identifiable culprit, and define a better future. It seems likely that movements led by or involved with agricultural organizations would be able to discern a somewhat defined perpetrator (e.g. the government, multi-nationals, other agricultural groups, or supra-national trade committees); however, as both Gundelach (2005, p. 258) and Klandermans et al. (1999) demonstrate, while injustices can readily be

\footnotetext{
5 In addition to "modes of attribution," frame functions include "punctuation" and "modes of articulation." See Snow and Benford (1992).
} 
made discernable, isolating and articulating an opponent is often a thorny task. In such a complex and bureaucratized matrix of players, accurately identifying a single actor as the wrongdoer is virtually impossible. As a result, agrarian movements often identify "market conditions" (Mooney \& Hunt, 1996, p. 181) as the target of their grievances. But placing blame on abstract forces that appear to operate without agency is relatively futile, for in such complex systems culpability falls simultaneously everywhere and nowhere at once. Moreover, articulating a specific perpetrator allows movements to also more clearly define themselves by delineating what they are not. The inability to do so not only poses tactical obstacles for movements, but, as Klandermans et al. (1999) point out, it also has a direct bearing on the development of collective action frames.

So, one should ask, within existing literature who or what are the opponents, perpetrators of injustice, and adversaries that pose threats to farmers and the movements they become involved with? While macro-actors such as the State, or large "systems" such as the market can be "pegged" as culprits, other actors, including organizations within the agrarian sector, also pose potential threats to movement efforts. Indeed, as Rucht (2004) and Greenberg et al. (2006) argue, competition and conflict among organizations within the same social movement sector is increasingly common.

On this note, it is important to understand that there is no single "agrarian movement." Rather, given the myriad political and economic interests of farmers, agrarian movements are typically constituted by multiple groups - these groups can be organized according to the commodities they produce (e.g. pork, dairy, honey, and wheat), on the basis of ethnicity or religion (e.g. the Christian Farmers Federation of Ontario, The Fellowship of Christian Farmers International, The Pastoral Land 
Commission [Adriance, 1994]), particular economic attitudes or ideologies (e.g. La Via Campesina [Rosset, 2006], The Canadian Agri-food Institute), etc. - that through processes of negotiation or "coalition work" (Rucht, 2004, p. 204) align goals and attempt to present themselves as a coherent whole. Historically there is evidence that alignment has been a daunting task, for agrarian movements in the past have often split along ideological lines. For instance, during the 1950 s, the American farming movement experienced a rift between those who wanted trade liberalization and those who wished to reinforce national markets through an increased level of government intervention (Robinson, 1989, p. 20). A similar issue but with a different language is emerging today with factions propounding free global trade and counter-factions pushing the idea of "food sovereignty" (Rosset, 2006). In other contexts, issues closer to identity and beliefs have cause friction within agrarian movements - e.g. religious farming groups counteracting their secular counterparts (Mooney \& Majka, 1995). In more recent times adversarial discourses have been dispersed by an external new social movement concerned more with the ethical dimensions of agriculture: the environmental movement sees agricultural practices as damaging to a region's "ecological heritage" (Tweeten, 2003 , p. 53), and in some cases has acted with militant force against farm organizations and agrarian movements.

Yet, as Reed (2004) illustrates, conflict does not necessarily dissolve or distort movements. Quite the contrary, for disruption can birth new movements carrying with them alternative discourses. Reed shows how a group of British farmers mobilized in defiance of the corporatist relationship in which their representative organizations had become embroiled. Central to this movement's mobilization was the role of the 
Countryside Alliance (CA), an interest group representing hunters who opposed the British government's mandate to ban game hunting with hounds. Leaders of the CA adopted a framing strategy aimed at bridging the prohibition of hunting with a threat to rural lifestyle. Of course, there is no immediate link between agriculture and hound hunting, but by aligning the CA's claims with the discourse of farmer exceptionalism (recognizing that many farmers also hunt) the group was able to enroll farmers to their cause. In the final analysis, the movement faltered and eventually petered out as no single notion of identity "based on a non-geographical 'rural way of life' [could take shape] due to the resistance of place and occupation-based identities" (Ibid., p. 40). Yet, this case shows how grassroots movements capable of radical action can still arise in political structures with institutionalized players ostensibly representing a spectrum of interests. Because the risks of institutional marginalization were non-existent, the farmers' movement was able to adopt a more confrontational repertoire of protest action, as well as an anti-statist posture.

Movements, however, do not only emerge out of the friction caused by corporatism $^{6}$. Not all farmers have readily available access to membership in mobilization-enabling agricultural organizations and are therefore unable to capitalize on, or for the matter mobilize against, the pre-established networks and institutional authority offered by them. This is particularly true in developing nations where farmers, unable to rely on existent power structures, must forge their own forms of grassroots organization, group solidarity, knowledge and skills.

\footnotetext{
${ }^{6}$ Corporatism can be loosely defined as the "fusion of the processes of interest representation and policy implementation into a reciprocal relationship between state and organized interest" (Cawson, 1986, p. 18).
} 


\section{The collective agrarian identity}

There are two main reasons why questions relating to identity have remained secondary to those focusing upon context or structure in the case of agrarian movements. First, the prominent role played by agricultural organizations in developing and articulating grievances has drawn attention to the macro-relations and power flows which shape organizational configurations, and which in turn feed back into political structure. Gundelach (2005) suggests that this is likely a symptom of a larger tendency in the sociological tradition "to focus more upon how social activities are determined by structural forces than upon how individual and collective actors have an impact on society" (p. 245). This has downplayed the roles of emotion and identity that are often infused in instances of both grassroots and more formally organized mobilizations (Goodwin et al., 2004). The second reason is the fact that agricultural movements do not fall so nicely in either "new" or "traditional" categories. That is, they are of a dual nature involving material and identity related issues, and accommodating this tension has proven to be a challenge to scholars tackling the topic. This is perhaps due to a shift in social movement theory away from movements related to production and towards ones that operate in civil society, such as the gay rights movement (e.g. Berstein, 1997). In these "new" cases, movement successes are perceived by scholars to be most contingent on the ability of activists to change the consciousnesses of people. As a consequence, limited attention is paid to structural forces. Thus, just as structural theories generally fail to adequately accommodate issues of identity, the same can be said about studies that emphasize identity, which tend to overlook or underplay the role of structure. As in other areas of sociology, a theoretical equilibrium linking the two streams of social movement 
theory has been difficult to establish, even though the literature recognizes the importance of accounting for both approaches.

Alvarez and Escobar (1992) suggest that we move beyond this conceptual roadblock to examine social movements "as the product of complex social processes in which structure and agency interact in manifold ways and in which actors produce meanings, negotiate and make decisions" (italics added, p. 4; in Conway, 2004). Even though agrarian action is aimed at reorienting dominant political structures, agricultural movements are, underneath it all, a group of individuals working together towards what they perceive to be a better future. This realization has prompted scholars dealing with agrarian mobilizations to adopt a new social movement paradigm (Pichardo, 1997), which emphasizes issues of collective identity and the (re)production of meaning.

Yet contemporary agrarian movements are consistently challenging Inglehart's (2003) claim that in post-industrial societies, social movements are most interested in changing cultural codes and defending identities. On one hand, mobilization occurs when market conditions affect or threaten the material well being of farmers - this, theorists would tell us, makes the movement a "traditional one" (Pichardo, 1997) for it is concerned foremost with the issues of redistribution rather than recognition (see Fraser, 1995). On the other hand, agrarian protest is fuelled by discourses about the decay of rural culture and the farming "way of life" (Woods, 1997). This gives evidence of a dual pathway to participation, "one guided by instrumental reasoning about the costs and benefits of participation, the other guided by processes of identification" (Klandermans et al., 2002, p. 236). 
In response to these conceptual issues, Castells (1983) argues that social movements need not be placed into such dichotomous categories as "old" and "new," and argues that the dialectical interplays between these forms deserve the most attention (Mooney, 2004, p. 91). Agrarian movements contain elements from each orientation simultaneously. Mooney applies this insight to his case, showing that by examining the organizational structure of a movement, and by studying internal power struggles over the preferred "logic of action," one can see how movement members seek institutional reforms on the basis of material and non-material interests.

Thus, the identity of movement adherents cannot be taken as a "given" (Polletta \& Jasper, 2001, p. 286), just as it cannot be interpreted as an artifact of political structures, for organization alone is not enough to procure incentive and commitment to a cause. The ways in which movement adherents perceive and capitalize on opportunities is to a degree contingent on a movement's ability to define, build and mobilize identity (Pichardo, 1997, p. 411). Touraine (1981) suggests that contemporary social movements are concerned primarily with information, and that scholars need to shed more light on the internal relationships that can alter the shape, the nature and the flow of information. Framing theory (Snow et al., 1986) attempts to address this shift in interest, and in doing so brings us into a more communicative realm that is concerned with the meaningmaking work implicit in the activities of social movements.

Collective action frames focus "attention by punctuating or specifying what in our sensual field is relevant and what is irrelevant, what is 'in frame' and what is 'out of frame,' in relation to the object of orientation" (Snow, 2004, p. 384). Framing theory views movement actors as "signifying agents actively engaged in the production and 
maintenance of meaning for constituents [and other targets] (Benford, 2000, p. 613). Though not "things" (Benford, 1997, p. 418), frames attempt to "make a compelling case for the 'injustice' of the condition and the likely effectiveness of collective 'agency' in changing the condition" (Poletta \& Jasper, 2001, p. 291). Frames, of course, are not constructed in a vacuum. Rather, they are in resonance with the cultural values or belief systems that circulate in a given society and in relation to the values and beliefs of the organization.

With respect to agrarian movements, Mooney and Hunt (1996) outline three dominant master frames ${ }^{7}$ that have proven to have the greatest resonance among farmers. The "agrarian fundamentalism" frame propounds that farming functions as the economic basis for all market activity. The "competitive capitalism" frame poses a critique to freemarket economic ideologies, and pleads for state intervention in order to break up agricultural monopolies. The final frame has been identified as the "producer" frame, which "contends that only direct producers are entitled to the rewards of production" (lbid., p. 184). According to the authors, these three frames are part of a larger "abeyance" process that allows "movements [to] sustain themselves in nonreceptive political environments and provide continuity from one stage of mobilization to another" (Ibid., p. 178). Though economic and political context remains in flux, agrarian grievances remain strikingly stable, arising as potent discursive mobilization tools time and time again.

\footnotetext{
${ }^{7}$ Snow and Benford (1992) define master frames as "modes of punctuations, attributions, and articulations may color and constrain [the collective action frames of] any number of movement organizations" (p. 138). Mooney and Hunt (1996) conceptualize master frames as being part of a larger "repertoire of interpretations" that are readily mobilized by social movements (p. 181).
} 
This interpretation is strikingly similar to Reed's (2004) study of the Countryside Alliance, in which he showed that the discourse of "farmer exceptionalism," "which [stresses] the unique role and burden of the farmer" (Ibid., p. 33), has been effectively used as a mobilization platform, even when dispatched by peripheral groups seeking farmer support for "rural" protests. Yet Reed does not attribute this idea as a form of master frame, and instead views farmer exceptionalism as an historically "stable discursive configuration ${ }^{8 \%}$ (Ibid., p. 34). Regardless of the theoretical underpinning, this research shows that in other contexts preexisting claims to identity and other ideological continuities (Mooney \& Hunt, 1996, p. 192) can be discursively attached to new identities and claims to injustice to which movement members can adhere.

Woods (2003) provides a more compelling analysis of how agrarian movements become linked up with broader "rural movements" that are constituted by different interest groups - in both institutional and grassroots forms - but are aligned under their shared goal of defending an identity (p. 310). Although he provides a partial analysis of the same case studied by Reed, Woods' analysis is supported by a much stronger theoretical paradigm that allows him to probe the specific techniques by which a collective identity has been forged in the face of difference. Central to his argument is the point that when confronted by an injustice, group solidarity and a shared collective identity can provide motivation for political action (Ibid., p. 316), and crucial to accomplishing this is the ability of a movement's leadership to successfully achieve frame alignment (Snow et al., 1986). Frame alignment refers to the process by which movements mobilize messages that can be "integrated with some cultural component

\footnotetext{
${ }^{8}$ Reed does not define the difference between a master frame and stable discursive configuration, but it seems reasonable to suggest that the former is sustained in a cultural field, while the latter is more of a tactical element dispersed by social movement organizations during times of protest.
} 
from the population to which they are addressed" (della Porta \& Diani, 1999, p. 74; in Woods, 2003). In the case of Woods' research on an emerging rural movement, the "rural preservation" frame provided the basis of this task, for it was a discourse relevant to all members of a rural population, including farmers. While extracting this ideological thread from rural movements is a theoretically feasible undertaking, isolating agrarian movements' claims to collective identity remains a problematic task. Nonetheless, the author brings attention to role that framing plays in mobilizing the consciousness of public opinion, which is established through frame bridging and frame transformation ${ }^{9}$. The former refers to the linking of "two or more ideologically congruent, but structurally unconnected frames regarding a particular issue or problem" (Benford \& Snow, 2000, p. 624). The latter - frame transformation - "refers to changing old understandings and meanings and/or generating new ones" (Ibid., p. 625).

In the past, agrarian movements have employed disruptive protest tactics (Tweeten, 2003), such as a group of Nebraskan farmers that violently confronted union busters, and attempted to raise the price of food products by blocking supply and trade routes during the Great Depression (Ganzel, 2003). However, in most contemporary contexts, where movements are increasingly enmeshed in relationships with the public, other agricultural actors, and political institutions, new risks are associated with radical action. Nonetheless, farmers are often willing to jeopardize established rapport to garner public support and generate media attention. Agrarian movements are at an advantage in this area, for they have a deeply established and tested "repertoire of contention" (Taylor \& Van Dyke, 2004) from which to draw. It is important to be aware that movement tactics are not always informed by prior protest, and that in many instances transferable

\footnotetext{
${ }^{9}$ Both of these processes are component parts of Benford \& Snow's concept of frame alignment (2000).
} 
strategies employed by other movements with similar or dissimilar grievances have provided tested methods of contention.

Woods (2003, p. 322) provides an excellent account of how farmers apply new protest strategies in the modern British context. In some contexts protest will take rather orthodox disruptive forms, occurring outside of institutions relevant to grievances, such as restaurants and supermarkets ${ }^{10}$ (the points where the public usually comes into contact with farmers' products). But in other cases more dramatic and radical action has been staged. Such was the case in 1997 when British farmers, upset about imported beef, dumped Irish beef burgers into the Atlantic Ocean. In another context, farmers staged a series of fuel blockades designed to draw attention to the rising price of petrol and its negative effects on the profitability of agriculture. Disruptive tactics, however, are not always successfui; the fuel protests posed a serious threat to the personal mobility of the public and eventually drew the ire of politicians, consumer groups, and the general British population who did not develop the sympathy protest leaders required to alter the fuel prices at the legislative level.

Though tactics may not resonate with the public, protest serves another function by helping to consolidate commitment and shape collective identity (Klandermans et al., 2002). As has been argued above, scholars have attributed the crystallization and reinforcement of identity to framing strategies employed by an agrarian movement leadership; however, such a theoretical posture downplays the intellectual capacities of farmers, who, given the nature of their occupation, are very much a "hands on" group. Indeed, the framing approach does show that membership itself has an effect on the

\footnotetext{
${ }^{10}$ For example, on June $11^{\text {th }}, 2008$, Irish farmers picketed at a local branch of the Lidl supermarket chain (Independent, 2008).
} 
character of individual and group identities - supporting the fluid view of identity - but such research relies heavily on discursive and ideological theories that can lead to the reification of abstract concepts. Frame theory and the bulk of identity-related studies argue that collective identity stimulates participation; Klandermans et al. advance this claim by bringing in an empirically analyzable behavioral component - emphasizing the protest practices of agrarian movements - demonstrating a causal link implicit in agrarian protest dictating that "membership stimulates participation and participation stimulates membership" (Ibid., p. 239). While the study downplays the effects that internal and external power struggles have on agrarian movements, its claims are reinforced by its methodological framework, which compares empirically the behaviors of two separate movements. This extends past studies of the same topic that have focused on participants within a single movement, because the comparative approach makes it clearer whether or not participation in collective action made the difference.

\section{Towards a more inclusive paradigm}

While these studies have shed light on many of the political and socio-cultural dimensions that are fused into this type of protest, they often base their findings on theoretically foggy assumptions about the social psychological functions that organizations play in the formation of collective identities. On the other hand, those most interested in issues of collective identity and meaning in relation to farmers have lost sight of the ways that organizational processes influence mobilization and signification processes. It is evident, then, that there is some difficulty in connecting context to consciousness without downplaying either category of analysis. This reflects what seems 
to be a larger problem with research on social movements, which attempts to posit theoretical emphasis into an ostensible dualism.

It is argued in the next chapter that the best path to linking consciousness to context is by paying more attention to the ways that farmers actually come to participate in protest. By socially embedding farmers into prior existing relationships - i.e. organizations - we can also come to a better understanding of how macro-level processes affect the mobilization of consensus amongst agricultural actors. 


\section{Chapter 2: Theoretical framework}

As was made evident in the last chapter, the concept of the social movement organization (SMO) has played a central role in understanding the processes through which farmers develop politically salient identities and in turn come to participate in protest. By situating the micro-processes of actors within the macro-structural operations of organizations, some scholars have attempted to develop a means to analyze the change without overly mitigating the agency of movement participants, nor over-emphasizing the structuring effects of their environments.

In order to understand the reasons why people participate in one organization over another, early studies in social movements tended to focus upon on how movement organizations "solicit, coax, and secure participants" (Snow et al., 1980, p. 799). However, due to their analytical reliance on a presumption of rational action, issues of collective interest came to be seen as individualistic in nature, meaning that mobilization is a matter of an individual weighing the personal benefits of participation in protest against any possible costs. This conceptualization has received a considerable amount of criticism from scholars who see protest as a process that extends well beyond political and material redistribution and the calculation of benefits and costs (McClurg Mueller, 1992; Polletta \& Jasper, 2001).

By problematizing the motivations behind peoples' decision to protest, new social movement scholars have de-privileged the focus on organizations in explaining mobilization processes. In a sense they have fused questions of why social movements emerge with questions pertaining to how they have emerged (Hannigan, 1985). Although 
these more sociological approaches have expanded our understandings of organization, very few scholars have approached the cultural dimensions of mobilization from the multi-organizational perspective.

As suggested by the theory's title, employing the multi-organizational perspective requires an analysis of multiple organizations. But understanding the dynamics between different organizations is not always a matter of comparing and contrasting their structural composition. Because the mere availability of an organization is not enough to explain collective action (Rucht, 2004), we must examine the factors that influence one's decision to participate in protest (McAdam, 1988, 2004). Organizations are fundamentally constituted by individuals who cannot be defined only in terms of their involvement. Instead they can be better understood by examining their membership in other social groupings both within and beyond a field. Such an approach necessarily links context with the actions of individuals.

This chapter establishes the theoretical framework that will provide the foundation for the case study. First I turn to Klandermans' concept of multiorganizational fields in order to provide an understanding of the new realities which SMOs face. This is followed by a re-conceptualization of social movement actors and the dynamics they share with their environments. I then turn to a discussion of the implications posed by the multi-organizational perspective with regards to actors' ability to use strategic knowledge in making the decision to protest. Finally, I turn to Michel/Webers" "iron law of oligarchy" (Ansell, 2001) to conceptualize how macro-level processes can affect the stability of participants' collective identities, and provide opportunities for emergent SMOs. 


\section{Multi-organizational fields}

Social movement action has typically been understood as a two-party struggle between well-defined movements and the State. Yet there is a body of literature drawing attention to the reality that collective action is not necessarily a bilateral or dichotomous process. Theorists are becoming increasingly aware that social movements must coordinate their activities amongst many other movements that are, to varying degrees, oriented towards the changing cognate social conditions. In a classic article Curtis and Zurcher (1973) defined these micro-political environments as multi-organizational fields, which in their most rudimentary form are "the total possible number of organizations with which the focal organization might establish linkages" (p. 53). While the foundation for the concept of multi-organizational field is over thirty years old, recent scholars such as Evans (1997), della Porta and Rucht (1995), and especially Klandermans (1997; 1999; 2002; 2004) have begun to further explore its implications to understanding contemporary social movements by fusing it with frameworks that were not in circulation when Curtis and Zurcher initially wrote about multi-organizational fields.

In today's socio-political systems, rarely can a single SMO claim authority over a particular issue. Depending on the issue there will exist myriad groups sharing similar goals and objectives, but differing in terms of their social compositions (Klandermans, 1992), size, preferred strategies, self-identities, and decision-making apparatus. Under certain circumstances these groups will negotiate amongst each other, cooperating and combining resources in order to reach a preferred objective. Staggenborg (1986) calls these cooperative efforts "coalition work." By forging alliances and networks with other groups, SMOs are offered more chance to expand the robustness of their membership 
base, mobilize other previously unattainable resources, identify and capitalize on new opportunities, and exert political influence in previously inaccessible arenas. From this perspective SMOs are hardly the autonomous, homogeneous agents of social change they were once thought to be, but are instead constituted by complex networks of relations between individuals and organized groups operating at the field level. Though the scholarship focusing on multi-organizational fields is relatively small, scholars have placed the most amount of attention on analyzing these cooperative alliance systems (Kriesi, 1985; Klandermans, 1989).

Where there are opportunities for cooperation, there will also be opportunities for conflict, dissent and antagonism. Conflict systems (Klandermans, 1990; 1997) are also manifested in multi-organizational fields, but they have received considerably less attention from scholars. Social movements must almost always interact with antagonistic movements that make up conflict systems, which Klandermans (1992) defines as the "representatives and allies of the challenged political system, including countermovements organizations" (p. 95, see also Kriesi, 1985). Conflict systems are primarily concerned with draining resources and limiting the political opportunities of their opponents (Gerlach, 1999).

How these systems come into existence varies. More often than not they form as counterarguments to the efforts of other thematically opposed social movements (Conover \& Gray, 1983; Mansbridge, 1986). Conflict systems will sometimes gain allies, or even come into existence, when alliance systems fall apart (Rucht, 2004, p. 206). For a multitude of reasons coalitions do not usually endure for long periods of time (Klandermans, 1997, p. 149). This implies that under certain circumstances the ties 
within an alliance can be severed, creating new organizations that can better facilitate new or alternative grievances.

It is becoming increasingly apparent that variance between conflict and alliance systems are not necessarily the result of antagonistic relationships, an example being the distinction between the pro and anti-abortion movements. Following Meyer \& Staggenborg, (1996) counter-movements - or oppositional movements - should be thought of as "networks of individuals and organizations that share many of the same objects of concern as the social movements they oppose" (p. 1632). Thus the separation between the alliance and conflict systems is fluid and often overlapping, depending on the social and political circumstances in which they come into fruition and whether or not the organizations come from the same social movement industry (McCarthy \& Zald, 1977, p. 1220). Accordingly, we must be aware that the make-up and character of a multi-organizational field can change dramatically over time. Because alliance building between groups with similar goals strengthens their chance of success, most of these changes occur in peak protest times when organizational coalition work is most important; at these politically salient times nearly every organization will become engaged in one system or the other (Klandermans, 1992, p. 96).

Yet mobilization, collective action and coalition work cannot operate solely at the field level. Organizations must also compete within a much broader political and cultural environment. Klandermans (1997) addressed this issue by distinguishing the supporting (i.e. alliance system), antagonistic (i.e. conflict system), and indifferent (i.e. neutral) elements of a movement's environment. The indifferent segment includes bystander publics, media, and potential allies, i.e. those actors that are being "courted by the 
alliance and conflict sectors" (Evans, 1997, p. 452). As Rucht (2004) indicates, winning the support of these groups often marks the difference between a successful and failed movement, and their support is especially crucial for organizations that lack financial resources and direct access to political elites (p. 200; Gamson, 2004, p. 251).

The multi-organizational perspective marks a significant move towards integrating agency and structure into social movement theory. Since interpersonal microprocesses cannot be wholly contingent on structure, and since mobilization cannot occur in a socio-political vacuum, then any claims to the salience of symbolism, identity, and other micro-processes are hollow unless they are anchored in the "actual operations of specific social structures" (Klandermans, 1992, p. 78). By conceptualizing both of these dimensions - agency and structure - as fluid, dialectical, concurrently emergent, elements within the lives of social movements, the multi-organizational perspective allows us to bypass the overwhelming centrality of the concept of the organization.

\section{(Re)conceptualizing actors: SMOs and the (re)construction of collective identity}

According to the rational actor model, individuals mobilize through a process of "weighing the relative costs and benefits of social movement participation and opting for participation when the potential benefits outweigh the potential costs" (Buechler, 1993, p. 218). Conversely, as Olson (1965) argues, rational actors will not necessarily act towards collective benefits because public goods cannot be denied from members of a group regardless of whether or not they have participated in protest. This theoretical hitch has appropriately been conceptualized as the "free rider" dilemma (Ibid.). One response to this problematic was that SMOs could offer active participants certain privileges and incentives that could be withheld from non-participants (Buechler, 1993, p. 218). 
Because the paradigm understood the occurrence of protest as contingent on a collectivity's ability to recognize political opportunities (Polletta \& Jasper, 2001, p. 286), organizations were considered the channels through which opportunities were "revealed" to potential participants. Mobilization was therefore understood as a matter of disseminating information amongst potential participants in order to provide them with the logical grounding required to facilitate the informed decision of whether or not they would participate. In other words, the role of the organization was to "lure" participants by rhetorically "selling" the reasons why participation would be beneficial to an individual $^{11}$.

Armed with this understanding of the relationship between individuals and movement organizations, resource mobilization scholars interested in organizations began to focus on the ways groups attained and secured the commitment of individuals (Marx \& Wood, 1975; Zald \& McCarthy, 1979; Snow et al., 1980). In most basic form, the logic behind the resource mobilization paradigm was based on the notion that the more resources a movement could acquire or accumulate, the greater the likelihood that it would realize its political goals. Analyzing the processes through which organizations recruited members seemed an effective way to explain the success of some movements and the failures of others. However, depending on the relevance and the historical rootedness of a social issue (Conover \& Gray, 1983; Mansbridge, 1986), social movement industries may house myriad organizations that vie for the support of those individuals that have not yet adhered to a particular movement. By the late 1970 s

\footnotetext{
${ }^{11}$ This economistic view of organization was later criticized by Fireman and Gamson (1979, see also Buechler, 1993) for it failed to account for the fact that people often become involved in protest for nonselfish, moralistic reasons as well.
} 
scholars realized that like any other resource, movements must compete for the consensus of potential participants (Edwards \& McCarthy, 2004, p. 127).

At the time this raised a critical analytical question: given the prevalence of competing and functionally equivalent movements, how is it that people come to participate in one movement and not another? Snow et al. (1980) followed this line of inquiry in their study, which employed a "micro-structural approach to differential recruitment" in a comparison of three separate movements. Knowing that participation in a social movement could not be random, the authors analyzed the various social and spatial factors that structured mobilization. They found that being recruited into a movement was to a great degree contingent on an individual's "links to one or more movement members through a preexisting or emergent interpersonal tie" (p. 798). Thus face-to-face interaction occurring in extra-movement social networks became the one of the primary means to explain how the benefits of participation were communicated to potential adherents.

Though Snow et al. (1980) problematized the question of the social location of actors, they concluded that shifts in organizational structures matter, and explained the basic features of structured social groupings and their subsequent connection with successful recruitment campaigns. Yet, the authors can really only answer questions about the channels through which movements disseminate information to bystanders. These channels, however, are social bonds, and, as Snow would tell us ten years later, the nature of the information that flows contains subjective cultural and symbolic elements that are analytically salient to the study of movements (Snow, 2004). Moreover, this literature problematically binds the agency of participants to the rhetorical activities of 
SMOs, and fails to see that people often shape organizations in terms of both their structure and discourse.

\section{Identity and the construction of meaning in the context of multi-organization fields}

Resource mobilization theory implicitly assumes that the robustness of organization leads to movement success. We now know that the acquisition of resources is only one of the many dimensions of collective action and only partially contributes to the failure or triumph of social movements. Framing literature (Snow et al., 1986; Benford \& Snow, 2000; McAdam, 1996) has highlighted the symbolic character of social movements; political and cultural opportunities theory (Tilly, 1995; Diani, 1996; Tarrow, 1994; Kubal, 1998) have drawn a considerable amount of attention to the structures and contexts in which movements operate; and the new social movements paradigm (Offe, 1985; Melucci, 1985; Polletta \& Jasper, 2001; Buechler, 1993) has challenged the positivist (instrumentally rational) assumptions underpinning orthodox resource mobilization theory and replaced them with one focused on the interpersonal dimensions and processes of collective identity and discourse. No longer can the discipline theorize assumptions about grievances, goals, and preference structures, nor can it "sidestep the controversy over the explanation of 'subjective experience' and such 'things' as meanings, intentions, ideas, values, and emotions..." (Shweder \& Fiske, 1986, p. 7, see also McClurg-Mueller, 1992, p. 4).

Whether a movement is geared towards changing dominant cultural understandings or altering the direction of policy, empirical evidence supports that establishing a collective identity is a prerequisite for collective action (Gamson, 1991; 
1984; Hunt \& Benford, 2004). Polletta and Jasper (2001) have defined collective identity as:

an individual's cognitive, moral, and emotional connections with a broader community, category, practice, or institution. It is a perception of a shared status or relation, which may be imagined rather than experienced directly, and it is distinct from personal identities, although it may form part of a personal identity... Collective identities are expressed in cultural materials - names, narratives, symbols, verbal styles, rituals, clothing, and so on - but not all cultural materials express collective identities... And unlike ideology, collective identity carries with it positive feelings for other members of the group (p. 284).

Whether in formal or informal organizations, people perceive, debate, contest, interpret, and attach meanings to events, social issues, and objects over which, for a variety of reasons, they may share concern.

These constructions, however, are not based on any a priori reality. It is tempting to conceptualize people according to social categorization -- e.g. race, age, religion, sex, etc. - but it would ultimately misrepresent the actual ways that collectivities are constructed. Social networks are not constituted by homogeneous populations possessing an inherently shared understanding of an ostensibly objective reality; rather, individuals are almost always embedded in multiple, overlapping interpersonal "networks of small groups emerged in everyday life" (Melucci, 1984, p. 829) from which they appropriate their individual beliefs (Klandermans, 1992, p. 82; Gould, 1998). The point is that identity cannot be treated as though it were a thing, and instead should be understood as a subjective, and therefore not longstanding, set of meanings produced primarily through communication.

Through ongoing processes of negotiation, individuals partaking in collective action are required to position themselves within a multi-organizational field that also 
comprises other identities. Situating oneself must therefore involve the establishment of boundaries. According to Taylor and Whittier (1992) "boundaries mark the social territories of group relations by accentuating putative moral, cognitive, affective, behavioural, and other attributed differences between social movement participants and the web of others in the contested social world" (Hunt \& Benford, 2004, p. 442). The definition "who we are" entails a construction of a collective self and collective other; a phenomenon very similar to Anderson's concept of the imagined community ${ }^{12}$ (2006). The contours of a movement may be spatially mapped, as hinted at by Evans and Boyte's (1986) idea of free spaces; they may also manifest themselves in the practices of movement participants (Eliasoph, 1998, p. 21). Though movements certainly exist without formalization, SMOs are often central in the construction and maintenance of boundaries, for they lay out in detail the appropriate grounds for interaction required for membership. Via a process identified as "boundary framing" (Hunt et al., 1994, p. 193, see also Hunt \& Benford, 2004, p. 442), SMOs actively encourage meanings of inclusion which serve to solidify a collective identity, demarcate what beliefs are acceptable, and in turn what beliefs are to be excluded from participation.

Boundaries, meanings, behaviours, and all the other elements that come to form collective identity processes are not produced through the efforts of atomistic individuals alone. Rather, identity is a socially constructed element, and is therefore necessarily an interactional process occurring amongst multiple (sometimes thousands) of individuals. Yet, some scholars fail to see that these processes do not always take place in the settings of SMOs. Meanings about protest occur far beyond the confines of the practice of protest

\footnotetext{
${ }^{12}$ Anderson conceptualized large communities and nations as being social constructions. Because in no group of considerable size can every single person establish bonds in face-to-face interaction, they possess a mental image of the ties that bind, hence "imagined" communities.
} 
itself; they also take place in the interpersonal life circles and other spaces which house individuals who have yet to participate in collective action with a particular group. These are the environments in which actors first gain their collective beliefs that influence how it is that they make sense of the social and political world(s) out there. There, individuals engage in face-to-face communication to interpret events and construct the meanings that come to define certain social conditions as problematic, or worthy of grievance (McClurg Mueller, 1992, p. 11).

Like all other social processes, these relations do not occur in a hermetically sealed environment removed from public discourse. Following Klandermans (1992) we must pay attention to how the construction of meaning is mediated by other extramovement players. Gamson $(1989 ; 2004)$ has made clear that the mass media now plays an increasingly important function in mobilization processes. The mass media is perhaps the largest public arena in which argurnents about new information and events are subjected to debate. Often newsmakers will pick up a story based on its sheer relevance to other parts of their socio-political environment. Anti-nuclear activists, for example, were able to garner a great deal of media attention due to the amount of coverage environmental issues received in the lead up to their protests (Mazur, 1981). Social movement messages are not always so fortunate as to enter into environments so sympathetic to their goals. It follows that SMOs themselves invest a great deal of resources into generating media attention through such methods as planning spectacular protest tactics, building insider relationships with members of the media, enrolling prominent public figures to their cause, or creating their own media products (Ryan, 1991; Gamson, 2004; Greenberg et al., 2006). Whether or not the integrity of an 
organization's message will be upheld is contingent on the biases that may influence the decisions of editors, as well as the "standing" of other competitive or antagonistic groups within a multi-organizational field.

Media discourses, of course, are not spoon fed into the consciousnesses and practices of individuals, as if they could transform identities directly. Instead, "the actual formation and transformation of collective beliefs [pertaining to media discourse] take place in exchange within the groups and categories with which individuals [already] identify" (Klandermans, 1992, p. 89). Information may be framed in certain ways, but there is no guarantee that individuals, embedded within social groups, will understand or agree with the message(s). Whether or not the information can be incorporated into the interpretive frameworks of these groups is contingent on numerous factors, not the least of which is its congruence with their collective beliefs (Ibid.). Yet an awareness of grievances can by no means actually be considered protest; before collective action can occur, the consciousnesses of actors must be transformed or mobilized in a way that they seem necessary or appear as crucial to social change, and that the subsequent protest will meet their "success expectations" (Klandermans, 1984).

Organizations are frequently "the critical element distinguishing ineffective grievances from potentially consequential protest" (Minkoff, 2004, p. 155). Perceived injustices are often transformed from words to action via SMOs that target and attempt to persuade prospective participants and existing members to mobilize into collective action by anchoring their arguments for action in the beliefs of individuals and groups. Snow et al. (1986) define this process as collective action framing. Through framing processes, movement actors attempt to attach particular meanings to collective action; however the 
degree to which these meanings will resonate depends on the ability of movements to align the belief systems of the individuals they are seeking to mobilize with the values and claims of the organization.

According to Snow and Benford (1988) the "content" of collective action frames consists of three elements which the authors have identified as the core framing tasks. Diagnostic framing attributes the responsibility for a problematic or unjust situation onto an identifiable culprit. Prognostic framing "involves the articulation of a proposed solution to the problem, or at least the plan of attack, and the strategies for carrying out the plan" (Benford \& Snow, 2000, p. 616). Finally, in accordance to the first two tasks, motivational framing provides the rationale for partaking in protest. By dispersing a vocabulary promoting "severity, urgency, efficacy, and propriety" (Ibid., p. 617) social movements provide activists with convincing logic for partaking in protest and sustaining commitment throughout action. For instance, Greenberg et al. (2006) showed how a homelessness advocacy group in Ottawa attempted to bring a "fresh" sense of urgency to a topic that teetered on the mundane by portraying a much more diverse face of homelessness, inclusive of women and children - not exactly the "disheveled, drunk, lazy, middle-aged, white male... that past studies identified as the typical image of homelessness" (p. 143).

It is important to be aware that these framing activities take place in multiorganizational fields. In addition to targeting members, potential allies, media, and bystander publics, SMOs must also practice counter-framing (Benford, 1987), which can be defined as the symbolic refutation of the logic of collective action frames dispersed by oppositional movements. If left unchallenged, the frames of antagonistic or even 
competitive organizations can eventually dismantle the fabric of an alliance by altering perceptions of an issue (Evans, 1997, p. 453). In a study about the religious pro-choice movement, Evans (Ibid.) points out that because there are potentially thousands of groups that a movement organization may perceive as either supportive or opposed to its goals, the activity of targeting involves precarious and strategic effort. Movements must meet the framing needs of multiple and often competing targets, while at the same time constructing frames that resonate with potential participants, the media and bystanders (Gamson, 2004). This process involves a sense of vigilant reflexivity that entails constantly weighing "the anticipated responses of these various groups and seek through their choices to balance the conflicting demands of the organizational environment in which they are embedded" (McAdam et al., 1988, p. 726, see also Evans, 1999, p. 455). From a symbolic standpoint, the consequence of this practice is that characteristics of one target affect the framing efforts towards another, thereby affecting the mobilizing vocabularies and logics available to movement organizations. This suggests that the mobilization efforts of SMOs are inextricably linked as they vie for the hearts of individuals.

At the field level the "politics of signification" (Hall, 1982) are all about which organization's version of reality will prevail. Though it is often difficult to define the boundaries of a multi-organizational field (Klandermans, 1992, p. 95), the ostensibly amorphous nature of alliances and conflict systems can be determined by studying different meanings or frames. These meanings, however, are subject to change as a protest cycle (Tarrow, 1994) pans out, and as organizational boundaries take on new forms. Furthermore, depending on the events that precipitate a protest, conflict systems 
might not be identified by SMOs until well into a protest cycle. In fact, new opportunities for conflict systems often arise out of the mobilization efforts of the movements they oppose (Klandermans, 1997, p. 145). For example, the womens' movement in the U.S. came to experience great levels of success (Conover \& Gray, 1983; Mansbridge, 1986; see also Klandermans, 1997 , p. 145) early in its career because the movement itself constructed the "women's rights industry." However, as women's issues began to take on a heightened level of social and political significance, the New Right ${ }^{13}$ aligned itself to a conservative American government, and a powerful conflict structure quickly materialized. By restricting available opportunities, this newly formed conflict system severely challenged the efficacy and the inter-organizational bonds of the women's movement. The significance of the women's movement eventually rebounded, but only after it had rebuilt and "fortified" the connections between the actors of its alliance system. As studies like these show, attention must be paid to the ongoing interactions occurring within alliances and in relation to conflict organizations throughout a mobilization period.

\section{Multi-organizational fields and strategic knowledge}

It is important to note that new participants within a SMO are not necessarily bright-eyed newcomers to collective action. Social movements are increasingly coming to be comprised of coalitions of organizations, some of which may be new to a particular social issue, but many that have already gained significant experience in an area. Through prior participation in other SMOs, actors are able to gain considerable knowledge about

\footnotetext{
${ }^{13}$ The New Right refers to a conservative political movement that arose through grassroots organizing in the early 1960 s.
} 
such things as the grievances, ideologies, strategies, opportunities, and other organizations operating within a specific, or broad social movement sector. Armed with this knowledge, actors are better able to critically assess those organizations operating within their field of interest, making the marketing of participation a more difficult process on behalf of movement organizations. While the argument that actors are rational, and thus purely instrumental, has become less certain, there does not seem to be any concrete reason why we cannot conceptualize mobilization as a process involving actors possessing both instrumental and non-instrumental logics of action.

The very idea of multi-organizational fields suggests that movements are moving increasingly towards communities of practice (Brown \& Duguid, 2001), which, according to Suchman (1987), are brought into fruition through the "moment-by-moment interactions between actors, and between actors and their environments of action" ( $p$. 179). Through the relationships necessary to establish alliance systems, groups learn from each other, share cultural and pragmatic resources, and work collectively towards developing technical knowledge in terms of their particular interest(s), though this activity might not be the result of a conscious effort. The outcome of the processes occurring in communities of practice is expertise, particularly in the area of protest.

It is generally understood that strategic knowledge is formed and put into practice through the direction of an organization's leadership cadre (Morris \& Staggenborg, 2004). Because of their in depth knowledge of political action, leaders are the ones that set movement trajectories by accomplishing tasks such as the construction of collective action frames and the development of tactical repertoires of action (Taylor \& Van Dyke, 2004). From the multi-organizational perspective, they are often central actors in 
determining whether or not participation in an alliance would be beneficial to their membership base. In most cases it can be expected that rank-and-file members will agree with the decisions of organizational elites, assuming that elite decisions are not out of alignment with the core beliefs of the group, the levels of solidarity and commitment are high, and that leaders have maintained a good rapport with their constituency.

Activists, however, are not sheep, and though the role of leadership cannot be excluded from examining the strategic dimensions of protest, focusing on elites alone risks marginalizing the agency and critical role of rank-and-file members by relegating them to "follower" status (Morris \& Staggenborg, 2004, p. 171). Moreover, not all organizations are endowed with adequate leadership. Some formal organizations are built on a principle of democratization in which there is never any clearly defined leader; others, conversely, are overly bureaucratized (see below), while many more may not yet have had the opportunity or need to establish a well-defined core group of leaders.

The point is that leaders are not the only actors that gain technical knowledge in communities of practice. Everyday members too are actively participating in the production and exchange of technical knowledge about social problems and protest. This knowledge extends beyond cultural norms, but it is certainly part of the mental schemata that constitutes collective identity. As organizations and communities cross-pollinate, members are exposed to the current and past strategies and tactics of their interlocutors, as well as the opportunities of gaining perspective about the inner dynamics of other groups operating within their field. On one hand this information can reinforce the boundaries of membership; on the other, it can bring awareness to the structural or 
strategic problems that might pervade one's own group, in turn lowering their success expectations and commitment to a particular association.

Organizational cooperation and communities of practice have implications for collective identity processes as well. As overlap occurs, the individuals within different groups are rendered first hand in face-to-face interaction to alternative ideologies, beliefs, grievances, protest narratives, and symbolic meanings circulating beyond the immediate confines of a single organization. Unlike debates occurring in public arenas, such as the mass media, where discourse tends to flow in a linear fashion, actors are able to pose arguments for and against the elements that constitute one another's beliefs. At a general level, because alliances are typically constituted by cognate organizations, individuals within them are more likely to be sympathetic to each other's beliefs systems. Through this process actors are endowed with new interpretive mechanisms from which to understand the social problem that has brought them together in the first place. Though it is doubtful that this effect occurs due to deliberate efforts on behalf of actors, alliance building nonetheless sets the stage for the transformation of collective identities. From a micro-level approach this suggests that alliance building is more than an outcome; it is also a means and process through which the consciousnesses and identities of adherents are formed.

\section{The destabilization of multi-organizational fields through institutional limitations}

As Zald and McCarthy (1979) postulated, social movement industries house organizations varying in size and power. And like firms in economic industries, SMOs aim to reduce the power of their competition and establish themselves as the dominant actors within their field. It follows then that social movement industries can become 
oligopolistic and monopolistic (Ibid., p. 4) with very few players controlling the direction and meanings of protest. For example, any environmentalist organization wishing to initiate international-level protest will sooner or later encounter (and likely have to deal with) Greenpeace. However, this power is by no means eternal, in part because groups are required to make certain concessions that can limit their ability to uphold the popular sovereignty ostensibly associated with democratic participation in organizations.

In contrast to the many scholars that have proclaimed the empowering aspects of organization, there are those that see organization as antithetical to effective protest (Clemens \& Minkoff, 2004, p. 155). The iron law of oligarchy ${ }^{14}$ (Michels, 1966; Piven \& Cloward, 1979) puts forward the notion that the formalization of an organization entails the implementation of a bureaucratized hierarchy, which, once in power, suppresses the capacity for any disruptions that may threaten its leadership. As organizations grow larger and more complex there must be an assigned leadership cadre to coordinate their activities (Freeman, 1970), thereby creating a differentiation between elite and rank-andfile. The process of participatory democratic decision making is replaced by the delegation of power into the hands of very few - the "oligarchy" - that will use their influence in any way necessary to preserve their status and esteemed role (Ansell, 2001, p. 10853). With regards to social movements, one way to do this is to deny radical forms of protest.

The close proximity that some organizations hold to formal political structures compounds this paradoxical situation. Often it is the goal of SMOs not only to change the

\footnotetext{
${ }^{14}$ A number of scholars have questioned the analytical utility of this concept, claiming that bureaucratization is not necessarily a final outcome of organization (Voss \& Sherman, 2000; Clemens \& Minkoff, 2004; Ansell, 2001). Even though it may be a "tendency," the applicability of the iron law can not be discarded.
} 
direction of policy, but to also become incorporated into the policy-making processes in the sector that holds their concern (Reiss, 2005). On one hand entering into policy networks ensures that movement goals are officially integrated into governmental mandates and strengthens the sustainability of an organization. On the other hand, it can have significant implications for managing the interests between membership and the organization. As Greenberg et al. (2006) argue, SMOs that employ radical "front-stage" strategies risk distorting their prognostic frames, as public discourse is more likely to focus on their tactics rather than their proposed policy changes.

SMOs spend a great deal of resources in order to become vocal in decisionmaking processes, usually in policy communities. Though they must negotiate with other players active in their sector, alienation from decision-making processes would be counter-productive to the ongoing efforts of thousands, if not hundreds of thousands of people. Accordingly, organizational elites will sometimes attempt to suppress collective action, particularly State-oriented protest, in order to mitigate the risk of institutional marginalization. In addition to this, Klandermans et al. (2002) suggest that this macrolevel concern problematizes diagnostic framing tasks, resulting in an attribution of blame towards broad systematic factors rather than identifiable culprits.

Organization can therefore place a movement in a potentially problematic position. In its most professionalized form it can open up an ideological rift between elites that are more likely to represent their own interests than those of their membership base that might see protest as the most suitable route to changing dominant structures to their favour. Yet, while these interrelated processes expose a weakness to politically entrenched organizations, they also create valuable opportunities for upstart SMOs to 
garner the support of individuals already active within a particular sector (Reed, 2004). This rupture is particularly salient for emerging groups active in social movement industries that house limited pools of adherents. The developments associated with formalization set the stage for "identity destabilization" (Gamson, 1995); the "we-ness" of collectivity is diminished, collective action frames are put into question, and new intraorganizational grievances come into fruition when the interests of an organization are prioritized over its own members. These effects give members the impetus to seek or form other movements that offer opportunities for more radical or direct action.

It follows that for people participating in social movement industries that have grown stagnant due to monopolization and bureaucratization, emerging organizations will seem much more appealing to disgruntled activists. Though they may experience bureaucratization in their futures, new groups are typically not bound in the problematic relations that threaten their more established counterparts. Most new SMOs begin as relatively small-scale initiatives consisting of predominately interpersonal relations -- i.e. "grassroots." This makes democratic participation more likely, for participants are able to communicate directly amongst each other, thereby actively influencing the character and direction of protest. Elites are included in this process, for their technical knowledge and leadership skills are essential in the early stages of mobilization. In turn, leaders play an active role in the creation and maintenance of an organization's collective identity: a process that is especially essential for new groups (Franzen, 1993, p. 304). With elites actively engaged in communication with rank-and-file participants, the risk of ideological rifts and boundary distortions are mitigated. Moreover, though cozying up to formal political structures might be an objective of an emergent movement organization, in their 
formative stages new SMOs will not yet have obligations to the State; alienation from policy communities is not a concern for newly formed SMOs for the simple reason that they have not yet established formal relations with governmental actors. They consequently have nothing to lose from incorporating an anti-State diagnosis into their framing strategies - that is unless mobilization occurs in an overly oppressive government. 


\section{Chapter 3: Research Methodology}

This chapter elaborates on the research strategies employed in this project as a means to examine the processes that multi-organizational dynamics play in how Ontario farmers may interpret social issues, and how these constructions influence their adherence to different organizations, particularly the Ontario Federation of Agriculture and the Lanark Landowners' Association.

As suggested in the introduction to this thesis, rather than coming to this project as a "detached observer," I approach it with a background in both farming and union organizing for the NFU in Renfrew County. I have a working relationship with some of the participants in this study, while others I have known through activities associated with my family farm. I have been referred to many respondents through these associations, while I cold-called others.

As noted in the previous chapter, farmers are embedded in a series of interactions and organizations that can be conceptualized as a context. It is through their relations with and within organizations that they come to develop shared meanings about their identities, grievances, collective action, and organizations. It is doubtful that the entire array of relevant actors will come to share the same meanings, and for this reason one can expect multiple realities to be (re)constructed and circulated amongst them. Because protest is a socially constructed and subjectively interpreted phenomenon, the methods of investigation employed in this study are aimed in part at highlighting its experiential dimensions. Such an approach allows for an analytical account of the many organizations that make up the province's agrarian multi-organizational field. 
This project employs a case study research strategy, which according to Snow and Trom (2002), entails an "investigation and analysis or an instance or variant of some bounded social phenomenon that... seeks to generate a richly detailed and 'thick' elaboration of the phenomenon studied through... the use and triangulation of multiple methods or procedures that include but are not limited to qualitative techniques" (p. 147). By adhering to this definition of the case study method, this project is designed to avoid the anachronisms associated with positivistic approaches to social processes, such as resource mobilization theory, which approached the analysis of social movements as more of a chance to test hypotheses about the causal factors which influence a social movement's level of success. This project is congruent with the turn in social sciences towards descriptive and general explanations about particular processes that are more contextually embedded phenomena rather than formulating universal generalizations (Yin, 2003).

Snow and Trom argue that a case study must have a single, relatively bounded "object" of analysis (Ragin, 1992, p. 6; see also Gerring, 2003; and Chima, 2005, p. 6). For the purposes of this project the "object of study" (Ragin, 1992, p. 6) has been defined as the agricultural social movement sector in Ontario between January 2003 and September 2005, a period that witnessed a swift mass mobilization of significant numbers of Ontario farmers.

While the Lanark Landowners Association can be defined as a social movement organization, there exists a greater difficulty conceptualizing the Ontario Federation of Agriculture as such. The LLA came into fruition in 2003 in response to what many perceived to be an injustice against rural constituents, specifically in the area of 
landowner rights. And though farmers did not make up the organization's entire population, they did constitute the majority of its membership (Randy Hillier, interview, 26 May 2008), and provided the majority of tactical resources for the group's protest strategy. Moreover, as this project will show, farmers brought a significant agricultural presence to the discourses developed and articulated by the LLA. Unlike the LLA, the OFA functioned primarily as a traditional interest group with existing connections to formal political institutions and decision-making powers. As Kriesi (1996) and Rucht (1996) have shown, though these groups may have a presence within governmental structures, they may also promote movement objectives. The lines between nonmovement organizations and social movement organizations can be blurry, and depending on context a group can fall into one of either category, or both at the same time. In this case study we witness how the issues that arise when the OFA teeters between a conventional representative organization and a social movement group in its efforts to spearhead the "One Voice" rally at Queens Park, the province of Ontario's legislative assembly.

Minkoff (2002) notes that there must be criteria "for including organizations as members of the population [of a study]" (p. 264). That is, there must be a clarification of what binds these groups together and where their shared boundaries lie so that they warrant what Yin $(1989 ; 2003)$ calls a multiple case study. Though there is not a single method of delineation, based on their shared concern with the issue of agriculture and the rights of farmers within particular boundaries, we can conceptualize these organizations as being part of the same social movement industry: "all of the [social movement organizations] with relatively similar goals" (McAdam and Zald, 1979, p. 3). Moreover, 
because Ontario farmers themselves are the most likely candidates to protect the rights of agricultural production in the province, this created limited opportunity for competing or conflicting organizations to mobilize adherents based on the simple reason that they have a limited pool of adherents to draw from. In addition to competing over other non-human resources, during the 2003-2005 protest cycle the OFA and the LLA were linked via a struggle over the support of perhaps the most important resource of all: people. Implicit in this process is a form of inter-organizational mobilization, by which adherents shift allegiances to one organization over the other. This case of "shared resource dependency" (Minkoff, 2002, p. 265) is perhaps the most salient element binding these two organizations.

Yet the ties that bind organizations are not always explicit from the outset, and movement organizations are not always born into antagonistic relationships. Throughout even the smallest part of an organization's career - i.e. an individual protest cycle - its relationship with other organizations, as well as the relationship amongst its internal network(s) can take on new forms and new dynamics. The central questions of this project are in part focused on these ongoing dynamics. Klandermans (1984) has argued that mobilization and participation are processes that occur over long periods of time (Klandermans et al., 2002, p. 325). Accordingly, the longitudinality (Snow \& Trom, 2002 , p. 155) of the case study allows this project to capture the developments and processes that have shaped organizational ecologies (Minkoff, 2002) and contributed to how protest is both constructed and interpreted.

Methodologically, this project analyzes the macro-level dynamics of multiorganizational fields; however, given the project goals of examining motivations behind 
participation, attention must also be paid to certain interpersonal micro-level processes that influence and are influenced by inter-organizational dynamics.

From a definitional standpoint it is important to clarify how this project uses the term "organization." In social movement studies there exists a tendency for scholars to categorize formal institutionalized groups as organizations, and those informal groups without any explicit claim to identity as wholly cultural entities. Moreover, organization is sometimes pegged as being a grouping of homogeneous individuals. Yet as the multiorganizational field theory argues, individuals often become involved in collective action via their relationships in these informal groups, such as church groups, neighborhood groups, recreation associations, social networks, and so on (Klandermans, 1997, p. 146). The paradigm also draws attention to the overlapping heterogeneous networks of association that constitute them. This implies a rearticulation of the important role that these groups play in structuring the relations and social constructions of both existing and potential participants. This is not to imply that informal organizations are necessarily social movement organizations - though they can develop into such (Walsh et al., 1993). That said, this project retains the understanding that a social movement organization is a "complex, or formal, organization which identifies its goals with the preferences of a social movement or counter movement and attempts to implement those goals" (Snow et al., 1980. p. 787).

This project looks past the social movement organization to its heterogeneous components. More specifically, it attempts to gain a better understanding of the interpersonal dimensions that fundamentally constitute organizations and the ways in which they affect how farmers develop meanings about their environments and 
themselves. When we remove the black box from organization, it becomes more apparent that individuals constitute them. We must keep in mind, however, that these individuals are not forged out of the fires of protests; rather, they are socially embedded into prior, overlapping relationship with other groups. These relations shape an individual's interpretations of the "world out there."

One aspect of the social construction of protest involves the ways that social movement organizations attempt to define the "nature" of a situation by dispersing certain rhetorical discourses or frames into the environments of their targets. In this project, framing processes occur at the multi-organizational, intra-organizational, and interpersonal levels. The project focuses a great deal on the interpretive side of framing, which concerns their ability to resonate in groups that have been targeted by social movement organizations (Evans, 1997). To gauge resonance, I make some inferences based on the socio-political environment at the time of the mobilizations, but I rely more on the responses and explanations contributed by certain individuals involved.

The concepts dealt with in this project are difficult to measure, although many authors have opted for quantitative approaches to social movement analysis (Marullo et al., 1996; Shapiro \& Markoff, 1998). Issues of collective identity, meaning, and interpretation are processes best "revealed by the in-depth focus and high validity that qualitative analysis offers" (Johnston, 2002, p. 75). Therefore this study draws from a triangulation of multiple and overlapping sets of data, all of which are aimed at yielding a "thick description" (Geertz, 1973) of the LLA/OFA protest cycle.

First, organizational documents such as press releases, pamphlets, policy statements, speeches, and other texts were subjected to analysis in order to identify four 
elements of frames: 1) the key issue in the frame; 2) its diagnosis and prognosis; 3) the symbols used, such as images, stereotypes, historical examples, and catch phrases, and; 4) the supporting arguments of the organizations aims (see Johnston, 2002, p. 73; see also Ryan, 1999; Fuks, 1998). This sample of data provides a glimpse into the logic of each movement organization, the differing ways that the two organizations have attempted to garner the support of existing and potential adherents - i.e. collective action frames - as well as demobilize the logics of other groups operating in their respective field - i.e. counter-frames (Evans, 1997).

The second set of data includes news clippings of the protest efforts of each group. This data provides an account of the major activities organized by each social movement and contributes to the overall "story" which this project tackles. Drawing from Hall's (1989) notion that "what we want to know of society depends on how things are represented to us" (p. 9; cited in Greenberg, 2004), analyzing news coverage of the protests enables an exploration of the ways that potential adherents understand and interpret movement activities. In other words, news itself also plays a role in the social construction of protest, for participants, potential adherents, and the public. Moreover, when dealing with conflicting groups, the media is a critical cultural field in which they interact; news articles provide much insight into counter-framing strategies. Accordingly, analytical attention will be paid to how frames were conveyed via the media, and how media discourse informed the constructions of participants in either organization. Sources for this type of data include rural, agricultural, and national newspapers.

It's important to note that frames are not "things," and examining the rhetorical discourses dispersed by movement organizations only scratches the surface of how they 
are constructed. Following Scott (1985), this project is concerned with getting behind the scenes and examining the "hidden transcripts" that might have been covered up or obscured by organizations. Moreover, without accounts from real-life participants, there is no reasonable way to gauge the degree to which collective action frames were appropriated.

To better understand this element of framing, I conducted eleven interviews with rank-and-file members and the leaders of the LLA and OFA. The interview data can highlight how organizational targets were perceived and addressed in the construction of frames, while interviewing participants can lead to a better understanding of how frames were interpreted and acted upon by those without decision-making power. Interviews with participants also enable an exploration of the other interpersonal, identity-related processes that have influenced the trajectory of protest. An additional interview with Ellard Powers was conducted to obtain some of his in-depth knowledge of the history of farm organizations in Ontario, rather than for insight into the LLA or OFA activities.

In no particular order, the following people were interviewed:

- Lauratta Rice, secretary for the Renfrew County branch of the National Farmers' Union, participant of both LLA and OFA sponsored protests;

- David Mackay, president of the Renfrew County branch of the National Farmers' Union, sheep farmer, former dairy, hog, and beef farmer;

- Ellard Powers, former executive of the National Farmers' Union, past protest organizer, retired farmer, past executive of many agricultural organizations, and member of Renfrew County agricultural hall of fame;

- Randy Hillier, founder and past president of the Lanark Landowners' Association, MPP;

- Earl Saar, member of the Lanark Landowners' Association, former dairy farmer, and former sawmill owner;

- Sara Wilson", executive for an OFA-affiliated commodity group;

- John Ramsay*, former board member of OFA;

\footnotetext{
* This name is a pseudonym - the respondent preferred to remain anonymous.
} 
- Mitch Stephenson, beef farmer in Middlesex county, member of the Ontario Federation of Agriculture

- Colleen Campbell, Secretary for Renfrew County Federation of Agriculture;

- John Bennett*, dairy farmer in Middlesex County, member of Lanark Landowners' Association and Ontario Federation of Agriculture;

- Ron Dickson, beef farmer in Renfrew County, member of Lanark Landowners' Association and Ontario Federation of Agriculture;

- Stephen Robinson, former dairy and hog farmer in Bruce County, member of Ontario Federation of Agriculture.

Each sample group has been subjected to slightly different questions, depending on their role in each organization's mobilization effort. Some of the questions posed include:

- What informed your decision to participate, or not participate, in the LLA?

- How did you hear about the LLA?

- In the early 2000s, did you think the OFA was meeting the needs of farmers?

- How did you view the protest tactics used by the LLA?

- Do you think that one or both of the organizations reached their goals?

Interviews were semi-structured. Blee and Taylor (2002) outline the benefits to employing this strategy of investigation in social movement analysis. First, semistructured interviews allow the researcher to gain access to broader and more diverse groups of movement participants than would be included in only an examination of documentary sources. Documents dispersed by movements are often loaded with rhetoric produced by organizational leaders that reflects their interests and objectives, but not always or necessarily those of movement participants. While these documents are important to my project, they potentially obscure the actions and mobilization strategies that characterize the movement. Second, semi-structured interviewing makes "it possible to scrutinize the semantic context of statements by social movement participants and 
leaders" (Ibid., p. 94). In other words, it allows the researcher to better understand the motivations behind collective action without having to rely on the discrete statements generated by more structured interview methods. Third, this method makes it possible to probe the ways that collective and individual identities are formed within social and political activism. Finally, it enables informants to develop, clarify, and rearticulate statements in ways that cannot be captured by more formal methods of information retrieval, such as survey questionnaires. Interestingly, the review of literature showed that farmers are rarely given "voice" in social movement research. It is therefore reasonable to expect that their responses will not be as succinct as other SMOs that are more often tapped by the scholarly community (e.g. women's, labour, environmentalist organizations, etc.).

My insider status posed both opportunities and constraints throughout the interview process. In the initial stages of gathering data I found myself connecting with respondents through pre-existing relationships. In several cases these respondents referred me to other players whom they saw as being relevant to my study. On one hand these factors allowed me to quickly get underway with research, and gain access to people who might have otherwise been hesitant to be interviewed by an unknown researcher. But on the other hand, this posed the threat of interviewing people with rather homogeneous perspectives on my topic, which in the end could potentially bias my analysis and interpretation. I overcame this potential problem by designing and drawing from a heterogeneous sample consisting of farmers and organizational players with varied, and often conflicting, political and social beliefs. 
Lindlof and Taylor (1995) note the importance of establishing rapport to ease the interview process and "lay the groundwork for a mutually gratifying conversation" (p. 181). Because I shared many of the experiences and concerns of respondents, breaking the ice and creating an interpersonal rapport was not a significant issue. Respondents were comfortable, and they seemed to recognize and respect my dual identity as both an academic and farmer, which I made apparent through certain self-disclosures earlier on interviews. But an issue continually arose with regards to upholding the scope and purpose of the conversation, even though I clearly outlined these aspects in the opening moments of our conversation. Farmers with limited organizational involvement were particularly prone to this. While information like this gave me insight into the perspectives of respondents, it tended to draw on and squander valuable interview time. After about three interviews, it became important to remind respondents that I was interviewing them on a very specific topic, and to re-establish our respective roles. I also developed strategies through which to guide conversation away from "chit-chat," arguably an occasional side-effect of the semi-structured interview method (Blee and Taylor, 2002, p. 98), to a more focused discussion of the project. These strategies seemed to be successful most part of the time.

I have exercised great reflexivity in order to mitigate any personal assumptions my history of involvement with the NFU, and my background in agriculture could bring to this qualitative study. Mauthner and Doucet (2003) assert the importance, during data analysis, of "situating ourselves socially and emotionally in relation to respondents" (p. 419). Though it is difficult to say exactly how I mitigated my own ontological and epistemological assumptions, there is a guiding principle I have placed on data analysis. 
Drawing from some of the methodological insights of Actor-Network-Theory, "no point of view [has been] privileged and no interpretation censored" (Callon, 1986, p. 200). In other words, the findings of this project have been based as much as possible on the actual experiences and opinions of respondents.

It is argued that an analysis of the phenomena surrounding the related mobilizations of the LLA and the OFA can yield significant empirical insights into understanding unseen dynamics of agrarian mobilization, as well furthering our understanding of a theoretical area - multi-organizational fields - and its related processes in the aims of contributing to our specific and general understandings of agrarian protest, social movement organizations and the social construction of protest. 


\section{Chapter 4: Case Study}

The farmer is the only man in our economy who buys everything at retail, sells everything at wholesale, and pays the freight both ways.

- John F. Kennedy

Farming looks mighty easy when your plow is a pencil and you're a thousand miles from the corn field.

- Dwight D. Eisenhower

This chapter first presents an historical overview of the agricultural multiorganizational field in Ontario. This section will allow a better understanding of how the OFA came to dominate agrarian issues and collective action, and thus the field and contextual environment in which the LLA would emerge as a new force on the province's political and agrarian scenes. Next, I examine the structure of the OFA and situate the organization as one that suffered from symptoms of the "iron law of oligarchy." This double bind provided the opportunistic "rupture" that a new SMO like the LLA would need to stake out any territory in the agricultural social movement industry. After an overview of the LLA's framing and mobilization strategies, I finally account for the conflicting interactions that ensued between the two antagonistic groups. In the following chapter I provide a discussion of the theoretical and empirical insights of the case study.

\section{Understanding the field: $A$ history of the $O F A$}

Prior to the urbanization characteristic of the late nineteenth century, farmers in Ontario held a privileged social and political status in their immediate and broader communities. Populations were inextricably linked with local agricultural economies, and farmers were central players in both the political and cultural spheres in society. But as 
populations flocked to urban centers, agricultural meanings took on new dimensions in society. For some, the cultural effects of this demographic shift was the beginning of the displacement of agriculture from part of one's "lifeworld" (Habermas, 1987) or "the sphere of personal relationships" (Hendrickson \& Heffernan, 2002, p. 348) into the instrumental rationality of the "systems world." Politically and economically, a great degree of influence over the trajectory of their own industry was transferred away from farmers and other rural constituents (Wood, 1975) and placed in cities far removed from the fields in which their food was grown. Without the privilege of popular consensus, farmers were drawn to the prospect of organization as a means to ensure the viability and protection of their industry.

At the turn of the twentieth century numerous organizations representing farmers rapidly emerged in Ontario. Groups such as the Grange, the Patrons of Industry, the United Farmers' Association, and the United Farmers' Co-operative Company came into fruition to ensure that Ontario farmers "got the best possible deal" (NFU, 2007). However, after decades of ineffective representation and internal quarreling, it was determined that a new direction was required. During this time, commodity groups were also beginning to come together, and in 1935 a handful of these organizations amalgamated to form the Ontario Federation of Agriculture. Unlike its predecessors, the OFA gave commodity groups a seat at the decision-making table, in turn introducing a new set of voices into an arena that had previously been the sole domain of farmers.

As the OFA grew it became apparent that commodity groups, and not farmers, were overwhelmingly controlling the direction of group's mandates and practices. As prices for agricultural goods began to plummet and farmers were being increasingly 
forced off their land, food producers had enough of the OFA, began looking for new leadership, and started demanding radical changes to their sector. The Ontario Farmers' Union (OFU) was officially founded in 1952 as a response to the lack of adequate representation. Unlike the OFA the OFU denied membership to commercial entities in order to ensure that its mandate would be free of corporate interests and influence.

From its very beginning, the OFU was plagued by antagonism from OFA aligned groups that must have seen the OFU as a legitimate threat. For instance, at its initial meetings OFA spokespersons actively attempted to discourage farmers from participating in OFU events (NFU, 2007). In other cases, OFA friendly companies refused to do business with OFU supporters. In what was undoubtedly a strategy to submerge the OFU, the OFA pressured the provincial government to force the amalgamation of the two organizations, but this arrangement never materialized.

Through a series of mass demonstrations, the OFU began to gain favour and influence in the eyes of Ontario's farmers and rural populations, partly because of its militant protest ethic and radical approach to influencing policy makers. The popularity of the OFU in turn fed back on the practices of the OFA: by the mid-1960s the OFA took on a new direction by reorganizing its structure and mandates to better represent the interests of farmers, rather than commodity groups. This move brought a heightened level of cooperation between the then more ideologically aligned farm groups, especially in the area of collective action. For instance, during the summer of 1964, farmers drove over 300 tractors along the 401, causing "hell for traffic" (Powers, interview, 21 April 2008). On May 24, 1967, under the coordination of the Milk Marketing Board the two organizations along with the Union catholique des cultivateurs (UCC) participated in a 
demonstration on Parliament Hill that mobilized more than 20,000 farmers (Ibid.). In a symbolic gesture of dissent, farmers marched through the city and met on the Hill where they demanded government protection of their markets and better trading conditions, which after some months they secured.

Perhaps part of a wider culture of protest, relatively radical multilateral protests such as these occurred throughout the 1960s and into the early 1970s. Their efforts were strikingly effective: within a matter of 10 years the provincial government endorsed the formation of a number of marketing boards for pork, beef, dairy, and poultry products; supply management systems were formally instituted to protect Ontario poultry and dairy markets, enabling farmers with a powerful means to control the prices for these commodities; a series of loan programs, crop insurance programs, incentives for young farmers, and other development acts were subsequently rolled out. Consequently, former OFU executive Ellard Powers described this period of time as one that saw farmers "get more action than any other time in [a] living history" (interview, 21 April 2008). Powers astutely indicated that the success of collective action could be attributed a great deal to the opportunities posed by the progressive socio-political climate of the 1960 s in which farmers' claims resonated much more within non-agrarian publics, and politicians were much more sympathetic to issues in agriculture.

In 1969 Ontario's agricultural organizational field underwent a significant transformation when provincial legislators, under pressure by the government-friendly OFA, brought forth and passed a vote mandating that the OFU become a regional 
member of the National Farmers' Union (NFU) - a group based in western Canada ${ }^{15}$. In the years that followed not enough attention was paid to the Ontario branch of the union, and by 1975 membership had dropped to an alarmingly small pool of people (Powers, interview, 21 April 2008). Meanwhile, during this period of demise, the OFA had also undergone several transformations, the most important being its shift to a legitimate member-based organization; before this move the OFA had been financed by a levy from counties and townships and other associations (Powers, interview, 21 April 2008). Though this decision ostensibly pointed towards a more populist agricultural organization, the OFA actually took the opportunity as a chance to bring back a structure very similar to the commercially inclusive, yet democratically problematic, model that they had distanced themselves from only years before. Nonetheless, with the backing of the provincial government and the Union's membership dwindling due to mismanagement, the OFA had concretized itself as the most dominant of all agricultural organizations in the province by the mid-1970s; its strength was built on an alliance system of farmers, producer groups, co-operatives, marketing boards and related educational organizations (OFA, 2006).

As the OFA continued its trajectory towards a lobby organization, it became apparent that a new funding model was needed to support its growing scope of activities. Membership in the OFA - or any other farm organization for that matter - was voluntary, and only those that chose to join out of volition were required to pay fees. By the early 1990s less than half of Ontario farmers were purchasing memberships, yet every one of them were benefitting from lobby work being done with the federal and provincial

\footnotetext{
${ }^{15}$ This vote was part of a campaign to establish a single "General Farm Organization" in Ontario. Support of the government was necessary to provide enabling legislation for the financing of this organization (OFA, 2007).
} 
governments (Struthers, 2001). In response to this free rider dilemma the provincial government, with recommendations from the OFA, drafted and passed the "Farm Registration and Funding for Farm Organizations Act" (1993). After the inception of the Act, farm businesses with gross sales of $\$ 7000$ per year or more were legally required to pay a fee of $\$ 150$ to one of the two accredited general farm organizations operating in the province: either the OFA or the Christian Farmers Federation of Ontario (CFFO), and after the autumn of 2002, the NFU (RNI, 2002).

After the passing of the Act, certified ${ }^{16}$ farmers were required to make an annual selection of which organization to support. With three agricultural associations competing over memberships, this process should have provided ample opportunity for the two smaller general farm organizations, the NFU and the CFFO, to garner support. Yet the majority of farmers had consistently purchased memberships from the OFA. Given the insignificant size of its competitors prior to the Act, and the inroads that the OFA had already made with commercial and governmental actors, farmers were most likely to be drawn to the Federation. NFU representative David Mackay asserts that this was also a result of pressures put on farmers from subsidiary commodity groups entrenched in the structure of the OFA (interview, 10 June 2008). For these groups, the OFA was an excellent channel for influencing relevant policy, generating and analyzing information about markets, and exerting influence over other agricultural sectors without dependence on formal political institutions. Without the support of commodity producers - i.e. farmers - these groups would sooner or later be forced out of these advantageous relationships.

\footnotetext{
${ }^{16}$ By "certified" I mean those whose gross income exceeds $\$ 7000$, as outlined in the Farm Registration and Funding for Farm Organizations Act.
} 
Mackay also attributes a general culture of apathy to the OFA's ability to hold onto its members, regardless of whether or not farmers felt their needs were being met. When the farm business registration document arrived in the mail, the OFA was de facto checked off for selection; farmers seemed complacent to continue to support the OFA. It would seem, then, that the sheer size and embeddedness of the OFA seemed to perpetuate its stability as the most credible general farm organization within the province's multiorganizational field.

\section{Contextualizing agriculture in 2003-2004}

The years 2003 and 2004 marked perhaps the lowest period in the history of Ontario's agricultural sector since the Depression. In the preceding years a breakout of bovine spongiform encephalopathy (BSE) or "mad cow" disease in Canada's western provinces prompted international trade authorities to halt the importation of live and slaughtered beef from across the entire country. Prior to the crisis, Ontario's already fledging beef economy had grown significantly reliant on exports primarily to the U.S. Closing the border promulgated an economic breakdown that was felt throughout the entire industry. With nowhere to sell cattle, farmers were forced to either operate below profits, or cut their losses by culling herds.

At the same time, grain and oilseed markets had also been hit hard by the "dumping" practices of their American counterparts. The Canadian market had been flooded with American grains, which in effect drastically lowered the domestic price of food commodities. This takeover was made possible by unfair subsidy practices of foreign governments, particularly those in Europe and the United States, which put their 
farmers at a competitive advantage by illegally funneling "covert" financial aid to them (Rosset, 2006). Critics of subsidization claimed that in these systems, "cities feed farmers" (Roberts, 2005) through tax dollars, and in doing so considerably lower farming costs - which raises profitability - thereby strengthening domestic agriculture industries and damaging foreign - i.e. Canadian - markets who still play by the rules etched out in the most recent WTO agricultural summit. Instead of fortifying the province's agricultural economy by limiting exports to the maximum extent allowed by international trade treaties, the government had actually increased the amount of foreign food products allowed to cross into the province (Mackay, interview 10 June 2008; Rice, interview, 23 March 2008).

Another area that was causing among farmers was the topic of landowner rights. After the Walkerton crisis in 2000 , a great deal of public anxiety was raised about the quality of drinking water in rural Ontario. After an inquiry into the tragedy, governmental officials began developing much more rigorous environmental policies for rural communities. As the most prevalent industry in rural areas, farmers were required to meet an intensive list of new rules and regulations pertaining particularly to chemical and organic waste management. Though not yet implemented, the proposed Clean Water Act legally sanctioned government officials to enter and inspect properties to ensure compliance, without the permission or knowledge of its owner(s). According to the Act, farmers who did not meet its strident standards would be fined a minimum of $\$ 50,000$ per day ${ }^{17}$. These new regulations affected not only farming operations, but it affected all landowning rural constituents in the province. The major issue, however, was not

\footnotetext{
${ }^{17}$ Avoiding these fines would be impossible, for bankruptcy would offer no escape from the debt incurred, which under certain circumstances could be paid via tax bills (OLA, 2006).
} 
necessarily over the actual implementation of these new regulations - though they were perceived as being too harsh (OLA, 2006) - but which group should pay for the necessary upgrades to meet them. The Act placed the onus of responsibility onto landowners, yet this was seen to be not only interventionist but also a threat to an already weakened economy. With the "good stewards of the land" (Rice, interview, 23 March 2008) facing restrictions relating to the use of their own land, "the government was kicking [farmers] right at the very moment that we needed their help the most" (Robinson, interview, 3 July 2008).

Elsewhere, small agricultural processors were feeling the pinch of regulation as well. Unable to keep up with emerging regulatory policies, local slaughterhouses were being shut down by government officials at an alarming rate. Other small processors such as cheese manufacturers and maple syrup producers were also being handed penalties by their very own commodity groups. Farmers' markets - perhaps the only location where farmers can conduct business without any "middlemen" - were also being placed under pressure from the provincial Ministry of Heath to conform to a series of new rules which would severely limit the types of products permitted to be sold. Even church groups that often cooked and served fundraising suppers were subjected to new demands by political authorities (Rice, interview, 23 March 2008).

\section{From grievance to (in)action}

While the conditions of the agricultural economy and its many markets were part of a slowly unfolding saga, farmers were not necessarily complacent with their conditions, as demonstrated by the numerous protests and rallies they held in certain locations of the province prior to 2004: in Cannington, located in Durham County, dairy 
farmers were dumping thousands of litres of milk to protest the trade constraints of supply management (Humphrey, 2003); when these farmers' demands were met by officials only weeks later, milk producers staged a protest against what they saw as a severe violation of supply management principles (Medd, 2003); beef farmers in Grey and Bruce County led a boycott against all products made in Japan in response to the Japanese government's ban of imported Canadian beef (Sajfert, 2003); in Owen Sound local farmers rallied to pressure government officials to provide support to the area's farmers after a drought affected the already compromised oilseed market (Henry, 2002); in 2001 the OFA led a "day of action" in Ottawa to pressure federal and provincial politicians into providing aid (Bailey, 2001; Struthers. 2005); members of Ontario Hogwatch - a group against factory pig farms - staged simultaneous protests in several areas of the province to bring awareness to the environmental and economic effects of factory hog farms (Gilday, 2003). The list goes on, but the point is that these protests demonstrate that farmers exhibited a willingness to participate in collective action even if their activities did not make front-page national news.

It is important to note that with the exception of the OFA's day of action in 2001, these were relatively sporadic and amorphous events occurring at varying times in different locations throughout the province. Collective action was also generally staged upon the basis of either commodity - i.e. dairy, beef and pork - or region, regardless of the fact that grievances regarding market conditions were relatively congruent. The fact that farmers protested along these lines suggests a lack of collective identity, or at least an awareness of shared circumstances; however, interviews indicate that farmers were generally aware of and sympathetic to one another's cause. Farmers were also aware that 
they were intrinsically linked through the precarious economic web that they shared - as one interview participant remarked, "when one [commodity] goes down the pipe, the others will usually follow" (Saar, interview, 22 March 2008).

Mackay suggested that farmers were also conscious that protests at the local and commodity levels could not possibly address the "big picture problems that [were] related to what was going on" (interview, 20 March 2008). At the time, farmers attributed their problems to provincial and federal decisions and practices in both domestic and foreign trade policies. As Stephenson stated, "[the government was] failing us, especially at the international level where [farmers had] almost no say in agricultural trade... [Protest] at the [regional] level could not address these issues" (interview, 3 July 2008).

It seems important then to question why protest was so narrow, when grievances and culprits were generally perceived as being much larger in scope? Moreover, even though farmers seem to have been aware of a shared identity, why didn't more or bigger protests occur? The answer to this question is much more macro in scope than issues of identity, and lies in the structural conditions of the multi-organizational field of Ontario's agricultural sector.

\section{Denying protest: The effects of the "iron law" on OFA activities}

Ideally, the OFA was structured to ensure that its 43,000 members had the most predominate voice at the organization's decision-making table. To fortify this mandate the organization had broken Ontario down into approximately seventy regions, each headed by a local member designated as an OFA representative who sat on the organization's board. This structure is somewhat similar to traditional labour unions, except that each regional federation was recognized as autonomous from the OFA. The 
accuracy of this distinction regarding autonomy is questionable though: regional subsidiaries are funded by the OFA, and most of their leaders have shown a propensity to comply with head office decisions (Mackay, 20 March 2008). Regardless, according to regional executive member Donna Campbell (interview, 22 April 2008), this mode of organization could make certain that local concerns, issues and the opinions of rank-andfile members were communicated to the OFA board of directors, based in southern Ontario. Conversely, regional representatives would also, in an "educational" capacity, disseminate information about pertinent legislative decisions and other OFA matters to farmers. By binding its local units in a strictly "hierarchical overarching structure" (Klandermans, 1997, p. 124), the OFA also ostensibly provided a means through which its top leaders were able to mitigate the actual physical distance between themselves and the member base.

By training, planting, and supporting locally embedded leadership cadres, the OFA was able to maintain a populist "feel" to their subsidiary organizations. As some of the participants in this study remarked, an explicit division "between farmers and leaders makes [an organization] seem like it's out of touch with the [actual issues] that farmers face on a day-to-day basis" (Wilson, interview, 11 August 2008). A grassroots organizational culture allows rank-and-file members to connect on an interpersonal level with low-level leaders. Moreover, establishing this hierarchy was necessary to ensure efficiency, especially after passing of the "Farm Registration and Funding for Farm Organizations Act" in 1993. With over thousands of members it was virtually impossible to conduct organizational meetings and decision-making under the ideal principles and procedures of a participatory democracy. 
It is important to note that regional representatives were not alone at the boardroom table. In order to account for "all voices in agriculture" (Campbell, interview, 22 April 2008) the OFA provided approximately 32 spots on the executive board for commodity-based lobby groups, such as the Chicken Farmers of Ontario, Ontario Pork, the Ontario Asparagus Growers, and Ontario Flue Cured Tobacco. These groups were less concerned with farming in general than were regional representatives - their interest, rather, was in promoting and ensuring the viability of a particular crop or livestock based market. Farmers were central in their day-to-day operations; however these groups tended to focus on issues that affected much more powerful actors situated at other levels of food commodity chains, including processing, marketing, and distribution.

Despite what representatives say, the incorporation of commodity groups into OFA decision-making significantly complicated the ability of the organization to be an advocate for food producers. One of the main problems with the existing arrangement was that processors - e.g. meat packing plants, dairies, canneries, etc. - had distinctly different interests from producers. Producers would seek to maximize profit, while mitigating costs; food processors would seek the same, yet mitigating their costs often entailed lowering the price of the relevant commodities. In other words commodity groups manifested a significant double bind: when farmers won, processors lost, and when processors won the farmers suffered.

Commodity groups were much more heterogeneous than their regional counterparts, and the multiple actors in their networks shared links with economic structures beyond the boundaries of the OFA. They served as a point of $\operatorname{contact}^{18}$ for the

\footnotetext{
${ }^{18}$ Autonomous agribusinesses are not allowed membership in the OFA, but there are not significant detriments to their participation in commodity group activities.
} 
interests of multinational agricultural corporations, such as meat-packing giant Cargill, Monsanto and Agropur (Powers, interview, 21 April 2008), which have shown time and time again to have divergent strategic interests from farmers (Rosset, 2006). The OFA valued the support of these groups not only for their political clout, capacity for consultation, and ability to provide a wealth of information about particular markets, but also for the significant amount of financial resources they could provide to Federation operations.

The interests of these regional and commodity group actors were orchestrated by the OFA executive board of directors, which was constituted by six elected individuals. But by the early 2000 s it was becoming increasingly apparent that the board was unable to manage the many interests bound up in the network of the OFA. According to dairy farmer John Bennett, "farmers [lost] their ability to speak up... the only voices that the board [would consider] were those of lobby groups who [didn't] care so much about farmers as they [did] about markets" (interview, 4 August 2008). The overabundance of heterogeneous interests manifested within the many layers of this organizational field problematized the fundamental mandate of the OFA, which was to serve and represent the interests of farmers (OFA, 2008). This impotence was best illustrated by the organization's inability to partake in meaningful protest reflective of the collective beliefs of farmers.

There are several reasons for why this occurred and these can best be analyzed through the Michel-Weber's iron law of oligarchy thesis - the notion that all "organizations have the natural tendency to develop oligarchical leadership and conservative goals [as they mature]" (Voss \& Sherman, 2000, p. 305). The OFA elite 
demonstrated the iron law in multiple ways, and the processes relating to protest are of particular interest. One of the tenets of this thesis is that organizations are rendered impotent to protest via bureaucratization, which many see as the inevitable outcome of formalization. Part of this bureaucratization is the process through which organizations develop a discernable leadership cadre who operate in ways that are distinct from rankand-file members. Although initially designed to mitigate the occurrence of ideological factionalism amongst members, the rigid hierarchy of the OFA had placed a significant amount of power over organizational trajectory into the hands of a select few, mainly the executive board, and the staff that oversees the ongoing activities of the group.

During the years leading up to 2004, the tension between the OFA's role as a lobby group and its role as a SMO became much more prevalent, as did the tensions between leaders and rank-and-file members. As farmers and a handful of commodity groups voiced their discontent in conditions by staging protests around the province, the OFA was avoiding the topic of protest altogether. In the past, the Federation board room had been filled with discourses of action: "I've been told [by peers in the OFA] that they used to discuss rallying quite a bit" (Wilson, interview, 11 August 2008); "in the [1980s] regional branches of the Federation would try and pressure the board [into protesting] a lot, but after a while everyone kind of let off... [the executives] wouldn't fold" (Ramsay, interview, 10 June 2008). Yet, in reviewing the OFA Board meeting minutes (January 2001-November 2004) throughout the early 2000 s there seemed to very little formal discussion of protest ${ }^{19}$ at all. Instead, OFA leadership tended to focus on matters relative to such things as administration, economics, and policy development. Although certain

\footnotetext{
${ }^{19}$ These assertions are based on a qualitative analysis of OFA Board meeting minutes - as made available of their website - between January 2001 and November 2004.
} 
contentious topics affecting farmers received attention, board members continually sought to address them through conventional political channels, much to the dismay of farmers and even some at the leadership table (Wilson, interview, 11 August 2008).

This severely limited the ability of various subsidiary groups to interact, in effect discouraging the creation of protest alliances outside of the OFA. With the exception of the Federation itself, there did not exist a single organization equipped to incorporate and coordinate the many perspectives and interests of its ancillary commodity and regionally based groups. As one commodity leader commented, "you need a high-level of cooperation between commodity groups... the problem is [that] everybody has their own concerns, ideas, and solutions... Sooner or later you need an [overarching authority] like the OFA to put their foot down and resolve all the fighting that goes on..." (Wilson, interview, 11 August 2008).

Thus, for the OFA to subvert the possibility of radical action it was not technically necessary for its leaders to actively repress the discourse of protest; they could do it by framing protest as a matter beyond organizational boundaries, even though protests as recently as three years prior indicated otherwise. By maintaining an economic discourse within decision-making spaces, the OFA was also able to mitigate the otherwise cultural aspects of farming, particularly those that were intertwined with the construction of grievances. And even if farmers could construct a collective identity outside of formal organizations, or even if a protest alliance had materialized out of commodity groups yearning for political action, acquiring the resources required to launch an initiative of any significant scope would have been incredibly difficult because the OFA had established a virtual monopoly over the field's already small pool of 
resources. Because it had positioned itself as the central node through which all organizations must pass to access resources, and because its board was given the ability to control inter-organizational discourse, the OFA was invested with the power to control most political action within the province's agricultural sector(s).

Yet this all begs the important question of why the OFA encouraged unilateral protests from regional and commodity based groups, but failed to facilitate the alliance building necessary for larger scale collective action. Echoing the iron law, David Mackay, Randy Hillier and number of other farmers interviewed for this study suggest that the OFA exhibited reluctance due to individual and organizational self-interests. Farmers had begun to construct grievances based on certain structural conditions of the provincial agricultural sector; it was no "mystery that the Federation was part of [this] problem," and that "leaders [had] lost their way" (Mackay, interview, 20 March 2008). In fact for a long time it was widely acknowledged that the OFA was not functioning to its full capacity, with respect to the interests of both farmers and commodity groups. As Powers states, "there [were] just too many conflicts of interest in the Federation... [with respects to its structure] farmers more or less got the cruddy end of the stick, but in a sense so did commodity groups... because any decision required an incredible amount of deliberation" (interview, 21 April 2008). Even the leaders of the OFA recognized its fallibilities: Brigid Pyke, OFA leader in the late 1980s, remarked that the organization was "overly large, expensive to operate and perhaps unwieldy as a policy-setting mechanism" (Struthers, 2001, p. 3). After her time, however, there had been numerous committees formed to deal with the structural shortcomings of the OFA, yet by 2004 their recommendations had never been enacted in a meaningful way. 
Moreover, because the OFA was coming under so much heat from its constituency for ineffective representation, to accommodate the system-oriented grievances of farmers would have undermined the credibility of the OFA because protest would, to a degree, be against the organization itself, in particular the executive board. Accordingly, the OFA propounded that deliberation, and not direct action, was the key to realizing better conditions for farmers. Or, as Halpin and Martin (1999) eloquently put it, the OFA had framed "a willingness to pay and not to act" (p. 92).

But this perspective seems overly critical against the OFA, and its leaders. They were, after all, elected to their positions, had for decades upheld the autonomy of their regional subsidiaries, and not all members were so discouraged by the Federation's leadership. Donna Campbell, for example, sympathized with leaders when she stated that "board members [had] a lot on their plates" (interview, 22 April 2008). Though her words should be taken with a grain of salt given her relationship with the OFA, she does have a point. In addition to maintaining the strength of their own multi-organizational alliance, OFA leaders had to maintain strong ties with various members and offices in the provincial government. Because the agricultural sector had grown so reliant on government subsidies and other forms of intervention, maintaining a good rapport with government officials was paramount in their activities. The allegiance to the government also went further than the prospect for future changes; the OFA received funding from the government to conduct economic and environmental studies, some of which contributed to the development of the very regulations that had drawn the concern of farmers. 
This affected the reasons why OFA leaders perceived protest differently from their rank-and-file members. According to leaders, addressing the anti-government grievances of certain members would send the wrong message and risk marginalizing the OFA from the very policy community that its leaders had in the past worked so diligently to influence. As one commodity group leader put it, "you can't just start throwing garbage at the government... they're the ones who in the end control the [agricultural industry]... they're our most important allies" (Wilson, interview, 11 August 2008). The OFA had participated in State-focused protest in the past; however it was by no means radical, or purely "anti-Statist." Because protests were frequently part of a broader effort to secure subsidies or other benefits to be channeled to farmers ${ }^{20}$, the OFA had on the most part adopted very non-confrontational, and "rational" (Campbell, interview, 22 April 2008) protest strategies.

Nonetheless, members who had been complacent with OFA leadership were beginning to express their discontent with the organization with greater force, particularly its leaders and its relationship to a government that had arguably done little to improve the agricultural sector. Yet their grievances were incompatible with the mandates that the OFA had established over several decades. While many farmers yearned to address root problems (Rice, interview, 23 March 2008), the OFA denied this type of protest in what leaders likely saw as the best interests of members. Though farmers did share a collective identity, they had grown to rely on organization as a vehicle to collective action. And without the backing of the OFA they were left relatively divided by the organizational boundaries of commodity groups and local branches of the Federation.

\footnotetext{
${ }^{20}$ Efforts of this type were undeniably successful; after a "day of action" in 2001 Ontario farmers were provided with a one-time $\$ 90$ million special grains and oilseeds program from the Provincial Government, and the Federal Government provided $\$ 104$ million for income relief purposes (Struthers, 2005).
} 
By 2003 the "realities" professed by the OFA would be challenged and an opportunity would emerge for a new player to exert itself in the provincial agricultural organizational field. Enter the Lanark Landowner's Association.

\section{The Lanark Landowners' Association}

In late 2002, a citizen named Randy Hillier assembled an advisory committee on agriculture on behalf of Lanark-Frontenac-Lennox and Addington MP, Scott Reid. Through this committee Hillier and a group of his closest friends and allies developed conclusions about the dire state of rural populations in Ontario, and realized that they "should start fixing things rather than advising" (Hillier, interview, 26 May 2008). Hillier, Merle Bowes, John Vanderspank and Bryan Hannah, with a handful of others, perceived the weakening of the provincial agricultural sector as a symptom of a larger problem that affected virtually all rural constituents. According to Hillier, "it came down to property rights: the freedom to own, use, and enjoy [one's own] property" (interview, 26 May 2008).

An electrician and part-time farmer, Hillier was nominated very early on by core organizers as the best person to lead the organization ${ }^{21}$. His charismatic, no nonsense approach to speaking publicly would play a central role in the success of the SMO.

The LLA began from ground zero. With the exception of a lone minority MP, the group had virtually no access to any reasonably effective political opportunities, it had a very limited pool of financial resources and it had no institutional legitimacy among its

\footnotetext{
${ }^{21}$ Hillier (2008) claims that his nomination was based on his propensity for "writing, and we needed somebody who could convey... thoughts in an effective manner... I didn't mind going out and meeting people to get things started." A major actor in the movement, Earl Saar, claimed that Hillier was by far the most personable of the group, and "definitely a good speaker" (interview, March 22, 2008). Powers agreed somewhat, calling Hillier a "demagogue" (interview, April 21, 2008).
} 
most important target, the area's rural population. In April 2003 the LLA held its inaugural meeting in Beckwith Township. Despite the group being a newcomer to rural politics, the meeting garnered the attention of "about ninety people or so" (Hillier, interview, 26 May 2008) - a considerable amount of people when one considers the sparseness of the regional population, and the organizers' apparent lack of experience. At the end of the session nearly every person in attendance purchased a membership to the association, and in doing so received a "this land is our land, back off government" sign (see Figs. $1 \& 2$ ). Months later the group began its campaign challenging the provincial government"s "attack" on rural Ontario.

The success of the meeting cannot be explained by the event itself, but by the relationships that key movement organizers shared with people in their community. The surprising ideological unity articulated in the initial meeting can be partly attributed to pre-established collective beliefs among residents in the Lanark area. Though they did post notices in the local newspapers and at public forums - e.g. recreation facilities, stores and restaurants - the overwhelming majority of those who attended the first meetings were made aware of the proposed association through interpersonal ties with a handful of organizers (Hillier, interview, 26 May 2008; Saar, interview, 22 March 2008). Attendees comprised a wide range of actors: farmers, sawmill operators, slaughterhouse operators, retail business owners, and people who simply owned land or lived in the area. Although each of these groups shared a concern in the economic viability of the region, the reason that initial attendees were so motivated to participate was due largely to the fact that they all shared personal bonds with the event organizers that had been cultivated over years or even decades. These relationships were both an independent and dependent 
variable in participation because they shaped to a large degree the Association's discourse. Moreover, as any elected politician will assert, face-to-face interaction is much more likely to garner the support of targets.

But grassroots communication and interpersonal friendship cannot alone explain how the LLA grew from a handful of supporters in Lanark County to a full-fledged political force with branches across the province capable of organizing a massive protest involving thousands of farmers, even in the face of direct opposition from other agricultural groups. In order for the LLA to reach this status it had to identify, articulate and absorb the belief systems of ideologically aligned bystanders. Farmers, however, were unlike other groups targeted by the LLA: they had histories of activism, and already belonged to one of several relatively politically active agricultural organizations that had in the past rarely expressed a willingness to cooperate with other groups. The question then became one of how the LLA could garner the support of rural populations and, most particular to this study, farmers.

The LLA accomplished this objective as a result of two interrelated factors: a) they were able to construct a framing strategy that connected to the belief systems of farmers, and b) they were able to seize opportunities born from the field-level "ruptures" revealed by the OFA and related commodity groups. Though resources and opportunities would certainly play a role as the organization grew and matured, the realization of these elements were first and foremost contingent on the LLA's ability to effectively drive the framing process. 
Selling consensus: the construction of the LLA collective action frames ${ }^{22}$

Klandermans (2004, p. 370) argues that before widespread action can occur, consensus must be mobilized among potential adherents through symbolic and persuasive processes of communication. Consensus mobilization, then, refers to the ways that the LLA attempted to transform conditions into politically salient grievances. Constructing and communicating grievances was the only way that the LLA could challenge the dominant belief system - both at the macro-and-mesostructural ${ }^{23}$ levels - that legitimized the status quo by replacing it with an "alternative mobilizing belief system that supported collective action for change" (Gamson, 1982, p. 15). This symbolic process is one of the characteristics that defined the LLA as a SMO, and not a traditional lobby organization like others within the multi-organizational field of agricultural politics. A major step in this process was to articulate and help to shape a collective identity; this was in turn contingent on the movement's ability to reconstruct pre-existing beliefs into a collective action frame. Following Aspinall (2007), I examine the ways that identity acted as a "prism" through which conditions were interpreted as problematic and framing constructions were appropriated.

\section{Injustice}

The group's grievances were based primarily on a well defined series of proposed and implemented government decisions (Hillier, interview, 26 May 2008; also Hillier,

\footnotetext{
22 This section employs Snow and Benford's (1998) "core framing tasks" as a framework.

${ }^{23}$ First coined by Maines (1982), mesostructure refers to the social processes and ordering that occur between the macro and micro levels of social organization. According to Ulmer (2007), "mesostructure is the level of social analysis within which more macrostructural or cultural arrangements shape and condition situations of interaction between individuals or groups, and within which the latter in turn maintain, modify, or change the former" (online).
} 
2004): the Clean Water Act; the lack of action on behalf of the Ministry of Natural Resources with regards to the problems of an escalating deer population; the gun registry which "created lifestyle criminals" among the rural population (Hillier, 2004); the Nutrient Management Act (2002), which sought to legislate new stringent policies on storing and handling animal waste; the Environmental Protection Act (1990) which threatened logging operations because it classified sawdust as a toxic byproduct, and; the Species at Risk Act (2008), which regarded limiting landowners' rights in situations when at-risk animals inhabited their properties. More specific to agriculture, the LLA attacked government rules implemented by the Canadian Food Inspection Agency that limited the abilities of farmers to sell their products directly to consumers. Though these injustices affected farmers, the organizational injustice frame constructed by the LLA was not focused solely around agricultural issues. They did, however, frame agricultural activity as one of several central economic components in rural communities (Hillier, interview, 26 May 2008), which, when threatened, jeopardized the social fabric of entire regions. These regulatory legislations were framed as attacks on the rural economy, to which farmers already affected by poor governance were being unduly subjected.

The insiders interviewed for this thesis were asked whether they perceived grievances along these lines, or if they even saw the regulations as an issue before the LLA began their campaign. Unsurprisingly, every respondent claimed that to some degree they saw conditions as projected by the LLA, though some did mention that they thought it was more a case of being "left behind" in economic development (Bennett, 2008) than an all out attack on the values germane to rural populations. Respondents also agreed that agricultural issues were part of a larger problem pertaining to rural 
economies, and they generally maintained the distinctness of agricultural activities compared to other activities in rural areas.

In many ways it was inevitable that farmers would perceive the issues that the LLA aimed to address warranting grievances, simply because they were or would directly experience the regulations. For some movements, the construction of grievances is a somewhat mysterious process. Take, for example, the peace movement, which was largely a matter of people protesting against non-materialistic issues with which they were not directly implicated. In this case SMOs had to work very hard to construct an issue as problematic because participants did not necessarily share a direct link with it. But the situation for farmers was much more explicit and experiential. Farmers had actually felt the effects of the overblown deer population in their pockets, because herds would feed on their crops. They were also paying a significant amount of money to upgrade their waste management facilities in order to comply with increasingly stringent rules. Farmers were also very aware of the many factors that constrained them from directly selling to consumers, such as the legal necessity for livestock farmers to have their products inspected by the Canadian Food Inspection Agency before they can be sold to individual customers, or enter mass marketplaces. Overall, farmers already felt cornered and "powerless over [their] own businesses" (Bennet, 2008), and the proposed regulatory legislations would only exacerbate their problems. As farmer and sawmill owner Earl Saar put it:

it was pretty obvious that [what was going on] was unfair, and... undeserved... I saw people all around me get out of farming; people that had been excellent farmers squeezed out of business because they just couldn't afford to do it anymore... not because they were bad businessmen, but because the market [was] just so... unfair, and the 
government didn't even notice. I myself was on the brink of folding up shop (interview, 22 March 2008).

Unlike the OFA, the LLA explicitly made the link between economic activity and the cultural dimensions of rural life one of the most prevalent dimensions of their day-today activities, and it was thus accorded a privileged status within their framing strategy. According to the LLA "any attack on the rural economy was an attack on the rural lifestyle... and a long heritage" (Hillier, interview, 26 May 2008). This projection allowed the LLA to bridge the interests of the farmers with most other stakeholders in rural areas, thus providing a linkage between a series of groups that had previously operated as relatively autonomous actors. Non-agrarian groups had indeed supported ${ }^{24}$ agriculturally oriented protest in the past, but their grievances were denied accommodation by the economically rigid and product-centric framing strategies of organizing commodity groups. By giving groups that had been unable to articulate their grievances as part of an agricultural movement, the LLA significantly increased its pool of potential adherents, thus allowing for more members, which has been shown to increase movement success expectations (Klandermans \& de Weerd, 2000, p. 68).

As Powers (interview, 21 April 2008) and several scholars have pointed out, the looming threat of depopulation in rural Ontario (Young, 1972; Watson, 1947) as well as in other regions of the world (Mann, 2005; FAO, 2006; Drudy, 1978) has historically been an issue of great concern for farmers. This suggests that for farmers - and other rural peoples - protecting the viability of agriculture stretches beyond mere economic and material distribution, and that the "rural way of life" plays a central role in their practices. Every participant in this study claimed that a lifestyle component provided some impetus

\footnotetext{
${ }^{24}$ In past instances, rural businesses had provided money for such things as transporting protesters to and
} from distant protest sites. 
to participating with the LLA. A common thread found throughout their replies was the assertion that in rural areas, "lifestyle and economic activity are one and the same" (Hillier, interview, 26 May 2008), more so than any other occupation. Mackay drew attention to the aspiration of preserving the legacy of farming life, and stated that he wanted his "daughter to experience the same things that [he] did when he grew up... and the only real way for that to happen is to save the family farm" (interview, 4 September 2008). Rice (interview, 23 March 2008) claimed that "the rural way of life in Ontario [would] disappear if... farmers aren't able to make any money." And Ellard Powers gave a historical perspective when asked about the cultural elements of agrarian protest: "Oh definitely. That's part of something that we've been working for the past 50 years. But we did not realize 50 years ago that it was going to get this bad"' (interview, 21 April 2008). These claims suggest that this emotional plea to protecting rural culture resonated among farmers, and it helps explain how the LLA was able to generate initial momentum in an environment of obstacles to mobilization.

\section{Identity}

In terms of identity, the LLA marked a significantly different direction for agrarian protest in the province. Though farmers had expressed class unity, the "mangled" (Pickering, 1995) structural conditions of the multi-organizational field had seemingly fragmented agrarian identities along lines of commodity and region. However, these conditions set the stage for a destabilization of OFA-aligned farmers' collective identity, and provided a key strategic opportunity for the LLA. 
While other organizations promoted exclusivity and established rigid boundaries in order to foster a stronger collective identity, the LLA allowed a new agrarian identity to come into fruition by actually expanding organizational boundaries by linking agricultural economics and culture to entire rural systems, giving farmers the conceptual tools required to reconstruct their identities along a more politically relevant line that could be shared beyond commodity and region. As I have suggested above, this required them to perceive themselves as part of a much larger rural system. Of course this meant that other non-agricultural players would enter into the movement, but farmers "desperate for action" (Stephenson, interview, 3 July 2008) were more than willing to risk the compromises that would come with participating in a rural-oriented movement organization. Moreover, those members that were not explicitly engaged in agricultural production realized the value of having farmers as part of their organization, for in addition to expanding the robustness of the LLA they brought political experience to the table.

Compared to most other demographics within the LLA, farmers were experienced in protest and protest strategies, and as a group offered certain resources that other groups could not, such as the tractors that would be used so effectively in highway demonstrations. And compared to other groups, such as non-farming rural landowners, farmers were linked into much more cohesive informal and formal networks which were typically forged through business relationships. As the LLA grew in size, and branches of the organization began forming in most rural counties, targeting farmers became much 
more of a framing priority for the organization ${ }^{25}$. Though this frame transformation caused some conflict within the movement - e.g. some non-farmers felt alienated (Dickson, interview, 20 April 2008) - most groups agreed that farmers warranted a unique voice. "Besides," as one respondent said, "without them there could not have been a [LLA]" (Saar, interview, 22 March 2008).

Defining the values of a movement is only part of the process of identity construction - a movement must also reinforce boundaries by defining what they are not. Many of the claims emanating from the LLA were concentrated on the identity of their opponents. As illustrated by the "this land is our land, back off government" mantra, ${ }^{26}$ the LLA explicitly attributed blame and causality to the provincial government. For example, the group frequently referred to a 2004 report commissioned by the Province entitled "The Panel on the Role of Government" (2004). According to Hillier, the report "laid out and clearly stated... that the role of government would be to manage the demise of rural Ontario. Not to promote it, not to protect it, but to manage the demise of rural Ontario! ${ }^{27 "}$ (Hillier, interview, 26 May 2008). For the LLA, it was that farmers could not turn a profit because they were confronting a government opposed to the rural way of life and hellbent on destroying it.

The LLA emerged in the aftermath of Conservative Premier Mike Harris' "common sense revolution," a policy platform that "integrated economic policy changes (comprised of tax cuts, overall reductions in government spending, and the 'assault' on

\footnotetext{
${ }^{25}$ One of the ways that the LLA targeted farmers was by dispersing a frame which stressed the unique role of the farmer in society - much like Mooney and Hunt's notion of the "agrarian fundamentalism" master frame (1996).

${ }^{26}$ This slogan appeared on virtually all LLA materials: shirts, stickers, signs, protest posters, letterheads, etc.

${ }^{27}$ Hillier's statement has considerable substance to it. For a discussion of the Panel's recommendations pertaining to the rural phase out, see Solomon, 2004.
} 
trade union freedoms) with a social policy program that entailed close monitoring, policing, and a broader marginalization of 'problem' populations..." (Greenberg, 2005, p. 236). Although the Harris government (1995-2003) espoused a political philosophy more in keeping with the principles of the LLA, an anti-statist sentiment lingered from the failed Harris project, sowing the seeds for a populist attitude to protest, and providing a key political opportunity for the LLA to harness the sentiment in rural areas.

The government was framed as being out of touch with the realities of rural life in Ontario due to its bureaucratization, urban-centrism and esoteric elitism. Hillier stated in one interview, "we are people who have become fed up with over-regulation, government intrusion and special interest idealists from urban areas coming into the area and dictating how they should live their lives and manage the land they have so successfully managed for years" (McLeod, 2004). The populist undertones of this claim resonated greatly with farmers, for the LLA offered them what the OFA had been denying for years: a channel through which to express anti-government sentiment. Moreover, pegging blame on specific governmental actors - such as prominent politicians, bureaucrats and departments such as the Ministry of Natural Resources (and its Minister, David Ramsay) - marked a different direction in terms of mobilization; past agrarian protest in the province had tended to project abstract systems, mainly "the economy" as the culprit of injustice. But the economy would not react to angry farmers, nor could blaming it be expected to improve the success expectations of farmers. The government, on the other hand, was a much more real and identifiable villain, and in theory more likely to react to pressure. 


\section{Hidden transcripts}

Scott (1985) suggests that a distinction between outsider and insider discursive arenas must be accounted for if we are to comprehend a movement's "full transcript." By focusing on "backstage" action, we can see how the non-public, emotional aspects of collective action influence the trajectory of a movement. These are the hidden transcripts occurring within the interpersonal relations of movement adherents that if made public could jeopardize the integrity of the movement, and in some cases the livelihood of its members. Elaborating on Scott's (1985) concept of the hidden transcript, and drawing from Goffman's (1959) notion of framing, Kubal (1998) indicates that collective action frames are constructed in two distinct regions: the "back," where claims are presented in meetings, personal conversations and within movement literature, and the "front" region where claims for public consumption are made via media and open statements during public gatherings. For the OFA and its alliance, anti-government discourse was always relegated to the back region (Wilson, interview, 11 August 2008), due to its institutional obligations to the State. The LLA on the other hand made very little distinction between the two regions in their activities because they were not bound to the government financially or politically, making marginalization from policy circles and funding bodies a non-issue. Thus their organizational positioning allowed them to construct and maintain a vocal opposition to the provincial government.

One notable discourse not presented in the front had to do with the derogatory ways in which urban constituents were framed. Nearly all of the LLA and OFA participants for this study expressed to some capacity a heightened level of tension between farmers and city people, which they claimed was especially acute during times 
of mobilization. The general sentiment was that urbanites failed to appreciate the unique role of agriculture in their day-to-day lives, that farmers where experiencing an apparent crisis, and city imposed standards were failing to meet the needs of farmers (Hillier, 2004). However, as the OFA would make explicit, expressing this sentiment would have only served to alienate a significantly large pool of bystanders and potential adherents. Though they were not necessarily framed as opponents, farmers portrayed city people as having special access to opportunities that advanced their interests (e.g., lower food and commodity prices) at the expense of those in the country and on the farm. Nonetheless, by keeping in the back region farmers were able to develop a stronger sense of injustice through a process that Runciman (1966) defines as fraternal deprivation - a development through which groups compare conditions with their similar, yet detached, counterparts as well as strengthening their collective identities by constructing new boundaries around membership (i.e. defining "that which we are not").

\section{Prognostic framing}

According to Snow and Benford (1988), a SMO must be able to diagnose a problem, offer a solution and motivate people to act - in other words, it must do more than point fingers and cry foul; it must propose "what is to be done", the path which could lead to the realization of movement goals and ways of energizing adherents and prospective participants and supporters. The LLA proposed that the solution was to fight and reverse the regulatory policy decisions with which they held such disdain, and to enshrine property rights in municipal, provincial and federal laws. The LLA's prognosis, i.e. its proposed solution, embodied the free market and neoliberal ideologies of the 
organization, which would become much more prevalent as the movement grew in size. For instance, the group proposed to enact measures that placed private owners of property above the state, and, more relevant to farming, propounded an end to protected, or regulated trade. In a 2003 opinion piece, Hillier expressed that:

the only purpose for these unnecessary regulations is more employment for bureaucrats, more government control of people, and a deceptive means to justify more user fees and taxation. This attack is only possible because the legal means to protect and defend individuals from government interference and injustice was compromised in Canada's court of collective society. The 1982 Constitutional loss of the right to own, use, and earn a living from private property, removed the individual's last shield of protection against the bureaucracy's weapons of mass individual destruction (Hillier, 2003).

When the centrality of farmers was realized by movement elites, the LLA extended its prognosis by propounding changes to agricultural market regulation. According to them, subsidization and supply management systems were only perpetuating the problems in the agricultural economy; the organization saw economic responsibility as the path to a sustainable industry, and a more stable rural economy.

To bring these changes into fruition, it was proposed that a "rural revolution" had to take place. Reflecting this call, they adopted a very radical, confrontational, and disruptive set of protest tactics, based on making rural problems "someone else's until it could get fixed" (Hillier, interview, 26 May 2008). According to Hillier, civil disobedience ${ }^{28}$ was the only path to social transformation: "you can choose to work inside the democratic process and it will take you years to get nowhere. Or you can work in the legal industry and if you try that and you win, you'll be bankrupt... Ours is a class of action. We stand up together and tell the government what they will do, not what they will do for them" (quoted in Atkinson, 2005).

${ }^{28}$ Hillier (2008) claims that many tactics were appropriated from Greenpeace. 
One of the first protests that the LLA staged was its "father's day deer hunt" in $2004^{29}$ which symbolized the familial values of the group, and was designed to challenge the authority of the Ministry of Natural Resources over the maintenance of deer populations in Lanark County (Van Dusen, 2004). LLA members broke the law by shooting deer without the permission of the Ministry, but according to members, in the end their actions motivated the government to deal with deer populations, which they promptly did (Ibid.).

Early protests like this were not by definition "agrarian," nor were they necessarily specific to farmers; but they did symbolize with great potency the radical route of action that the LLA would take. More than one respondent claimed that it was after "seeing the LLA at work" that they decided to participate, suggesting that the prognostic frame resonated amongst agrarian classes, and created strong success expectations amongst participants. This in part can be attributed to the structural limitations put into effect by the OFA over tactical repertoires, which were generally very non-confrontational and "rational" methods of protest. But farmers - many of whom saw the effectiveness of the radical protests of the late 1960s and early 1970s - expressed a desire to employ different and more radical methods that would "reflect the seriousness of the issues at hand" (Mackay, 20 March 2008). Moreover, farmers were not new to protest, and had developed a high degree of knowledge about approaches to collective action. Mackay provides an analogy, “it's like having many girlfriends: after you've had a few, you learn what you want in a woman" (Ibid.).

Thus there is evidence that radical tactics of the LLA attracted farmers to the movement, more than its proposed policy solutions to problems in agriculture. While this

${ }^{29}$ A similar event was held the year before, but it garnered very little attention. 
prognosis was almost directly opposed to the path that the OFA had adopted, it was also off track from most framings constructed in the context of the American agrarian movement. In their study of agrarian master frames, Mooney and Hunt found that one of the three most stable discursive configurations that have mobilized farmers in the past was the "competitive capitalism" frame which claims that certain state interventions are needed to ensure competition in agricultural markets (1996, p. 183). Up until the arrival of the LLA, farmers in Ontario had taken this path with the OFA, pressuring the government to provide subsidies to damaged markets. Moreover, it was generally known amongst farmers that protected markets like dairy were the most safe and profitable. Thus it is interesting, if not suspicious, that the form of laissez-faire, free-market capitalism propounded by the LLA resonated with farmers who had shown such strong support for government subsidies in the past.

It should be noted that other than calling for stronger property rights, the LLA did not offer anything resembling concrete policy recommendations, or a detailed vision for future organizational activities. This can be attributed to the paradox of populist movements vying to permeate decision-making processes: they stand against governments and against experts, but they are as a result unable to clearly articulate exactly what they it is that they want.

Why, then, was it that farmers were willing to participate in a movement which was ideologically opposed to the current system upon which they had grown so reliant, and had a somewhat opaque vision of the future? The answer is that they were not so much dedicated to this cause, as they were to the idea of protest. It seems that most of them had serious doubts about whether the large-scope goals of the LLA's agricultural 
"policies" (rooted in the anti-statism of neo-liberal economics) could actually come to fruition. While they agreed that the sector was becoming overregulated, farmers were well aware that their grievances were rooted much deeper than the LLA had expressed (Dickson, interview, 20 April 2008). According to Mackay, farmers were so desperate to voice their dissent in a direct way, that they were willing to support the idea of an agricultural system which they knew would be problematic if it were to actually come into fruition as the LLA saw it (interview, 20 March 2008).

As farmers became more central actors in the movement, the symbolic dimensions of the LLA's tactics became much more "agrarian." The LLA staged "Here's our Beef" demonstrations, where food was sold which had not passed government inspection (Pascaul, 2004); mock triais were held, members were encouraged to use violent means if necessary to remove inspectors from their properties and restrict access to hunters and snowmobilers, and politicians were sent symbolic "gestures" in the mail". In March 2004 the LLA ramped up its efforts, staging a road demonstration in Ottawa involving close to 800 people blockading a busy intersection with farm equipment (see Fig. 3). In April 2004 the LLA converged on Parliament Hill with livestock and equipment in tow, bringing traffic in the city to a grinding halt (Lloyd, 2005). Later in the fall of 2004 the group staged another series of blockades in the Pakenham region, located approximately 60 kilometers from Ottawa.

These events were relatively small scale considering the LLA had extended its membership beyond Lanark County; much larger scale road blockades were planned and targeted towards neutral, particularly urban, audiences. One of the first of these

\footnotetext{
${ }^{30}$ Heath Minister Leona Dombrowski received a package containing a can of pop, candy, two bags of potato chips and two packs of chewing gum. The items were listed by government inspectors as the type of food fit to be sold at farmers' markets.
} 
demonstrations occurred on January 21, 2005 on a stretch of the 401 - one of the world's busiest highways -- around Ingersoll in southwestern Ontario (Rodrigues, 2005) (Figs. 4 $\& 5)$. The idea for the protest originated from a group of tobacco farmers who saw the government's anti-tobacco legislation ${ }^{31}$ as an unfair attack on their sector (Lloyd, 2005). Because the government was seen to be intentionally damaging tobacco sales, the group demanded a complete buyout of their quota (TFIC, 2007) - a move that aligned with the LLA's anti-statist ideology. Impressed with past LLA demonstrations the tobacco farmers turned to the group for assistance in organizing the protest - no doubt an illustration of the growing popularity and power of the LLA. On that day more than 250 tractors brought traffic to a halt on the highway, indeed "making rural problems somebody else's" and sending a powerful gesture to government.

Tractors are a powerful symbol of farming and were used in an impromptu demonstration directly against Ontario Liberal Premier, Dalton McGuinty who had paid a visit to a public school in Peterborough to announce education funding. Hearing this news less than a day before the speech, a handful of farmers began planning a demonstration. While McGuinty was inside making his announcement, farmers were outside barricading his vehicle amongst fifteen tractors. The premier left the premises using a different mode of transportation, crying foul because the LLA had not contacted him about meeting in advance (Atkinson, 2005).

Overall, the blockades marked a significant moment in the protest career of the LLA for they generated considerable amounts of attention from most of Canada's major news outlets, bringing the movement squarely into the media and public spotlight (see Figs. $6 \& 7$ ). But more importantly they got the attention of agricultural and rural

${ }^{31}$ These legislations generally regarded anti-smoking initiatives. 
newspapers, which would ensure that LLA activities were transmitted to the organization's primary target audience: farmers.

Though they might not have resonated well with the public (which is always ambivalent about protest activities that entail disruption or inconvenience) the blockades did function to reinforce the collective identities of participants, as well as their commitment to the LLA. One participant claimed that "the blockades were pretty risky for us... we had to deal with the cold... police, angry truck drivers, and [upset] people trying to get to work... it was pretty dangerous" (Bennett, 2008). When asked whether or not the protest brought about feelings of camaraderie he replied, "oh yes! When anyone goes through a situation like that with other people they're going to be [closer]... kind of like soldier... not exactly if you know what I mean." In other words, by participating in the relatively high-risk tactics employed by the LLA, farmers were able to encourage and develop what Goodwin et al. (2004) has called, "affective bonds."

Emotions were a central element in the LLA mobilization. Because the structure of the LLA was much less formal than its neighbours at the field level, it was able to strategically employ emotions as one of the central elements in its mobilization model. In speeches Hillier would use language that connoted feelings of anger, frustration, and resentment - ernotions that certainly reflect the cultural climate of farmers. Participants were able to articulate these discourses themselves in the presence of leaders at LLA gatherings where farmers were free to emote their anger and share experiences with one another. Meanwhile at the OFA meetings were kept "official" and emotional language was mitigated in formal spaces, even in times of mobilization - though they were certainly expressed within local branches. Nurturing certain "radical" emotions would in 
part guide and reinforce the construction of meanings that were in alignment with LLA framing, particularly the demonization of the provincial and, to a degree, federal governments.

\section{The emergence of a conflict system}

The LLA was less a network of organizations than it was a network of individuals with organizational ties. It had established local branches, but these groups were so intertwined and dependent on the Lanark association, they could not really be classified as autonomous. This aspect is best demonstrated by the decision to keep the "Lanark" component in the movement's name, ${ }^{32}$ even though participants originated in other counties. However some small groups, such as those representing farmers' markets and maple syrup producers, endorsed the group, yet its multi-organizational alliance was constituted by a small handful of local rural-related associations that were not explicitly tied to agricultural interests, such as Voices of Central Ontario (VOCA); that is, with the exception of both the NFU and CFFO (Dickenson, 2005; CFFO, 2005) - the only other two general farm organizations in the province. But these farm organizations only pledged weak support, citing that the LLA failed to have a long term policy plan, and that it might have been a "flash in the pan" movement (Powers, interview, 21 April 2008). The other area that worried these groups was the free market ideology of the LLA, which went against organized marketing - a "cornerstone" of the NFU (Ibid.) - because it has been proven to be the only system able to secure profitable farming. This anti-market

\footnotetext{
${ }^{32}$ By late 2005 the LLA changed its name to the Ontario Landowners' Association in order to better reflect the many regional branches.
} 
protection stance would also cause tensions with securing dairy farmers (Hillier, interview, 26 May 2008).

It is not too surprising to find that the overwhelming majority of organizations within the OFA coalition were not willing to commit to the LLA. The OFA agreed with many elements of the LLA's diagnostic frame (Gardiner, 2005), but had major issues with the organization's tactics and its prognostic frame for dealing with the problem. While the NFU and the CFFO were willing to make compromises, the OFA was unwilling to budge on the issue of supply management. Overall, the LLA's neo-liberal agenda was perceived to be too radical, too underdeveloped, and unreflective of the realities of global food chains.

Throughout the early stages in the career of the LLA there is very little evidence to support the notion that the OFA perceived it as an antagonistic movement, though there is some signs of competitive framing. This is likely because the LLA constructed its frames based on property rights rather than agricultural issues. In doing so they situated new issues beyond the self-proclaimed economically oriented boundaries of the OFA ${ }^{33}$ and gave their organization a degree of autonomy. After all, in the past, rural and municipal associations similar to the LLA governed rural politics. Consequently, the LLA was able to operate without much opposition or antagonism. Indeed, in its early days the OFA allied organizations saw the LLA as a movement that could "really help farmers out" (Wilson, interview, 11 August 2008).

Yet this autonomy proved to be short lived. As the LLA oriented itself more towards agricultural issues, it became apparent that it was infringing on the political boundaries of the OFA. Federation elites were aware of the LLA, and they had been

\footnotetext{
${ }^{33}$ Though as Rice (2008) pointed out, rural associations had supported the OFA via its regional branches.
} 
voicing concern over its radical tactics as early as fall of 2004 when OFA vice-president Geri Kamenz brought them to the attention of those who were attending the association's annual meeting (Van Dusen, 2005b) - he was concerned that LLA tactics would serve to "undermine consumer confidence in farm products" (Van Dusen, 2004). But the road blockades symbolized ${ }^{34}$ to the OFA and their allies that this new organization was a serious contender in "their" sector which could threaten to change the direction of agricultural policies in the province, reduce farmers' commitment to the OFA coalition, and displace the strength and power of the OFA - "Ontario's most persuasive farm group" (Van Dusen, 2005c). But the OFA could only do so much to limit the commitment of its members to the LLA, and though they tried to contain the sole allegiance of their constituents, farmers committed to the LLA in droves ${ }^{35}$.

Rather than launching straight into a counter-framing campaign, in December 2005 OFA vice president Geri Kamenz initiated a conciliation meeting with the LLA in order to discuss the creation of a possible protest linkage between the two groups (Van Dusen, 2005c). These negotiations quickly dissipated because neither side was willing to make any concessions (Rice, interview, 23 March 2008). The OFA offered Hillier a spot at the podium and full participation in the One Voice protest. Hillier requested that the OFA sponsor the LLA rally and the group's policies, but leaders from the Federation declined on the grounds that they did not have approval from their membership (Van Dusen, 2005). Talks were short, and their breakdown marked in all likelihood the point when the LLA became constructed as an antagonistic force by the OFA.

\footnotetext{
${ }^{34}$ As Mackay noted, "they were tractors... 'rural residents' don't own tractors... farmers do" (interview, September 04, 2008).

${ }^{35}$ Due to the obligations etched out in the the Farm Registration and Funding for Farm Organizations Act (1993), those that went over to the LLA did retain their OFA memberships, though.
} 
This consequently marked the initiation of counter-framing efforts on behalf of both sides. Although an anti-OFA discourse had been circulating behind closed doors since the organization began, the LLA launched its attack on the "incompetent" farm organizations, calling for field-level dissent by framing them alongside the government as the main culprits responsible for undermining the rural way of life (Hillier, interview, 26 May 2008). They voiced what many farmers had long suspected: that the OFA was "in bed" with the government and no longer protecting their interests first and foremost. The OFA reacted to these assertions by counter-framing the LLA's radical actions as unlawful and irresponsible (Lloyd, 2005): one OFA aligned leader claimed their tractor blockades only served to "slow down truckers... [without] affecting the government" (Gardiner, 2005). The OFA advocated for a more conventional lobby route involving negotiations with government, arguing that an amicable relationship with government would ensure that the needs of agricultural producers were met. This, according to one respondent (Wilson, interview, August 11, 2008), did not resonate well with many farmers who had joined the LLA, and served only to fortify their beliefs in the irrelevance of the OFA.

\section{Competing protests}

In March 2004, the LLA announced that it would stage a massive protest at the provincial legislative building in Toronto for March 9, 2005, titled the "All for One Rural Revolution." The rally was planned to be the peak moment of the LLA campaign. With the organization gaining momentum - even in the face of opposition from the OFA - it appeared that the LLA would deliver on this promise. But with what would have been the largest non-OFA endorsed agrarian protest in the province's history on the horizon, the 
OFA commenced discussions to pre-empt the LLA event, devising a demonstration of its very own.

In early 2005, a group of farmers concerned with the problematic matrix of agricultural groups in Ontario proposed the "One Voice" lobby initiative. The newly formed lobby would be devoted to developing more effective communication and creating opportunities for cooperation amongst the many commodity groups and farming organizations within the province's agricultural sector. Ostensibly "driven by the grassroots" (Atkinson, 2005c), the committee would coordinate the types of compromises which would have to be made in each commodity area and by each general farm organizations - i.e. the Christian Farmers, and the Farmers' Union - in order to better overall conditions. But in reality the One Voice committee was a somewhat hastily assembled group whose roles would be limited to a protest organization ${ }^{36}$.

According to the OFA, it had very little to do with the demonstration, and it claimed the protest had been planned by the One Voice steering committee. This claim, however, is hollow ${ }^{37}$ given that the committee itself was heavily involved with the OFA, and that many OFA leaders would end up speaking at the protest. It therefore suggests that distancing itself from the demonstration was a strategic effort aimed at mitigating the possible negative effects of the anti-OFA sentiment that had proven advantageous to the LLA. This strategy also allowed the OFA to frame the movement as more grassrootsoriented, farmer driven, and "bottom-up" force as compared to their previous protest efforts (Atkinson, 2005c).

\footnotetext{
${ }^{36}$ After examining OFA records made available on their website, it seems that less than a year after the announcement of the One Voice committee quickly, the group faltered into relative obscurity.

${ }^{37}$ For this reason, I refer to the "One Voice" protest as an OFA initiative.
} 
The One Voice committee announced news of the demonstration only one month before it would actually take place. Despite the claims of organizers to the contrary, ${ }^{38}$ it was no coincidence that they planned their appropriately titled "One Voice" rally just one week before the scheduled LLA event. The protest was designed as an effort to display the unity of commodity groups and pressure the government into providing much needed money for spring crops; but it was no secret to farmers that the demonstration was also an effort to deflate the LLA in terms of the perceptions of policy-makers, the public, but most importantly, farmers. The OFA needed to stage a symbolic event which would win back the support of protest hungry farmers, bring back centrality to commodity groups, and communicate to other players that the organization was still as relevant as ever. Staging the event before the LLA's would also provide the government with an opportunity to appear responsive to the more moderate claims of the OFA, and mitigate dealing with radical claims of the LLA.

Upon the announcement, OFA members involved with the LLA started placing immense pressure on OFA president Ron Bonnet to amalgamate. Bonnet reacted, and talks between the two groups were reignited with regards to linking the two demonstrations, but the OFA was unwilling to support the LLA's eleven-point manifesto "without membership approval" (Van Dusen, 2005c), and Hillier wanted complete control over the protest which the OFA refused to concede. This conflict caused some discontent with OFA members who had decided to pledge support to the LLA; they saw the protest as a waste of money and a distortion of the voices of farmers (Atkinson, 2005b).

\footnotetext{
${ }^{38}$ Kamenz claimed that the date was chosen because it was the only one that worked for all the organizations involved (Gardiner, 2005).
} 
Regardless, the OFA embarked on a boundary framing campaign targeted towards reframing and reconstructing the LLA. In newspapers Federation representatives claimed that farmers were more concerned with commodity prices rather than property rights (Van Dusen, 2005). In one instance, the Landowners' were framed as a fringe group out of the eastern locality of the province, and that "the LLA [hadn't] been heard much west of Toronto" (Meagher, 2005, p. 12). The OFA also attempted to delegitimize the LLA's goals, stated that they were too broad, opaque, and unrealistic to materialize (Meagher, 2005, p. 12; Gardiner, 2005). Aware that many of their own members were involved with the LLA, in some instances OFA leaders mitigated attacks against actual LLA adherents, and attempted to focus its antagonistic efforts on Hillier himself. With regards to tactics, OFA vice-president Geri Kamenz told reporters that:

all my peers have great contempt for the activities of Randy Hillier and what he's doing... Staging revolts and selling products which have not been approved by government inspectors could do the agricultural community more harm than good... There's just too much at risk in terms of jeopardizing consumer confidence through a bad food episode (Van Dusen, 2005d).

These targeting efforts were accompanied by an attempt to delegitimize Hillier's role as an appropriate leader of an agrarian movement, citing that he was an electrician and "just" a hobby farmer, incapable of understanding the nuances of agricultural issues and the business of farming (Rice, interview, 23 March 2008). Yet perhaps aware of the true mind states of farmers, the OFA did very little to delegitimize the free market solutions articulated by the LLA.

Even though farmers had a stake in both protests, the LLA attempted to discourage its members from participating in the OFA event, though Hillier himself admitted that some of its members would be attending. But in a bold move the OFA 
encouraged its members to participate in both - after all, the OFA had framed the LLA as belonging to a completely different social movement industry. This innovative strategy would not necessarily mitigate the amount of farmers who would attend the LLA event, but it would bolster support for their own demonstration. The NFU and CFFO also followed suit and encouraged two-fold support. With an assemblage of organizations vying for support - some of them with a hand in both demonstrations - and with the close proximity of the protests it was almost inevitable that a great deal of confusion would arise among farmers, as well as in the media, about which group really represented the interests of farmers (Dickson, 2005).

In an impressive display of the OFA's ability to quickly mobilize resources and organize, on March 2, 2005, approximately 10,000 farmers descended on Queen's Park in Toronto (Newman, 2005) (see Fig. 8). Over 150 buses packed with farmers came from across the province, and several dozens employed the LLA tactic of riding in farm equipment to the city. With very little time to spare before the demonstration, the OFA was unable to project a strong frame, but in the speeches at the demonstration leaders attempted to make it clear what the protest was about: to eliminate the divisions amongst farmers and foster a stronger collective identity. The protest was a call for Ontario farmers to stand "shoulder to shoulder with one clear message to our customers, the consumers of Ontario and to our elected officials." (Bonnet, 2005). Of course many of the over 60 farm industry leaders in attendance (Roulston, 2005) had their own voices heard too, so much so that one participant complained that it was "more like a convention... than a protest" (Robinson, interview, 3 July 2008). 
With the exception of the odd rousing speech, the protest was a sorrowful and emotional plea to the government for immediate aid, particularly so that farmers could afford to purchase the products necessary to plant crops in the approaching spring. Interestingly, there was also some articulation of injustices pertaining to unfair regulatory practices against farmers, though there was no mention of the LLA. Overall, the language of crisis was often projected, as was desperation, abandonment, and a general tone of tragedy. The tactics employed in the demonstration consisted primarily of peaceful acts such as chanting, cheering, marching, and posing symbolic depictions of the disparity between rural and urban conditions (Fig. 9). It was relatively docile compared to the events that the LLA had staged in the preceding months.

But by minimizing militancy, the One Voice rally was able to earn the backing of a number of MPPs and the leader of the provincial New Democrats, Howard Hampton, who appeared in solidarity with farmers (Howden Thompson, 2005). Though not necessarily a supporter of the protest itself, provincial Liberal agriculture minister Steve Peters also met with the farmers to discuss what type of aid the government would be working on. Meanwhile, inside the legislature, OFA friendly MPPs hounded Peters as he attempted to defend his ministry's stance. At the end of the day, the OFA hailed the demonstration as an overwhelming success (Howden Thompson, 2005b).

While the OFA had power in its alliances, the LLA had the advantage of much stronger collective identity amongst its members. The day after the OFA rally, dairy farmer and LLA member Pierre Etter dumped a dead cow on the driveway of Liberal MP Don Boudria (Cumming, 2005). Underneath the carcass was a note stating that the action was in protest against the recent border closings. The act would symbolize the reluctance 
to give way to the power of the OFA. In an effort to bolster support and attention to their protest, the following week saw the LLA feeding the hype machine: they promised huge numbers of participants, and threatened escalating militant action in the city (Van Dusen, 2005d). The police in Toronto were bracing for the worst (Greenberg, 2005).

On March 9, just one week after the "One Voice" rally, close to 6,000 LLA members converged on Queen's Park with three tractor convoys approaching from different directions in tow (see Fig. 10) - a significant showing, but nonetheless lower than what organizers had promised and expected. Nearly every farmer, child, tractor, car, bus, and truck involved in the protest donned mainly homemade signs exclaiming such things as "where's the OFA?," and of course "this land is our land, back off government" (Fig. 11). One tractor depicted a farmer in a casket, and cited that they were a "dying breed" (Fig. 12). In a symbolic gesture Hillier had ordered the stage upon which speakers would address the crowd to be faced towards the legislative buildings, as though they were talking directly to government. Compared to the One Voice rally only seven days earlier, the LLA showing was much angrier. Speeches damned the government for forgetting rural areas, and as he had throughout the career of the LLA, Hillier did not refrain from using profane language when addressing members and other attendees.

However, at about the time that the rally was to reach its peak a diversion of magnificent proportions at Queen's Park drew attention away from farmers: at 1pm a Vietnamese immigrant facing jail time stepped out of his mini-van just outside the perimeter of the protest, and began dousing himself with gasoline. After a standoff with police, the man set himself ablaze (Greenberg, 2005). The incident robbed momentum 
from the LLA (Fig. 13), although participants tried to periodically revitalize the energy. In the end, the protest that came in like a lion left like a wounded lamb.

This was not the only diversion on the day of the protest that negatively affected the efforts of the LLA. It became apparent that the OFA's efforts to reframe the LLA as a non-agrarian movement were gaining traction when Minister Peters dismissed the protesters and their claims, citing that his "goal [was] to deal with legitimate agricultural organizations" (Findlay, 2005). In a sense, it seemed that at the structural level, the efforts of the OFA had closed the very rupture it had promulgated.

The competing protest that had occurred a week earlier had also sopped up most of the attention that the news media were willing to pay to the issue. In other words, with nothing really new to say, the LLA was running the risk of over-saturating the issue. And from the perspective of bystanders and the media, the Landowners" protest seemed strikingly similar to the one that had occurred just days prior. The One Voice rally had successfully distorted the framing of the LLA, but quite possibly at the expense of compromising the clarity of its own positions. Hillier elaborates:

...it became confusing to the media and also the people in the public, you know, 'what's going on here, we're hearing conflicting messages.' We would have a far greater effect if the OFA had not gone a week ahead of us. And they would have a greater effect if they had chosen to not go at that time as well... I think their message got diminished as well (interview, 26 May 2008).

Perhaps Hillier is right, but if the OFA protest was designed to mitigate the presence of the LLA, then it was an overwhelming success.

Another factor that could explain the lower-than-expected turn out at the LLA event was the fact the farmers had invested resources and time into the OFA protest, leaving the LLA as a second option for only hard-core members. Many farmers were old, 
and Toronto was a long way from most agricultural areas. Going to "the city" twice in one week would have seemed a bit much, especially since many would have had to hire help to run their farms while they were away (Campbell, interview, 22 April 2008). The OFA protest offered much more immediate incentives to farmers whom were in dire need of money, even though as Hillier propounds, it "was more of the same" (interview, 26 May 2008). Furthermore, the One Voice rally might have also genuinely changed farmers' opinions of the Federation - perhaps the protests did mark a unity amongst farmers, commodity groups, and the OFA. Perhaps the OFA was turning a new leaf in its structure $^{39}$.

\footnotetext{
${ }^{39}$ In the following months it became apparent that the efforts of both movements did bear some fruit, but it is difficult to discern which movement organization was responsible for certain changes. The government did provide the bailout money to farmers which the OFA protest had demanded, yet the anger expressed via the LLA surely played a role in the decisions of Ministers. The government also unofficially backed off on enforcing its regulations in rural areas which was one of the many mandates of the LLA, but the OFA was also concerned in this area, and there is no way to know for sure whether they played a role in any decision making. Hillier is pleased with the action the groups got on sawmills and farmers' markets, and there is also the speculative topic of the injustices that their efforts may have halted from materializing (Hillier, 2008).
} 


\section{Conclusion}

"Has their ever been a society which has died of dissent?" Bronowski asked. "Several have died of conformity in our lifetime."

- John Raulston Saul, On Equilibrium

On 26 May 2008, a gentleman by the name of Charles shakes my hand and tells me, "he's ready to meet with you now." Our footsteps echo in the halls of the provincial legislature's north wing, and as we enter into the office I am greeted by the new Conservative MPP for Lanark-Frontenac-Lennox and Addington, Randy Hillier. Throughout our meeting Hillier is pretty much as I imagined him: a loud but articulate speaker, charismatic, and rather ambivalent to what people think of him - at one point, in mid-sentence he walked to his refrigerator, pulled out a bottle of "Laker" pilsner, kicked his feet up on his desk, and began sipping the beer as though it were a perfectly normal thing to expect during an interview in an office of an elected representative of the people. I can understand why farmers were so readily moved by the man's words and actions.

In 2007 Hillier left the Ontario Landowners' Association (OLA) - the current incarnation of the Lanark Landowners' Association - to seek the Conservative Party nomination for his riding which he handily won, although his victory was accompanied by controversy over his "activist past." Hillier is now the Conservative's critic for rural affairs, and he maintains that he has very little to do with OLA activities, and merely copublishes and co-edits the group's bi-monthly magazine "The Landowner". In reality, the OLA now has a man on the inside, except that now he can no longer so easily raise his fist against the government without facing repercussions from his own party and risking alienating members of other parties with whom he needs to work in the committee world 
of institutional politics. We have an excellent session, and as I leave he firmly shakes my hand, and proudly thrusts several issues of The Landowner into my arms.

Hillier has a lot of reasons to be proud. With over 15,000 members, the OLA is now growing more and more into a significant lobby group for rural issues, and it has brought a focus to rural movements that were rather fragmented in the past. Yet as its more recent shift in focus towards rural affairs indicates, the group could not forge a lasting presence in the agricultural social movement industry. Although many of its members continue to be farmers, and the group continues to operate with a marketoriented policy position regarding agricultural markets, it has since downplayed the farming focus. Since the protests of 2005, the Ontario Federation of Agriculture has resumed its role as the largest organization in Ontario's agricultural multi-organizational field.

These results have shown that dynamics at the level of multi-organizational fields affects the character and trajectory of protest, and that there exists a mutual relationship between structure and process. By historically situating agricultural organizations and their relationships with farmers, this project has attempted to articulate the factors that can explain how farmers developed meanings about protest, and how these constructions influenced the decision to participate with a relatively unknown group, which was not necessarily an agrarian movement organization: the LLA. In doing so, this project explained how it was that the LLA was able to penetrate a "dense" multi-organizational field, upon which a significant player - the OFA - was very dominant.

When applied to this case, the multi-organizational perspective shows that the success of a social movement cannot always be explained through what organizations can 
do, but what other organizations in a multi-organizational field cannot achieve. The LLA would not have come into existence if not for the ruptures created by the intense bureaucratization and heterogeneity of the OFA. After a long history, the OFA successfully positioned itself as the dominant organization in Ontario's agricultural sector, and in doing so also found itself to be the most central player in initiating collective action. But with expansion, and eventually institutionalization, the OFA would have to entertain the idea of a more hierarchic and bureaucratic structure, as it would also have to forge new relationships amongst multiple very important players. As it turned out, the inclusion of such a mixture of organizations into the OFA's alliance system created a mangle in which no interests could really be accommodated, rendering the organization impotent if not obsolete. In addition to constraining the occurrence of collective identity that would be meaningful to its members, these new macro-relations set into play a destabilization of the identities of OFA adherents, which in effect lowered their commitment to the group's protest thereby increasing the resonance of unconventional frames constructed by alternative SMOs. In this case it was the LLA that exploited the constraints of the OFA, but perhaps it could have been any number of SMOs, so long as they could withstand the difficult steps implicit in emergence/ Perhaps merely offering a path to protest was enough to generate support.

More recently, however, the OFA has started to take on a new structure. After years of deliberation the board has approved a move which will mitigate the problems associated with having commodity groups sitting at the decision-making table, and bring a stronger farmer presence to the Federation, though it has still not yet been revealed exactly what this restructuring will look like. Though there is no way to be sure, we can 
postulate that efforts of the LLA to create a new agrarian movement in part triggered the decision to restructure. In other words, just as the LLA protest provided the premises for the OFA to protest - and arguably save face - the popularity of the LLA amongst farmers also lit the fire in the minds of OFA elites to initiate organizational change. Though farmers in the LLA never saw the group's proposed solutions come to fruition, the very act of participating with the group transformed how business is done in the multiorganizational field of agricultural production and politics.

There is evidence in this project that the radical protest postured by the OFA to a great degree influenced farmers' decision to become involved with the movement. The two antagonistic organizations shared a general understanding of the injustices which were being posed to farmers, but the Landowners' anti-government stance allowed farmers to recognize themselves as part of a broader community, as well as articulate their dissent to a discernable group of actors, rather than the OFA more abstract target of blame. There is also evidence that the direct action tactics of the LLA resonated more with farmers in a state of agitation than the OFA's accommodationist approach to working with rather than against government. The OFA saw an explosion in membership after it began rolling out its road blockades across the province. On one hand this increased media attention, but on the other it demonstrated to farmers that disruptive militant tactics, popularized and put to good effect in the past, could be used in the present. Though tactics of this caliber have not been employed by the OFA since the protest cycle of 2005, it goes to show that even the most moderate social movement can be "re-radicalized." 
But the fact the OFA was so easily able to deflate the efforts of the LLA calls into question the commitment of members to the organization itself. While the organization provided a fertile climate in which a collective identity could flourish, it generally failed to retain a long-term commitment from many farmers, as illustrated in the smaller turn out for its Queen's Park demonstration in March 2005. The success of the OFA can be explained in part through a shift in the consciousnesses of adherents pertaining to their perceptions of the LLA, which on one hand we can attribute to the counter-framing efforts of the OFA; yet, we must take into account the reasons these frames were appropriated by farmers that had pledged allegiance to the Landowners Association. The only answer to this question I can think of is that the OFA was able to use its strong network of organizations to point farmers in the direction of the One Voice rally. Thus, while the LLA could construct a stronger sense of collectivity amongst farmers, the organizational power of the OFA was enough to destabilize these bonds, and (re)establish new ones.

This was only after a hard fought, yet reasonably short process through which the OFA projected new frames that redefined organizational boundaries and the identities of farmers. By creating the One Voice steering committee that had ostensibly organized the OFA's antagonistic protest, the Federation was able to symbolically marginalize itself from the event, thus mitigating the anti-bureaucracy sentiment circulating amongst farmers, due in part to the counter framing efforts of the LLA, but more so because of the history farmers shared with the organization. Moreover, the OFA was able to harness the suddenly rising popularity of grassroots protest by framing the One Voice event as one that was built from the ground up. 
In the years preceding this case, the OFA had mitigated the lifestyle elements of farming, preferring to reconstruct farmers as business people. Yet empirical evidence indicates that farmers do not necessarily see themselves as engaged in a solely economic activity; rather, implicit in their activities is a lifestyle, or cultural, component. When crisis was perceived to have hit the farming community, the OFA attempt to construct the identities of its constituents broke down, creating an opportunity for the LLA. By linking agricultural activities with the looming de-population of rural Ontario, the LLA was able to redefine what it meant to be a farmer in a way that resonated more so with the collective belief systems of farmers.

So, how antagonistic were the movements toward one another? They both arose to address the very same issues faced by farmers, although they did propose very different paths to changing conditions that discouraged any cooperation between the two. It seems plausible to suggest that the OFA reacted to the protest as a form of organizational self-preservation. Thus where "iron shackles" kept the OFA from acting in the first place, regardless of its constituency, they also brought the Federation into action against the LLA. Yet, this conceptualization might be overly critical. After all, the OFA fought for what it genuinely believed to be the best path for agriculture. It is doubtful that their decisions were built on malice against farmers, as Hillier suggested. If they had not acted, who knows how far the LLA would have been able to take their agenda, which many in the industry see as the worst possible direction for agriculture (Mackay, interview, 20 March 2008; Rice, interview, 23 March 2008; Wilson, interview, 11 August 2008; Rosset, 2006). Though the OFA protest might have shot Ontario's agrarian 
movement in the foot, perhaps it was worth it in the name of securing the future of farmers. Then again, their efforts might have just secured more of the same.

Regardless, this study only scratches the surface of understanding the problems that affect Ontario's agricultural sector. There are a multitude of other reasons that stretch far beyond the borders of the province that contribute to the promulgation of the issues about which farmers, and many urbanites, have grown to worry. But if farmers do not bind together to face that which has compromised their futures, and the futures of their farms, then who will? As this project has shown, even their own representative organizations, probably inadvertently, can turn against them.

As respondents have asserted throughout this project, the viability of rural economies are intrinsically linked with local agricultural sectors. Moreover, the study also demonstrates that the distinction between rural and agrarian movements is becoming increasingly blurred as the grievances of the two groups become more similar. This has serious implications for understanding the social and political forces behind rural and agrarian movements, if such a distinction still exists. From an empirical perspective, further, preferably more detailed ethnographic studies are needed to understand the interactions and decisions that lay behind the battle for rural areas in Ontario and similar foreign contexts. This is especially true if we are to understand the dynamics behind another topic that has recently begun to garner considerable currency in public affairs: food.

While this study has shed light on some of the internal dimensions of agrarian protest, it has paid limited attention to the cultural environments in which bystanders and other observers interpret the meanings that movements like them attempt to disperse. 
Relatively recently, due to emerging concerns over health and recent events (e.g. carrot juice in the southern U.S. tainted with botulism, packaged spinach from California found to contain E. coli, alfalfa sprouts deriving from Michigan and Virginia carrying salmonella, and the recent listeria outbreak at Maple Leaf foods in Toronto) new issues have quickly entered into the day-to-day interactions of urban populations, as have topics of agriculture, and food security (e.g. Underwood, 2008; Lahey, 2008; Roberts, 2008). It seems plausible to suggest that as the cultural environments of cities grow increasingly concerned with these topics, so will the ability of farmers'/rural movements to construct and project frames and meanings much more resonant to urban people. Yet as popular understandings of food are undergoing significant transformations, so must the framing strategies of agrarian movements. In addition to advancing understanding of the new and emerging relationships between rural and urban populations, further study in this area would contribute to the field of social movement studies by bringing attention to the ways that outsider groups gain the sympathy of those on the inside. 


\section{References}

Adriance, M. (1994). Base communities and rural mobilization in Brazil. Sociology of Religion, 55(2), pp. 163-178.

Alvarez, S. E. \& A. Escobar (1992). Theoretical and political horizons of change in contemporary Latin American social movements. In S.E. Alvarez \& A. Escobar (eds.), The making of social movements in Latin America. Boulder, CO: Westview Press.

Anderson, B. (1983). Imagined Communities. London: Verso.

Ansell, C.K. (2001). Oligarchy (iron law). International Encyclopedia of the Social \& Behavioural Sciences, pp. 10853-10855. Oxford: Elsevier.

Aspinall, E. (2007). The construction of grievance: Natural resources and identity in a separatist conflict. Journal of Conflict Resolution, 51(6), pp. 950-972.

Atkinson, S. (2005, March 1). Boxed in by frustrated farmers: Speaking at Peterborough high school, Premier McGuinty found his exit blocked by farm tractors. Ontario Farmer, p. B12.

Atkinson, S. (2005b, March, 15). Farm crisis prompting: Many aren't accustomed to confrontation but they say the severity of the situation is forcing them. Ontario Farmer, p. A3.

Atkinson, S. (2005c, March 29). Grassroots driving One Voice plan: Farmers are rallying together to try and maintain the momentum from recent rallies. Ontario Farmer, p. A24.

Bailey, L. (2001, March 22). County farmers participate in day of protest. Colborne Chronicle, p. 3.

Bartolini, S. (1993). On time and comparative politics. Journal of Theoretical Politics, 5, pp. 131-167.

Benford, R.D. (1993). Framing activity, meaning, and social movement participation: The nuclear disarmament movement. Social Forces, 71(3), pp. 677-701.

Benford, R.D. (1997). An Insider's Critique of the Social Movement Framing Perspective. Sociological Inquiry, 67(4), pp. 409-30.

Bernstein, M. (1997). Celebration and suppression: The strategic uses of identity by the lesbian and gay movement. The American Journal of Sociology, 103(3), pp. 531565 . 
Blee, K.M, \& V. Taylor (2002). Semi-structured interviewing in social movement research. In B. Klandermans, \& S. Staggenborg (eds.), Methods of social movement research, pp. 92-117. Minneapolis: University of Minnesota Press.

Bonnet, R. (2005, March 2). Speech, given at "One Voice" Rally. Toronto, ON.

Brown, J.S., \& Duguid, P. (2001). Knowledge and organization: A social practice perspective. Organizational Science, 12(2), pp. 198-213.

Buechler, S.M. (1993). Beyond resource mobilization? Emerging trends in social movement theory. The Sociological Quarterly, 34(2), pp. 217-235.

Callon, Michel (1986) Some elements of a sociology of translation: domestication of the scallops and the fishermen of St Brieuc Bay. In J.Law (ed.) Power, action and belief. A new sociology of knowledge?, pp. 196-233. London: Routledge \& Kegan Paul.

Castells, M. (1983). The city and the grassroots. Berkeley: University of California Press.

Cawson, S. (1986). Corporatism and political theory. Oxford: Basil Blackwell.

Chima, J.S. (2005). What's the utility of the case study method for social science research?: A response to critiques from the quantitative/statistical perspective. Paper presented at the Annual meeting of the American Political Science Association. Retrieved September, 11, 2008, from, http://www.allacademic.com//meta/p_mla_apa_research_citation/0/4/1/9/5/pages 41 952/p41952-1.php.

Christian Farmers Federation of Ontario (2005, February). The CFFO and public demonstrations [press release]. Guelph: CFFO.

Christian Farmers Federation of Ontario (2005b, February). The CFFO and "one farm voice" [press release]. Guelph: CFFO.

Clemens, E.S., \& Minkoff, D. (2004). Beyond the iron law: Rethinking the place of organizations in social movement research. In D.A. Snow, Soule, \& Kriesi, H. (eds.), The Blackwell companion to social movements, pp. 155-170. Oxford: Blackwell.

Conover, P.J., \& Gray, V. (1983). Feminism and the new right: Conflict over the American family. New York: Praeger Publishers.

Conway, J.M. (2004) Identity, place, knowledge: social movements contesting globalization. Halifax: Fernwood. 
Couch, C.J. (1968). Collective behaviour: An examination of some stereotypes. Social Problem, 15, pp. 310-322.

Cumming, I. (2005, March, 15). Farmer dumps dead cow on MP's laneway. Ontario Farmer, p. B1.

Curtis, R.L., \& Zurcher, L.A. (1973). Resources of protest movements: The multiorganizational field. Social Forces, 52(1), pp. 53-61.

della Porta, D., \& Diani, M. (1999). Social movements: an introduction. Oxford: Blackwell.

della Porta, D. \& Kriesi, H. (1999). Social movements in a globalizing world: An introduction. In D. della Porta \& H. Kriesi (eds.), Social movements in a globalizing world, pp. 3-22. New York: Palgrave Macmillan.

della Porta D., \& Rucht, D. (1995). Left-libertarian movements in context: A comparison of Italy and West Germany, 1965-1990. In B. Klandermans \& C. Jenkins (eds.), The politics of social protest: Comparative perspectives on states and social movements. Minneapolis: University of Minnesota Press.

Diani, M. (1996). Linking mobilization frames and political opportunity: Insights from regional populism in Italy. American Sociological Review, 61(6), pp. 1053-1069.

Dickson, K. (2005, February, 25). Converge on Queen's park [letter to the editor]. The Renfrew Weekender, p. 20.

Drudy, P.J. (1978). Depopulation in a prosperous agricultural sub-region. Regional Studies: The Journal of Regional Studies Association, 12(1), pp. 49-60.

Edelman, M. (2001). Social movements: Changing paradigms and forms of politics. Annual Review of Anthropology, 30, pp. 285-317.

Edwards, B., \& McCarthy, J.D. (2004). Resources and social movement mobilization. In D.A. Snow, Soule, \& Kriesi, H. (eds.), The Blackwell companion to social movements, pp. $116-152$. Oxford: Blackwell.

Eliasoph, N. (1998). Avoiding politics: How produce apathy in everyday life. Cambridge: Cambridge University Press.

Endangered Species Act, S.O., 2007.

Environmental Protection Act, R.S.O., 1990, c.7, s.13. 
Evans, J.H. (1997). Multi-organizational fields and social movement organization frame content: The religious pro-choice movement. Sociological Inquiry, 67(4), pp. 451469.

Evans, S., \& Boyte, H. (1986). Free spaces: The sources of democratic change in America. New York: Harper \& Row.

Farm Registration and Funding for Farm Organizations Act, R.S.O., 1993, c.19, s.8.

Findlay, A. (2005, March 8). Convoy ready to roll on Park. Toronto Star, p. B3.

Fireman, B., \& Gamson, W.A. (1979). Utilitarian logic in the resource mobilization perspective. In M.N. Zald, \& J.D. McCarthy (eds.), The dynamics of social movements, pp. 8-44. Cambridge: Winthrop.

Flacks, R. (2004). Knowledge for what? Thoughts on the state of social movements studies. In J. Goodwin \& J. Jasper (eds.) Rethinking social movements: Structure, meaning, and emotion, pp. 135-153. New York: Rowman \& Littlefield.

Food and Agricultural Organization of the United Nations. (2006). The role of agriculture and rural development in revitalized abandoned/depopulated areas. Paper presented at $25^{\text {th }} \mathrm{FAO}$ regional conference for Europe. Retrieved September 12, 2008, from, http://www.fao.org/world/regional/reu/eca/ECA_EN/eca34_3.pdf.

Franzen, T. (1993). Differences and identity: Feminism and the Albuquerque Lesbian Community. Signs, 18(4), pp. 891-906.

Freeman, J. (1973). The tyranny of structurelessness. In A. Koedt, \& E. Levine (eds.), Radical feminism, p. 290-301. New York: Quandrangle Books.

Fuks, M. (1998). Environment-Related Litigation in Rio de Janeiro: Shaping Frames for a New Social Problem. International Journal of Urban and Regional Research, 22(3), pp. 394-407.

Gallagher, P. (2005, March, 8). Border injunction pulls back prices: Some in the industry are predicting the ruling will trigger another price disaster for producers. Ontario Farmer, p. B27.

Gamson, J. (1995). Must identity movements self destruct? A queer dilemma. Social Problems, 42(3), pp. 390-407.

Gamson, W.A. (1982). Encounters with unjust authority. Chicago: Dorsey Press.

Gamson, W.A. (1991). Commitment and agency in social movements. Sociological Forum, 6, pp. 27-50. 
Gamson, W.A. (2004). Bystanders, public opinion, and the media. In D.A. Snow, Soule, \& Kriesi, H. (eds.), The Blackwell companion to social movements, pp. 242-261. Oxford: Blackwell.

Ganz, M. (2000). Resource and resourcefulness: Strategic capacity in the unionization of California Agriculture, 1959-1966. American Journal of Sociology, 4, pp. 10031062.

Ganzel, B. (2003). Radical farm protests during the Great Depression. Retrieved from http://www.livinghistoryfarm.org/farminginthe30s/money_11.html.

Gardiner, N. (2005). Landowners group, OFA as odds. Brockville Recorder and Times, p. 2.

Geertz, C. (1973). The interpretation of cultures. New York: Basic Books.

Gerlach, L.P. (1999). The structure of social movements: Environmental activism and its opponents. In J. Freeman \& V. Johnson (eds.), Waves of protest: Social movements since the sixties, pp. 85-98. Maryland: Rowman and Littlefield Publishers.

Gerring, J. (2003). Causation: A unified framework for the social sciences. Paper presented at American Political Science Association meeting. Retrieved September 11,2008 , from, http://www.allacademic.com $/ /$ meta/p_mla_apa_research_citation/0/6/2/7/6/pages62 768/p62768-1.php.

Gilday, A. (2003, September 24). Hog farm opponents picket. Dunnville Chronicle, p. 6.

Goffman, E. (1959). The presentation of self in everyday life. NY: Anchor Books.

Goodwin, J, \& Jasper, J. (2003). Editors' introduction. The social movements reader: Cases and concepts, pp. 3-7. Oxford: Blackwell.

Goodwin, J., Jasper, J.M., \& Polletta, F. (2004). Emotional dimensions of social movements. In D.A. Snow, Soule, \& Kriesi, H. (eds.), The Blackwell companion to social movements, pp. 413-431. Oxford: Blackwell.

Goodwyn, L. (1978). The populist movement: a short history of the agrarian revolt in America. New York: Oxford University Press.

Gould, R.V. (1995). Insurgent identities: Class community and protest in Paris from 1848 to the Commune. Chicago: University of Chicago Press.

Greenberg, J. (2004). Tories, teachers, and the media politics of education reform: News discourse and the 1997 Ontario teachers' strike. Journalism Studies, 6(2), pp. 353371. 
Greenberg, J. (2005). This news may come as a shock: The politics of press coverage of electricity restructuring in Ontario, 1995-2002. Canadian Journal of Communication, 30(2), pp. 233-258.

Greenberg, J., May, T., \& Elliott, C. (2006). Homelessness and media activism in the voluntary sector: A case study. The Philanthropist, 20(2), pp. 131-152.

Greenberg, L. (2005, March 10). Man sets himself ablaze. National Post, p. A1.

Gundelach, P. (2005). Visions in agriculture. Sociologia Ruralis, 45(3), pp. 245-262.

Habermas, J. (1987). The theory of communicative action: A critique of functionalist reason. (T. McCarthy, trans, vol. 2 Lifeworld and system). London: Polity Press.

Halpin D. \& P. Martin (1999). Representing and managing farmers' interests in Australia. Sociologia Ruralis, 39(1), pp. 78-99.

Hannigan, J.A. (1985). Alain Touraine, Manuel Castells, and social movement theory: A critical appraisal. The Sociological Quarterly, 26(4), pp. 435-454.

Hastings County Property Rights Coalition (2004). Response to Soloman's article, "Rural phase out." Retrieved September, 11, 2008, from, http://ruralrevolution.com/website/index.php?option=con_content\&task=section\&i $\mathrm{d}=75 \&$ Itemid $=127$.

Hendrickson, M.L. \& Heffernan, W.D. (2002). Opening spaces through relocalization: locating potential resistance in the weaknesses of the global food system. Sociologia Ruralis, 42(4), pp. 347-369.

Henry, B. (2002, April 3). Farmers say crisis looming. Owen Sound Sun Times, p. A1.

Hiller, R. (2003). The rural economy, caught in the line of fire. Retrieved November 01, 2008, from, http://www.quebecoislibre.org/aphillier.htm.

Howden Thompson, A. (2005, March 8). Peters questioned by farmers, in legislature, about aid. Ontario Farmer, p. B18.

Howden Thompson, A. (2005b, March 8). Inside the rally: evaluating the required logistics. Ontario Farmer, p. B1.

Howe, L.A. (2000). On Habermas. New York: Wadsworth.

Hunt, S.A., \& Benford, R.D. (2004). Collective identity, solidarity, and commitment. In D.A. Snow, Soule, \& Kriesi, H. (eds.), The Blackwell companion to social movements, pp. 433 - 457. Oxford: Blackwell. 
Hunt, S.A., Benford, R.D, \& Snow, D.A. (1994). Identity fields: Framing processes and the social construction of movement identities. In E. Larana, H. Johnston, \& J. Gusfield (eds.), New social movements: From ideology to identity, pp. 185-208. Philadelphia: Temple University Press.

Independent. (June 11, 2008). IFA mount pig meat protest at Lidl supermarket. Retrieved November 20,2008, from, http://www.independent.ie/breaking-news/nationalnews/ifa-mounts-pig-meat-protest-at-lidl-supermarket-1405541.html.

Inglehart, R. (2003). Changing values in post-industrial societies. In J. Goodwin, \& J.M. Jasper (eds.), The social movements reader: cases and concepts, pp. 64-71. Oxford: Blackwell.

Jenkins, J.C. (1983). Resource mobilization theory and the study of social movements. Annual Review of Sociology, 9, pp. 527-553.

Jenkins, J.C, \& Perrow, C. (1977). Insurgency of the powerless: Farm workers movements (1946-1972). American Sociological Review, 42(2), pp. 249-268.

Johnston, H. (2002). Verification and proof in frame and discourse analysis. In B. Klandermans, \& S. Staggenborg (eds.), Methods of social movement research, pp. 62-91. Minneapolis: University of Minnesota Press.

Jordan, T., Lent, A., McKay, G., \& Mische, A. (2002). Social movement studies: An opening statement. Social Movement Studies, 1(1), pp. 5-6.

Klandermans, B. (1984). Mobilization and participation: Social-psychological expansions of resource mobilization theory. American Sociological Review, 49, pp. 583-600.

Klandermans, B. (1987). Potentials, networks, motivations, and barriers: Steps towards participation in social movements. American Sociological Review, 52(4), pp. 519531.

Klandermans, B. (1989). Organizing for change: Social movement organizations in Europe and the United States. Greenwich, CT: Jai Press.

Klandermans, B. (1992). The social construction of protest and multi-organizational fields. In A.D. Morris \& C. McClurg Mueller (eds.), Frontiers in social movement theory, pp. 77-103. New Haven: Yale University Press.

Klandermans, B. (1997). The social psychology of protest. Oxford: Basil-Blackwell. 
Klandermans, B. (2004). The supply and demand of participation: Social-psychological correlates of participation in social movements. In D.A. Snow, Soule, \& Kriesi, H. (eds.), The Blackwell companion to social movements, pp. 360-379. Oxford: Blackwell.

Klandermnas, B. \& de Weerd, M. (2000). Group identification and protest. In S. Stryker, T.J. Owens, \& R.W. White (eds.), Self, identity, and social movements, pp. 68-92. Minnesota: University of Minnesota Press.

Klandermans, B., de Weerd, M., Subecedo, J.M, \& Costa, M. (1999). Injustice and adversarial frames in supranational political context: farmers' protest in the Netherlands and Spain. In D. della Porta \& H. Kriesi (eds.), Social movements in a globalizing world, pp. 134-147. New York: Palgrave Macmillan.

Klandermans, B., \& Staggenborg S. (2002). Introduction. In B. Klandermans, \& S. Staggenborg (eds.), Methods of social movement research, pp. ix-xx. Minneapolis: University of Minnesota Press.

Klandermans, B., Sabucedo, J.M., Rodriguez, M., \& de Weerd, M. (2002). Identity processes in collective action participation: farmers' identity and farmers' protest in the Netherlands and Spain. Political Psychology, 23(2), pp. 235-251.

Kornhauser, W. (1959). The politics of mass society. Glencoe, IL: Free Press.

Kriesi, H. (1996). The organizational structure of new social movements in a political context. In D. McAdam, J.D. McCarthy, \& M.N. Zald (eds.), Comparative perspectives on social Movements: Political opportunities, mobilizing structures, and cultural framings, pp. 152-184. Cambridge: Cambridge University Press.

Kubal, T.J. (1998). The presentation of political self: Cultural resonance and the construction of collective action frames. Sociological Quarterly, 39(4), pp. 539554.

Lahey, A. (2008, January/February). Do we have the right to know what's in our food? The Walrus, p. 22.

Lindlof, T.R., \& Taylor, B.C. (2002). Qualitative communication research methods. Thousand Oaks, California: Sage.

Lloyd, A. (2005, January 22). "Rural revolution" takes to the road: Lanark farmers joined counterparts from southwestern Ontario in a blockade of highway 401 to bring attention to growing anger at a host of issues affecting rural life. Ottawa Citizen, $\mathrm{p}$. D2. 
Maines, D.R. (1982). In search of mesostrucure: Studies in the negotiated order. Journal of Contemporary Ethnography, 11, pp. 267-279.

Mann, S. (2005). The depopulation of rural areas and the farming system. Paper presented at the $94^{\text {th }}$ EAAE seminar. Retrieved September 13, 2008, from, http://ageconsearch.umn.edu/bitstream/24415/1/sp05ma01.pdf.

Mansbridge, J. (1986). Why we lost the ERA. Chicago, IL: University of Chicago.

Marullo, S., Pagnucco, R., \& Smith, J. (1996). Frame changes and social movement contraction: U.S. peace movement framing of the Cold War. Sociological Inquiry, 66, pp. 1-28.

Marx, G.T., \& Wood, J.L. (1975). Strands of theory and research in collective behaviour. Annual Review of Sociology, 1, pp. 363-428.

Mauthner, N., \& Doucet, A. (2003). Reflexive accounts and accounts of reflexivity in qualitative data analysis. Sociology, 37(3), pp. 413-431.

Mazur, A. (1981). Media coverage and public opinion on scientific controversies. Journal of Communication, 31(2), pp. 106-115.

McAdam, D. (1982). Political processes and the development of Black insurgency, 19301970. Chicago: University of Chicago Press.

McAdam, D. (1988). Freedom summer. New York: Oxford University Press.

McAdam, D. (1996). The Framing Function of Movement Tactics: Strategic Dramaturgy in the American Civil Rights Movement. In J.D. McCarthy, \& M.N. Zald (eds.), Perspectives on social Movements: Political opportunities, mobilizing structures and cultural framings, pp. 339-340. Cambridge, UK: Cambridge University Press.

McAdam, D. (2004). Recruits to civil rights activism. In D.A. Snow, Soule, \& Kriesi, H. (eds.), The Blackwell companion to social movements, pp. 55-63. Oxford: Blackwell.

McAdam, D., McCarthy, J.D., \& Zald M.N. (1988). Social movements. In Smelser, N. (ed.), Handbook of sociology, pp. 695-737. Newbury Park CA: Sage.

McCarthy, J.D. \& Zald, M.N. (1973). The trend of social movements. Morristown, NJ: General Learning Press.

McCarthy, J.D. \& Zald, M.N. (1977). Resource mobilization and social movements: A partial theory. The American Journal of Sociology, 82(6), pp. 1212-1241. 
McCarthy, J.D., \& Zald, M.N. (1979). Social movement industries: Competition and cooperation among movement organizations. (CSRO working paper no. 201). Retrieved July 12, 2008, from, http://deepblue.lib.umich.edu/bitstream/2027.42/50975/1/201.pdf.

McClurg Mueller, C. (1992). Building social movement theory. In A.D. Morris \& C. McClurg Mueller (eds.), Frontiers in social movement theory, pp. 3-25. New Haven: Yale University Press.

McLeod, J. (2004, September, 27). Coming to a town hall near you: The rural revolution. Canadian Free Press. Retrieved September 11, 2008, from, http://www.canadafreepress.com/2004/cover092704.htm.

Meagher, P. (2005, March). Catching a tiger: Can Ontario's farmers and the Lanark Landowners' Association get along?. Farmers Forum, pp. 1, 12.

Medd, B. (2005, July 12). Dairy farmers gather in Cannington. The Peterborough Examiner, p. B3.

Melucci, A. (1984). An end to social movements? Social Science Information, 23(4/5), pp. 819-835.

Melucci, A. (1989). Nomads of the present: Social movements and individual needs in contemporary society. Philadelphia: Temple University Press.

Melucci, A. (1996). Changing codes. Cambridge: Cambridge University Press.

Meyer, D.S., \& Staggenborg, S. (1996). Movements, countermovements, and the structure of political opportunity. American Journal of Sociology, 101(6), pp. 16281660.

Micheletti, M. (1990). The Swedish farmers' movement and government agricultural policy. New York: Praeger Publishers.

Michels, R. (1966). Political parties. New York: The Free Press.

Minkoff, D.C. (2002). Macro-organizational analysis. In B. Klandermans, \& S. Staggenborg (eds.), Methods of social movement research, pp. 260-285. Minneapolis: University of Minnesota Press.

Mooney, P.H. (2004). Democratizing rural economy: institutional friction, sustainable struggle and the cooperative movements. Rural Sociology, 69(1), pp. 76-98. 
Mooney, P.H., \& Hunt, S.A. (1996). A repertoire of interpretations: master frames and ideological continuity in U.S. agrarian mobilization. The Sociological Quarterly, 37(1), pp. 177-197.

Mooney, P.H. \& Majka, T.J. (1995). Farmers' and farm workers' movements: social protest in American agriculture. New York: Twayne Publishers.

Morris, A. (1984). The origins of the civil rights movement: Black communities organizing for change. New York: Free Press.

Morris, A.D., \& Staggenborg, S. (2004). Leadership in social movements. In D.A. Snow, Soule, \& Kriesi, H. (eds.), The Blackwell companion to social movements, pp. 171196. Oxford: Blackwell.

Mukherji, P.N. \& B.B. Sahoo (1992). Agrarian structure, contradiction and mobilization: a framework for the analysis of emerging rural power. Social Scientist, 20(9/10), pp. 77-86).

National Farmers' Union (2007). History of the N.F.U. Retrieved August 15, 2008, from, http://www.nfu.ca/on/misc_files/History.htm\#Part1.

Nutrient Management Act, R.S.O., 2002, c.4, s.37.

Offe, C. (1985) New social movements: Challenging the boundaries of institutional politics. Social Research, 52(4), pp. 817-868.

Olson, M. (1965). The logic of collective action. Cambridge: Harvard University Press.

Panel on the Role of Government (2004). Investing in people: Creating a human capital society for Ontario. Toronto, ON: Daniels, R.J.

Pascaul, J. (2004, October). How to direct-market your beef: Takes 2 years to build clientele, Scott says. Farmers Forum, p. 16.

Pichardo, N.A. (1997). New social movements: A critical review. Annual Review of Sociology, 23, pp. 411-430.

Pickering, A. (1995). The mangle of practice: Time, agency and science. Chicago: University of Chicago Press.

Piven, F., \& Cloward, R. (1979). Poor people's movement: Why movements succeed and fail $\left(2^{\text {nd }}\right.$ ed.). NY: Pantheon.

Polletta, F., \& Jasper J. (2001). Collective identity and social movements. Annual Review of Sociology, 27, pp. 283-305. 
Ragin, C.C. (1992). Introduction: Cases of "what is a case?". In C.C. Ragin, \& H.S. Becker, What is a Case: Exploring the foundations of social inquiry, pp. 1-17. New York: Cambridge University Press.

Reed, M. (2004). The mobilization of rural identities and the failure of the rural protest movement in the UK, 1996-2001. Space and Polity, 8(1), pp. 25-42.

Reiss, J. (2005). Social movement unionism and progressive public policy in New York City. Just Labour, 5, pp. 36-48.

Rice, L. (2004). Letter of support. National Farmers' Union. Retrieved from National Farmers' Union records.

Roberts, O. (2005, September 12). Farmers fire up urban awareness effort. The Guelph Mercury, p. A2.

Roberts, W. (2008, September 10). Where's the beef tax? Now Magazine, 28(2), p. 8.

Robinson, K.L. (1989). Farm and food policies and their consequences. New Jersey: Prentice Hall.

Rodirigues, H. (2005, January 12). LLA plans total shutdown of highway 401 for January 21. Agricultural Reporter, p. 13.

Rosset, P.M. (2006). Food is different: why we must get the WTO out of agriculture. Malta: Gutenberg Press.

Roulston, K. (2005, April). Still sending the message. The rural voice, pp. 34-37.

Rucht, D. (1996). The impact of national contexts on social movement structures: A cross-movement and cross-national comparison. In D. McAdam, J.D. McCarthy, \& M.N. Zald (eds.), Comparative Perspectives on Social Movements: Political opportunities, mobilizing structures, and cultural framings, pp. 185-204. Cambridge: Cambridge University Press.

Rucht, D. (2004). Movement allies, adversaries, and third parties. In D.A. Snow, Soule, \& Kriesi, H. (eds.), The Blackwell companion to social movements, pp. 116-152. Oxford: Blackwell.

Ryan, C. (1991). Prime time activism. Boston: South End Press.

Saifert, A. (2003, July 8). Local farmers protest Japanese beef boycott. Hanover Post, p. A2.

Saul, J.R. (1995). The unconscious civilization. New York: The Free Press. 
Scott, J.C. (1985). Weapons of the weak: Everyday forms of peasant resistance. New York: Yale University Press.

Shapiro, G., \& Markoff, J. (1998). Revolutionary demands: A content analysis of the Cahiers de Doléances of 1789. Stanford: Stanford University Press.

Shweder, R.A., \& Fiske, D.W. (1986). Metatheory in social science: Pluralisms and subjectivities. Chicago: University of Chicago Press.

Snow, D.A. (2004). Framing processes, ideology, and discursive fields. In D.A. Snow, Soule, \& Kriesi, H. (eds.), The Blackwell companion to social movements, pp. 380412. Oxford: Blackwell.

Snow, D.A., \& Benford, R.D. (1988). Ideology, frame resonance, and participant mobilization. International Social Movement Research, 1, pp. 197-218.

Snow, D.A., \& Benford R.D. (1992). Master frames and cycles of protest. In A.D. Morris, \& C. McClurg-Mueller (eds.), Frontiers in social movement theory, pp. 133-155. New Haven, CT: Yale University Press.

Snow, D.A., \& Benford R.D. (2000). Framing processes and social movements: An overview and assessment. Annual Review of Sociology, 26, pp. 611-639.

Snow, D.A., Rochford, E.B., Worden, S.K., \& Benford, R.D. (1986). Frame alignment processes, micromobilization, and movement participation. American Sociological Review, 51(4), pp. 464-481.

Snow, D.A., \& Trom, D. (2002). The case study and the study of social movements. In B. Klandermans, \& S. Staggenborg (eds.), Methods of social movement research, pp. 146-172. Minneapolis: University of Minnesota Press.

Snow, D.A., Zurcher, L.A., \& Ekland-Olson, S. (1980). Social networks and social movements: A microstructural approach to differential recruitment. American Sociological Review, 45(5), pp. 787-801.

Solomon, L. (2004, April 21). Rural phase out. The National Post, p. FP19.

Staggenborg, S. (1986). Coalition Work in the Pro-Choice Movement: Organizational and Environmental Opportunities and Obstacles. Social Problems, 33(5), pp. 374390.

Struthers, G. (2001). OFA evolves with changing times. August 15, 2008, from, http://www.ofa.on.ca/site/main.asp?pic=./cutting/maintit_history.jpg\&line=900\&I $\mathrm{nc}=. . /$ whoweare/history.asp 
Suchman, L.A. (1987). Plans and situated actions: The problem of human/machine communication. Cambridge: Cambridge University Press.

Tarrow, S. (1989). Democracy and disorder: Protest and politics in Italy, 1965-1975. Oxford: Clarendon Press.

Tarrow, S. (1994). Power in movement: Social movements and contentious politics. Cambridge UK: Cambridge University Press.

Taylor, V., \& Van Dyke, N. (2004). “Get up, stand up": Tactical repertoires of social movements. In D.A. Snow, Soule, \& Kriesi, H. (eds.), The Blackwell companion to social movements, pp. 262-293. Oxford: Blackwell.

Taylor, V., \& Whittier, N.E. (1992). Collective identity in social movements communities: Lesbian feminist mobilization. In A.D. Morris \& C. McClurg Mueller (eds.), Frontiers in social movement theory, pp. 104-129. New Haven: Yale University Press.

The Clean Water Act, R.S.O., 2006, c.36, s.16.

Tilly, C. (1978). From mobilization to revolution. New York: Addison-Wesley.

Tilly, C. (1995). Popular contention in Great Britain. Cambridge: Harvard University Press.

Tobacco Farmers in Crisis (2007). About us FAQs. Retrieved October 1, 2008, from, http://www.tobaccofarmersincrisis.org/aboutfaq.html.

Touraine, A. (1981). The voice and the eye. An analysis of social movements. Cambridge: Cambridge University Press.

Tweeten, L.G. (2003). Terrorism, radicalism, and populism in agriculture. Oxford: Wiley-Oxford.

Ulmer, J.T. (2007). Mesostructure: Blackwell encyclopedia of sociology: Blackwell reference online. Retrieved November 7,2008 , from http://www.blackwellreference.com/public/tocnode?id=g9781405124331_chunk_g 978140512433119_ss1-84.

Underwood, N. (2008, January/February). The future has begun: Vertical farms in cities could take local to the next level. The Walrus, p. 32.

Van Dusen, T. (2004, June 17). Renegades aim for the weekend kill. Ottawa Sun, p. 26.

Van Dusen, T. (2005, March). "Enough!"- Kamenz ends conciliation between OFA, LLA. The AgriNews, p. 7. 
Van Dusen, T. (2005b, March). Geri-mandering [editorial]. The AgriNews, p. 4.

Van Dusen, T. (2005c, March). LLA set to march in Toronto like lions. The AgriNews, p. 15.

Van Dusen, T. (2005d, March 15). LLA leader fires back at OFA critics. Ontario Farmer, p. A12.

Voss, K., \& Sherman, R. (2000). Breaking the iron law of oligarchy: Union revitalization in the American labor movement. American Journal of Sociology, 106(2), pp. 303349.

Watson, J.W. (1947). Rural depopulation in southwestern Ontario. Annals of American Geographers, 37(3), pp. 145-154.

Woods, M. (2003). Deconstructing rural protest: the emergence of a new social movement. Journal of Rural Studies, 19, pp. 309-325.

Yin, R.K. (2003). Case study research: Design and methods. Newbury Park, NJ: Sage.

Young, W.R. (1972). Conscription, Rural Depopulation, and the Farmers of Ontario, 1917-1919. Canadian Historical Review, 35(3), pp. 289-320.

Zwerver, H. (1986). A brief history of the OFA: The general farm organization campaign. Retrieved August 15, 2008, from, http://www.ofa.on.ca/site/main.asp?pic=../cutting/maintit history.jpg\&line=2000\& $\mathrm{Inc}=. /$ whoweare/History/history_6.asp. 
Reproduced with permission of the copyright owner. Further reproduction prohibited without permission. 


\section{Appendix A: Figures}

Figure 1. Two farmers converse before a tractor convoy in February, 2005.

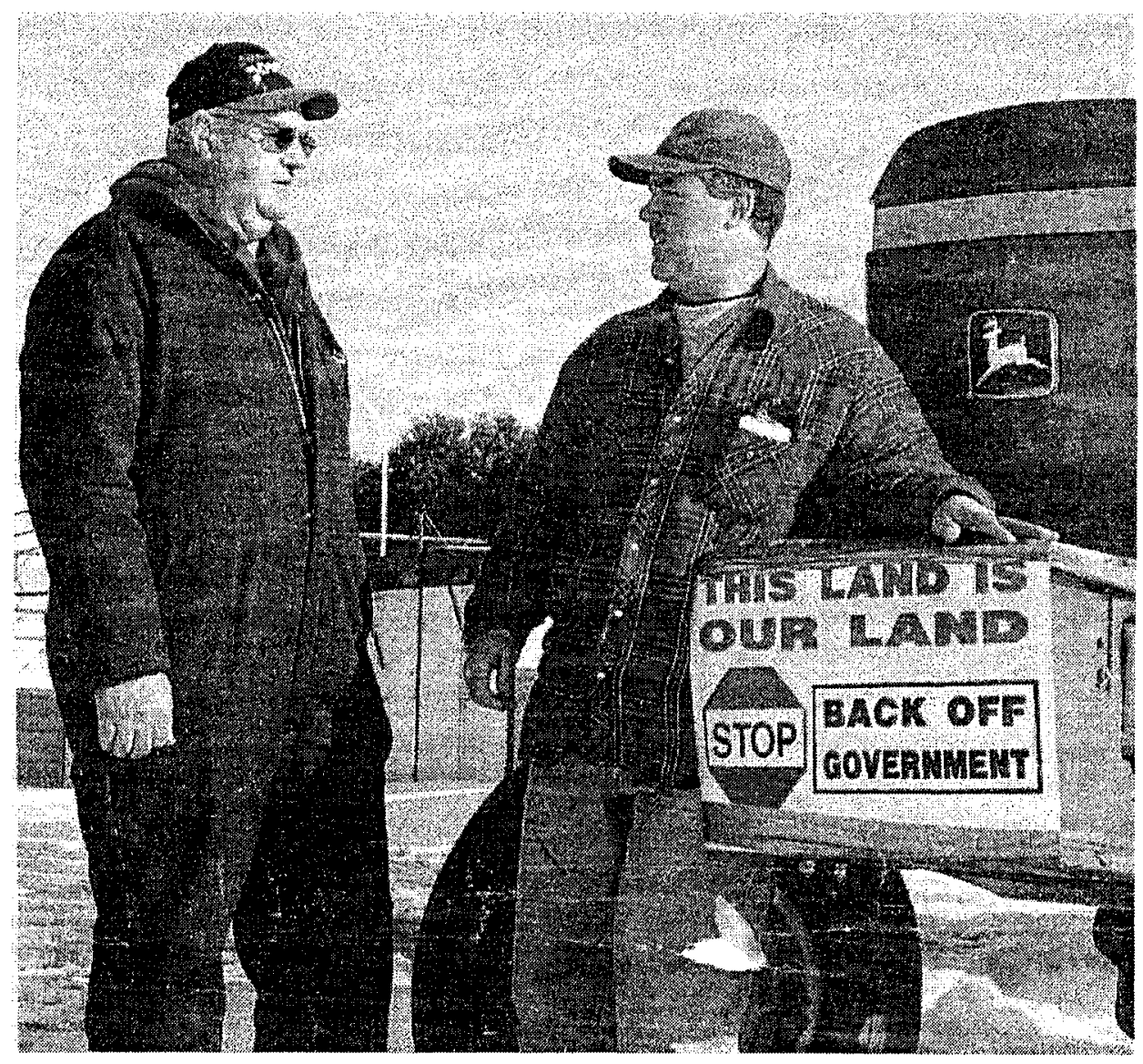

Photo by Paul Sontrop, Ontario Farmer

Figure 2. LLA leader Randy Hillier poses next to a "back off government" sign.

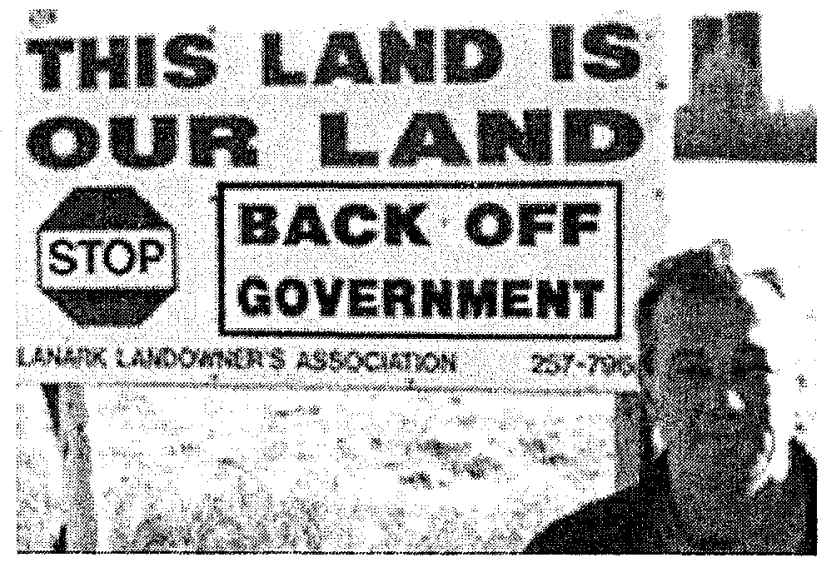

Photo by R. Lomas, Capital News Online 
Figure 3. Members of the LLA stage a demonstration at a busy Ottawa intersection in 2004.

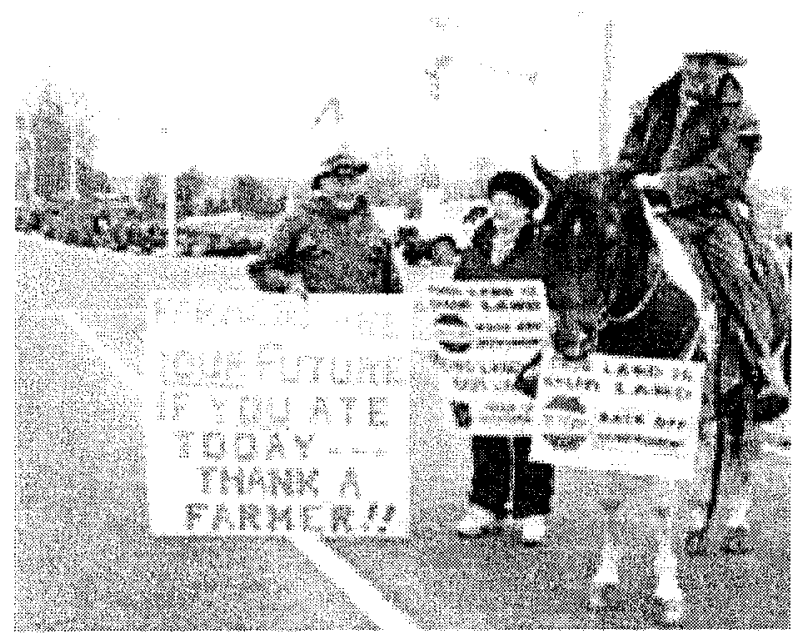

Photo by R. Kralik, Capital News Online

Figure 4. Tractors line the side of highway 401 outside Ingersoll, Ontario.

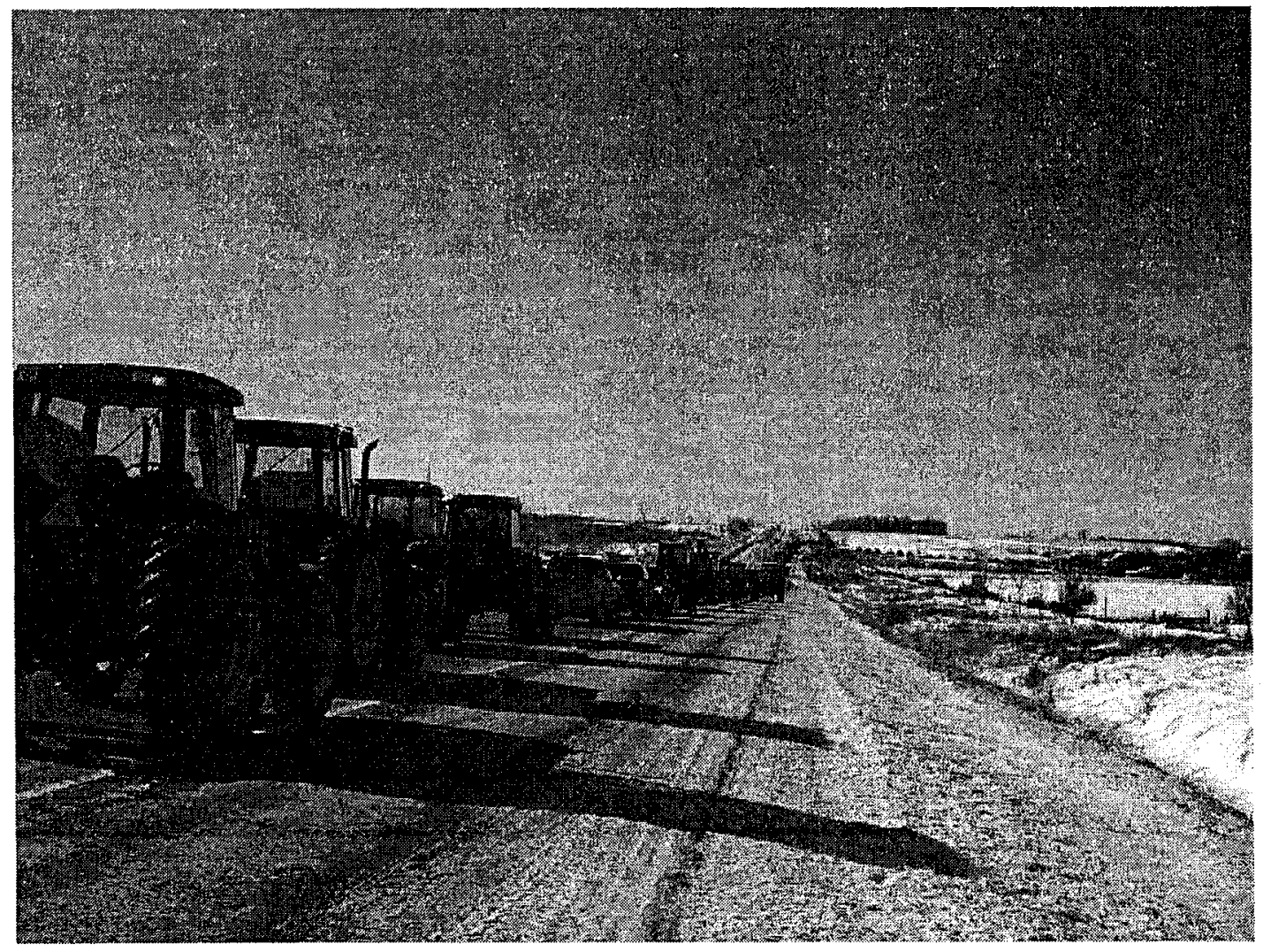

Photo by Voices of Central Ontario (VOCO) 
Figure 5. An LLA convoy brings traffic in both directions to a stand still.

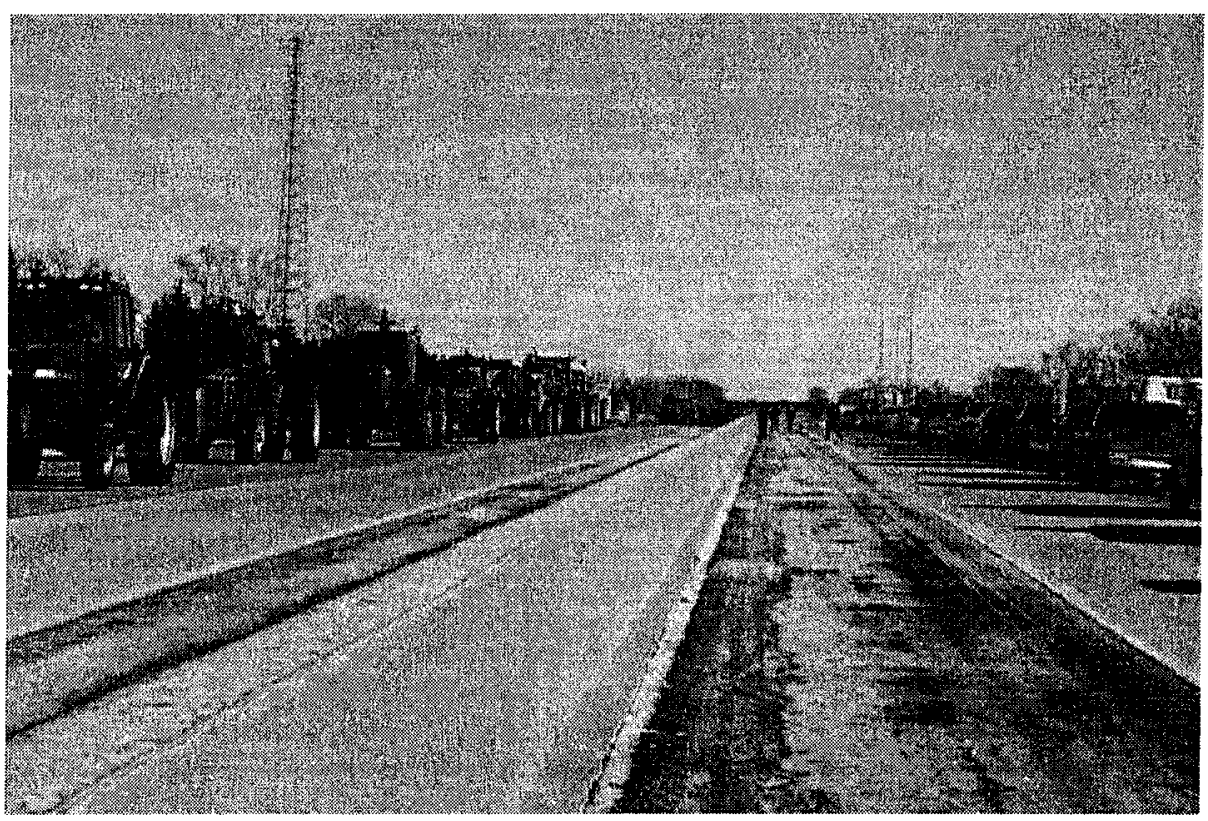

Photo by Voices of Central Ontario (VOCO)

Figure 6. LLA leader Randy Hiller speaks to several reporters at the side of highway 401.

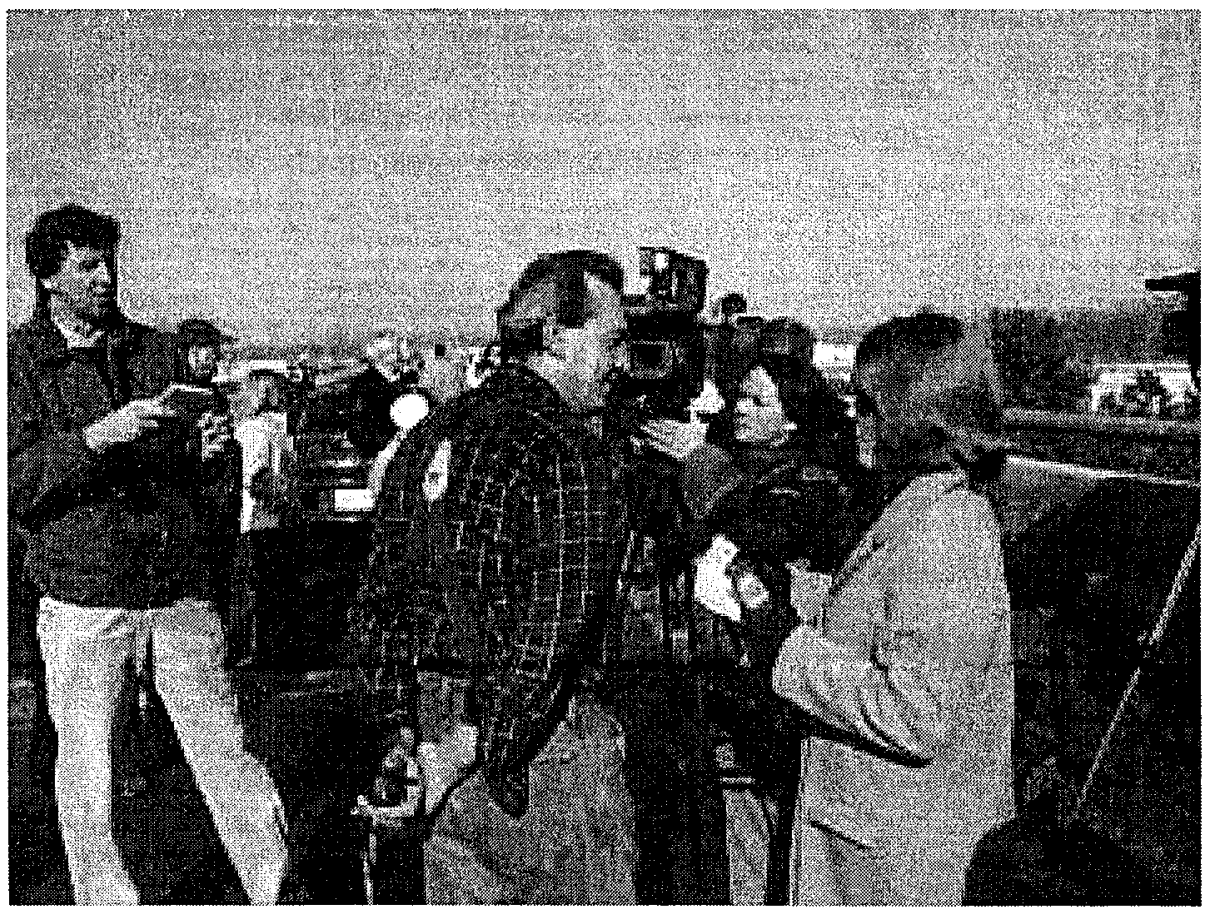

Photo by Farmgate 
Figure 7. LLA tractor protests garnered the attention of most news bureaus in Ontario.

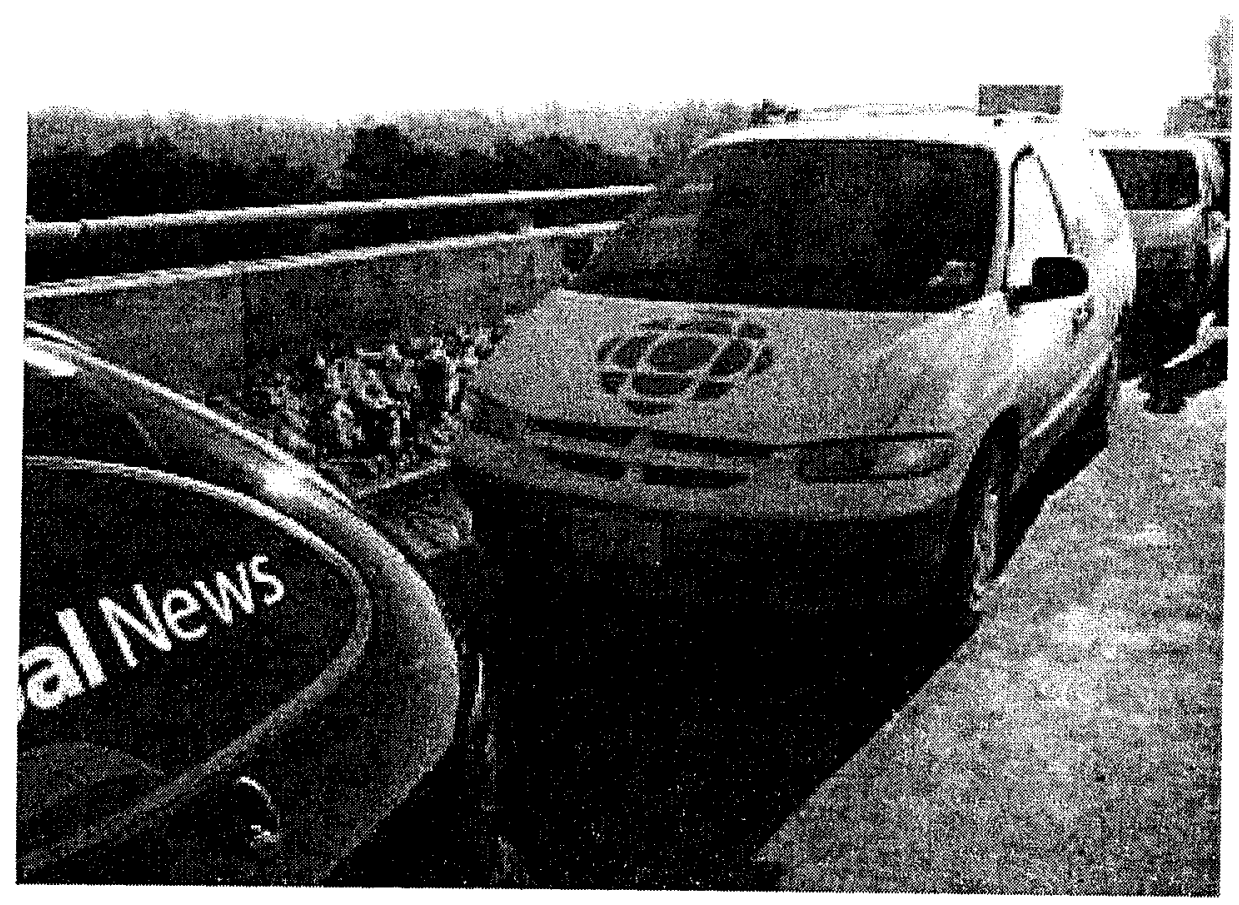

Photo by Farmgate

Figure 8. Thousands of OFA supporters take the fight for farming to Queen's Park.

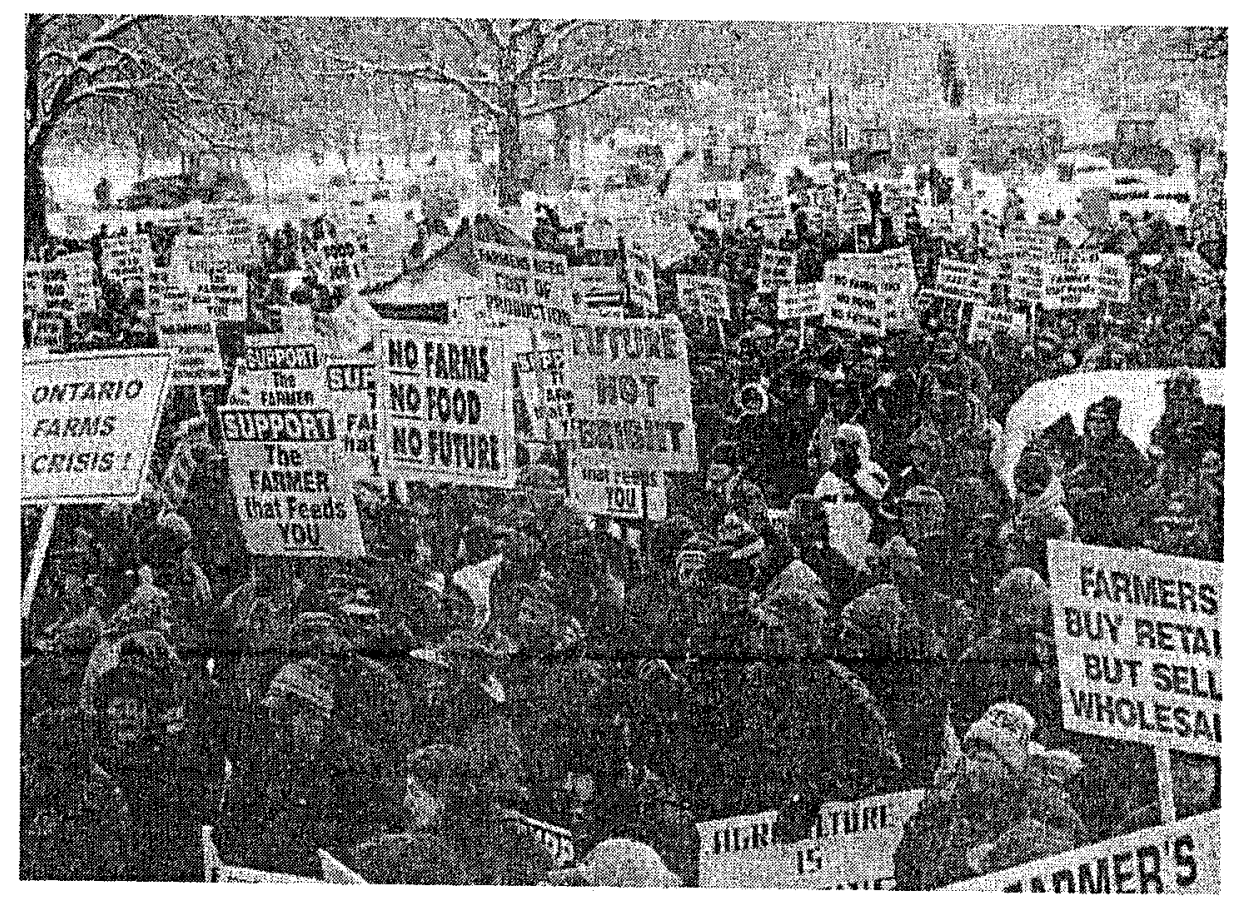

Photo by Rural Voice 
Figure 9.

OFA supporters depict the disparity between rural and urban conditions.

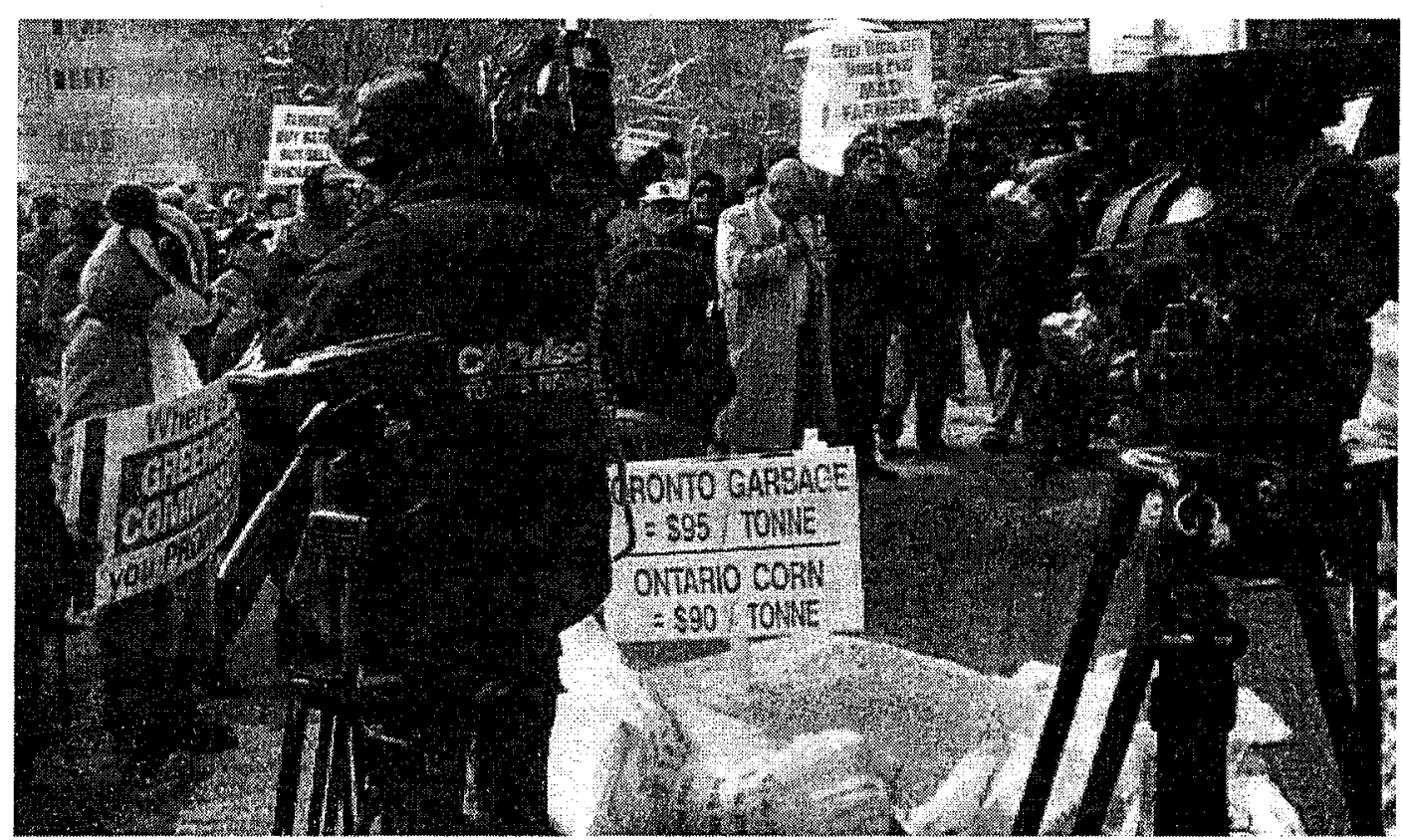

Photo by Anne Howden Thompson, Ontario Farmer

Figure 10. LLA supporters drive down a busy Toronto street on their way to Queen's Park.

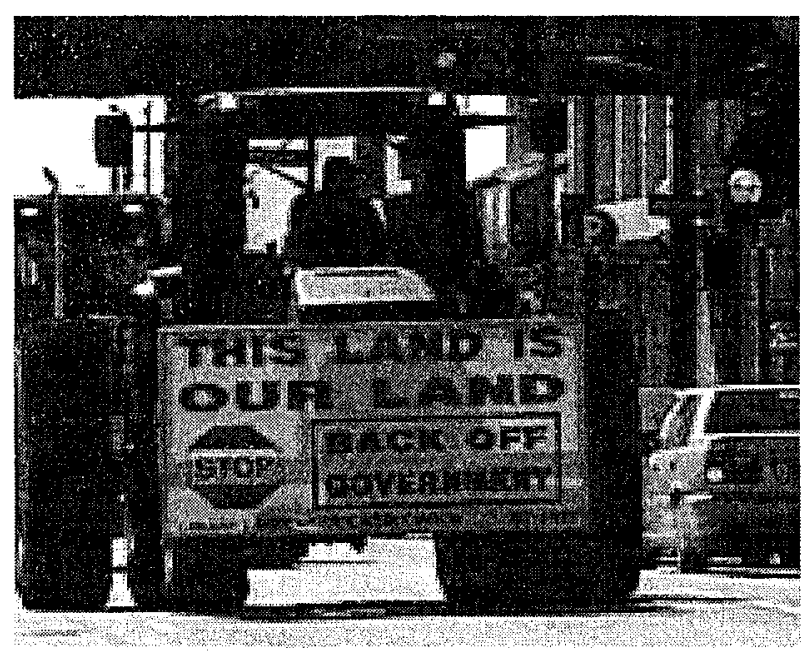

Photo by CBC News Online 
Figure 11. A display of signs as presented by a LLA supporter on March 9, 2005.

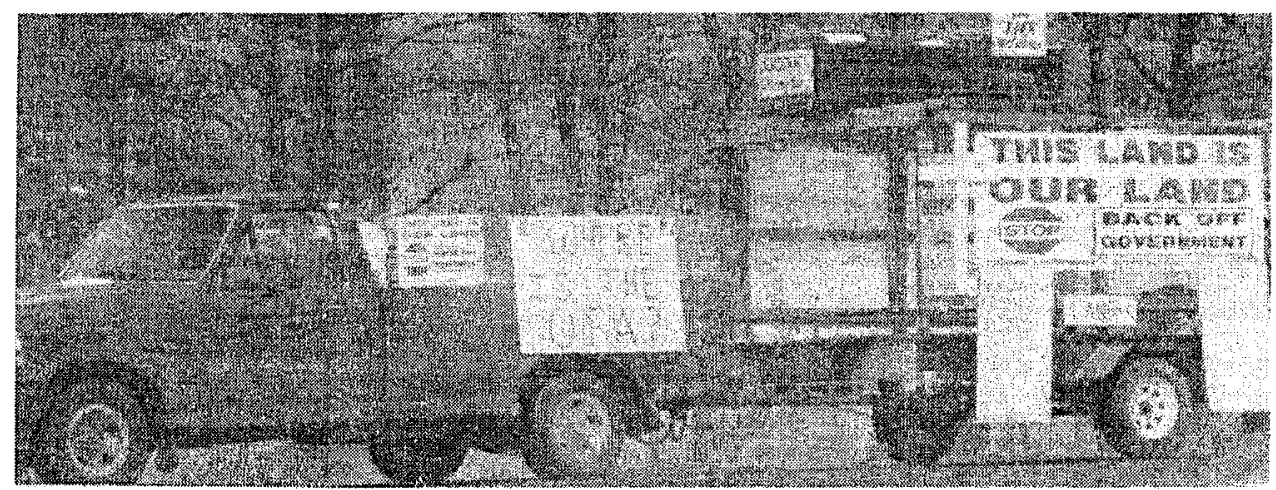

Photo by AgriNews

Figure 12. A more radical display by LLA supporters at Queen's Park depicting a farmer in a casket.

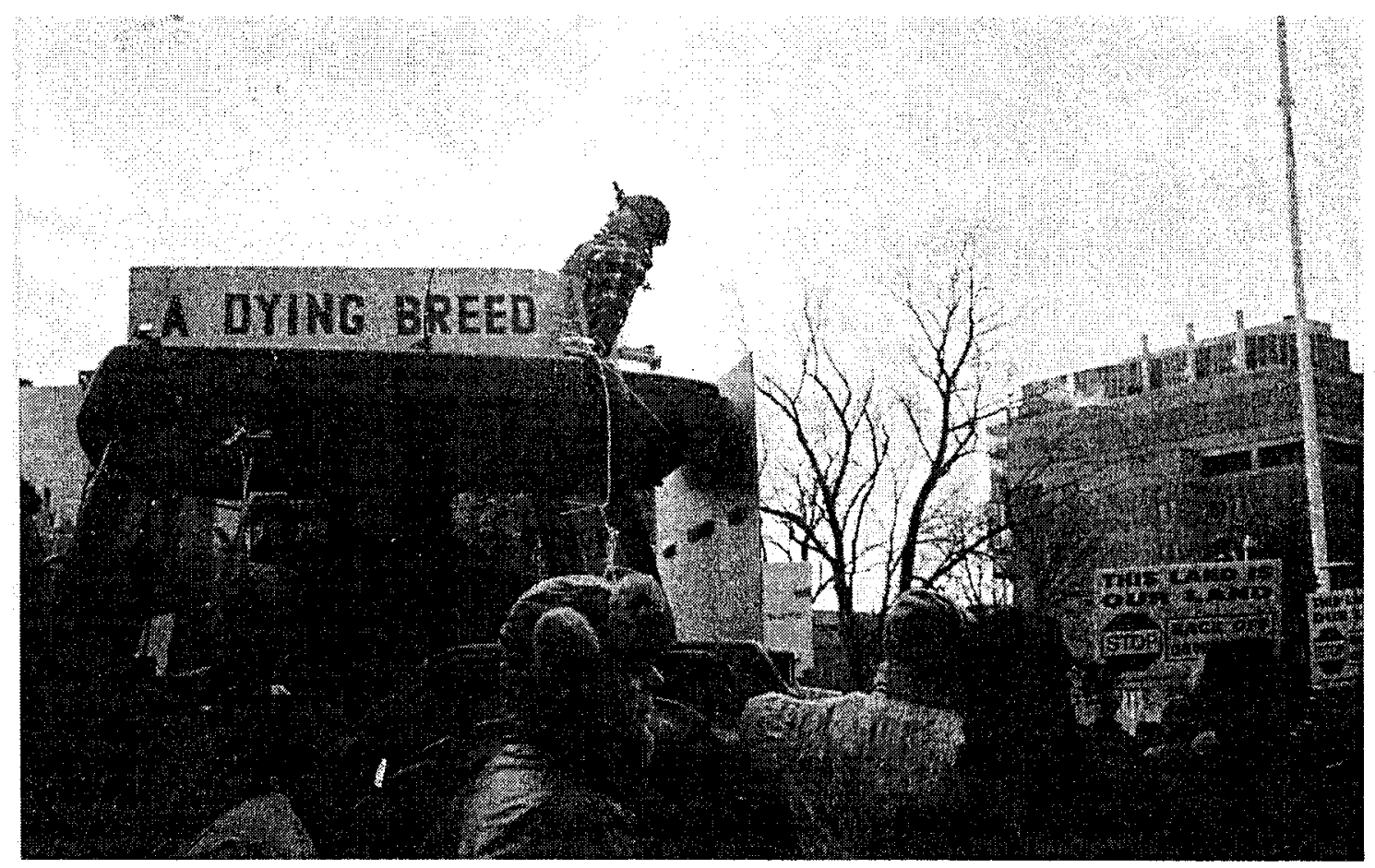

Photo by Lauretta Rice 
Figure 13. Another incident close to Queen's Park draws attention from the LLA.

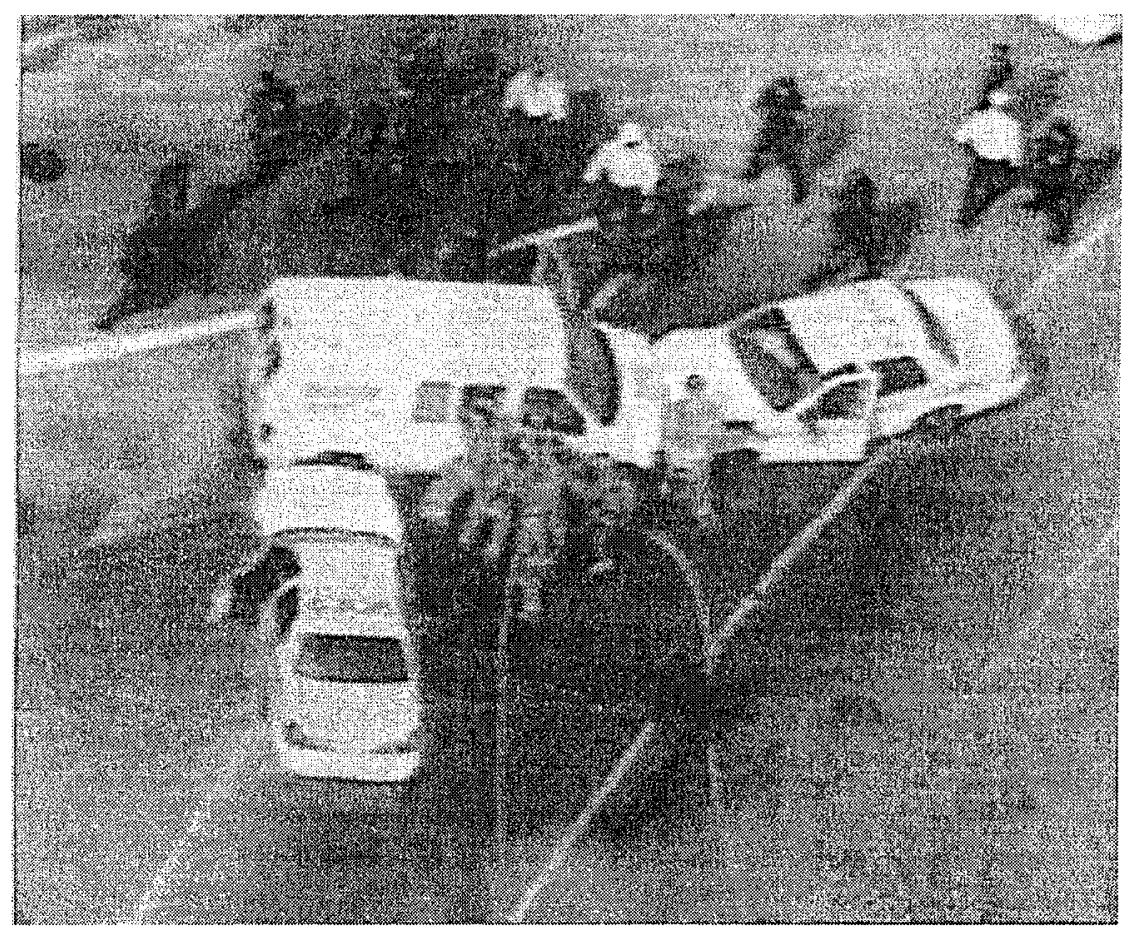

Photo by Global TV, appeared in National Post 


\section{Appendix C: Interview questions}

- What informed your decision to participate, or not participate, in the LLA?

- How did you hear about the LLA?

- As a farmer, did you agree with the solutions or policy moves proposed by the LLA?

- In the early $2000 \mathrm{~s}$, did you think the OFA was meeting the needs of farmers? If no, what do you think were the reasons for this?

- What were the main issues that your protest was focused on?

- Do you think farmers are united across Ontario any more now then in the early 2000s?

- How did you view the protest tactics used by the LLA?

- Did the LLA's choice in strategy influence your decision to participate with them?

- Could you describe the mood at one or both protests?

- As an executive in the OFA/LLA, what kind of rhetoric did you use/see/hear in the lead up to the protests?

- Do you think that one or both of the organizations reached their goals? In your opinion were they successful?

- Did participation in either of these protests influence which general farm organization you would pledge commitment to in the future? 